Universidade de São Paulo

Instituto de Física

\title{
Modelagem numérica de alto nível de filtros do tipo Fabry-Pérot e de redes de difração holográficas para o instrumento BTFI
}

\author{
Bruno Corrêa Quint
}

Orientador: Prof. Dr. Mikiya Muramatsu

Dissertação apresentada ao Instituto de Física da Universidade de São Paulo como requisito parcial para a obtenção do título de Mestre em Ciências.

Banca examinadora:

Prof. Dr. Mikiya Muramatsu (orientador) - IFUSP

Prof. Dr. Antonio Domingues dos Santos - IFUSP

Profa. Dra. Claudia Mendes de Oliveira - IAGUSP

São Paulo 


\section{FICHA CATALOGRÁFICA \\ Preparada pelo Serviço de Biblioteca e Informação do Instituto de Física da Universidade de São Paulo}

Quint, Bruno Corrêa

Modelagem numérica de alto nível de filtros do tipo Fabry-Pérot e de redes de difração holográficas para 0 instrumento BTFI. São Paulo, 2010.

Dissertação (Mestrado) - Universidade de São Paulo. Instituto de Física, Departamento de Física Geral

Orientador: Prof. Dr. Mikiya Muramatsu

Área de Concentração: Óptica

Unitermos: 1. Física computacional; 2. Instrumentação (Astronomia);3. Física experimental. 
Aos meus pais e ao meu irmão. 



\section{Agradecimentos}

Antes de mais nada gostaria de agradecer à professora Claudia Mendes de Oliveira pela oportunidade cedida em trabalhar no projeto BTFI e ao meu orientador Prof. Mikiya Muramatsu por ter me aceito como seu aluno.

Além deles, agradeço a todo o time do BTFI (Prof. Keith Taylor, Prof. Fabrício Ferrari, Renato Severo, Giseli Ramos, Denis Andrade, Luiz Cavalcanti, Álvaro Calasans, René Laporte) por estarem comigo durante todo o projeto, por tudo o que me ensinaram e por fazer este trabalho mais divertido.

Agradeço à Nádia Frota, Marina Nunes e Érica Andrade por terem me suportado por grande parte do período em que estive envolvido neste trabalho, chegando muitas vezes cansado e mal humorado em casa. Neste caso eu também tenho que agradecer aos que me aturam atualmente (Marcelo Feal, Bruno Tonon, Vinícius Nagarotto, Marília Rissato e Rafael Schiavetto) e que aceitaram morar comigo já sabendo o que teriam que enfrentar.

Quero agradecer aos meus amigos de Florianópolis (Ian Jordy, Júnior Koch - Ninja, Rafael Seemann - Beiço, Diego Grams, Juliana Machado, Rodrigo Jacob, Gustavo Tontini, Wagner Tenfen - Loser, Glauco Ruiz, Lucas Arrigoni, Marcelo Pagani, Vanessa de Oliveira - minha amorinha, Cândice Boff - Candy, Fernanda Hoffmann) por simplesmente ficarem sempre ao meu lado mesmo estando tão longe.

Além de todos estes amigos, agradeço também ao Renato Marques e Leandro S. (Ael) que serviram de suporte numa fase bastante complicada da minha vida. Se os dois não tivessem surgido, eu não sei dizer se teria completado este trabalho.

Quero agradecer à toda minha família pelo apoio dado nas diversas dificuldades que encontrei ao morar longe dela e pelo carinho que recebi nas poucas vezes que tive oportunidade de visitá-los, assim como pela confiança depositada em mim toda vez que tive que 
enfrentar algum desafio muito maior, como o caso da viagem ao ADASS2009, no Japão.

Ao meu pai e à minha mãe, simplesmente por estarem na minha vida e por hoje serem as pessoas que me aceitantam da maneira que sou e por ser pessoas que eu amo tanto. Não somente os dois, mas tembém o meu irmão mais novo, que hoje segue o seu próprio caminho e me ajudou a mudar diversos traços da minha personalidade que carrego atualmente.

Por fim, agradeço ao CNPQ pelo apoio financeiro sob o projeto $\mathrm{n}^{\circ} 136015 / 2008-5$, ao Instituto de Física e ao Instituto de Astronomia, Geofísica e Ciências Atmosféricas e à própria Universidade de São Paulo. Agradeço também à Pró-Reitoria de Pós-Graduação pelo apoio financeiro na participação da conferência ADASS 2009 em Sapporo - Japão.

Esta tese/dissertação foi escrita em LATEX com a classe IAGTESE, para teses e dissertações do IAG. 
"... And it takes some work to make it work ..."

Jason Mraz 



\section{Resumo}

O trabalho apresentado nesta dissertação foi motivado essencialmente pelo projeto de construção de um novo instrumento a ser instalado no telescópio SOAR, no Chile. Este instrumento, chamado de Brazilian Tunable Filter Imager - BTFI, conta com várias novidades dentro da área de instrumentação astronômica.

Uma delas envolve a utilização de duas redes de difração em série de modo a atuarem como um filtro espectral com uma resolução mais baixa. Aqui é mostrado o estudo realizado envolvendo dois diferentes modelos encontrados na literatura para simular numericamente a eficiência destas redes. Com estas simulações foi possível escolher um conjunto de redes a serem utilizadas no instrumento visando cobrir todo o espectro óptico com diferentes resoluções espectrais.

Outra ferramenta estudada foi o filtro espectral do tipo Fabry-Pérot. Partindo de uma revisão teórica de interferência de raios múltiplos, apresenta-se também algumas características encontradas nos cubos de dados obtidos ao fazer uso de filtros deste tipo.

Por fim, é descrito o software que foi criado buscando fornecer cubos de dados sintéticos para o desenvolvimento de novos pacotes numéricos para trabalhar com dados obtidos com um interferômetro Fabry-Pérot, além de auxiliar na compreensão de obtenção destes cubos. 



\section{Abstract}

The work presented in this dissertation was motivated primarily by the construction project of a new instrument to be installed on the SOAR telescope in Chile. This instrument, called Brazilian Tunable Filter Imager - BTFI, features several innovations within the area of astronomical instrumentation.

One of them involves the use of two diffraction gratings in series in order to act as a spectral filter with a lower resolution. It is shown here the study involving two different models found in the literature to simulate the efficiency of these gratings. With these simulations it was possible to choose a set of gratings to be used in the instrument in order to cover the entire optical spectrum with different spectral resolutions.

Another tool studied was the filter spectral type Fabry-Pérot. Starting from a theoretical review of interference of multiple beams, it is presented some features found in the data cubes obtained by making use of filters of this type.

Finally, we describe the software that was created to provide synthetic data cubes for developing new packages for working with numerical data obtained with a Fabry-Perot interferometer, in addition to helping to raise understanding of these cubes. 



\section{Lista de Figuras}

1.1 Imagens do BTFI. À esquerda, foto do instrumento como um todo. $\grave{A}$ direita, foco dado na montagem mecânica do iBTF. . . . . . . . . . . . . . 23

1.2 Esquema simplificado do instrumento BTFI mostrando a atuação dos filtros Fabry-Pérot (FP) e do iBTF, representado por duas redes de difração holográficas (VPH1 e VPH2). M1 simboliza o espelho principal do telescópio, COL é o colimador e CAM1 e CAM2 são as câmeras ópticas acopladas a cada um dos filtros. . . . . . . . . . . . . . . . . . . . . . . . . 24

1.3 Feixe de luz originado em um cabo contendo diversas fibras ópticas e espalhado por uma rede de difração holográfica. O desenho à esquerda representa a primeira ordem de difração da primeira rede, ilustrada na foto à direita. . 27

1.4 À esquerda: representação simplificada de duas redes de difração em duas diferentes configurações. À direita, fotos obtidas em laboratório mostrando um feixe de luz proveniente de um cabo de fibras ópticas iluminado por uma lâmpada incadescente passando através do iBTF com as redes a $45^{\circ}$ (figuras superiores) e $35^{\circ}$ (figuras inferiores). . . . . . . . . . . . . . . 28

2.1 Representação esquemática da diferença de caminho óptico entre dois feixes luminosos incidindo com o mesmo ângulo sobre um material cristalino qualquer. . . . . . . . . . . . . . . . . . . . 34

2.2 Imagem obtida em laboratório de uma rede de difração holográfica. . . . . 35

2.3 Representação genérica de uma rede de difração. Veja a definição das variáveis no texto. . . . . . . . . . . . . . . . . . . . . . . . 37 
2.4 Modos de atuação de uma VPH. A figura à esquerda representa uma rede atuando em modo de transmissão. A da direita representa uma rede em modo reflexão. . . . . . . . . . . . . . . . . . . . . . 39

2.5 Diagrama de vetores para incidência satisfazendo critério de Bragg. . . . . 42

2.6 Rede \#WTX01 . . . . . . . . . . . . . . . . . . . . . . . . . . . . . . . . . . 51

2.7 Rede \#WTX02 $\ldots \ldots \ldots \ldots \ldots \ldots \ldots \ldots$

2.8 Rede \#WTX03 $\ldots \ldots \ldots \ldots \ldots$

2.9 Rede \#WTX04 $\ldots \ldots \ldots \ldots$

2.10 Rede \#WRX01 . . . . . . . . . . . . . . . . . . . . . . . . . . 54

2.11 Rede \#WRX02 $\ldots \ldots \ldots \ldots \ldots$

2.12 Rede \#WRX03 . . . . . . . . . . . . . . . . . . . . . . . . . . . 55

3.1 Representação gráfica de uma onda luminosa plana com amplitude $A^{(i)}$ in\begin{tabular}{|c|}
\hline cidindo sobre uma placa com superfícies planas e paralelas. O p-ésimo raio \\
\hline refletido é representado por $a_{p}^{(r)}$ enquanto o p-ésimo raio transmitido é rep- \\
\hline
\end{tabular}

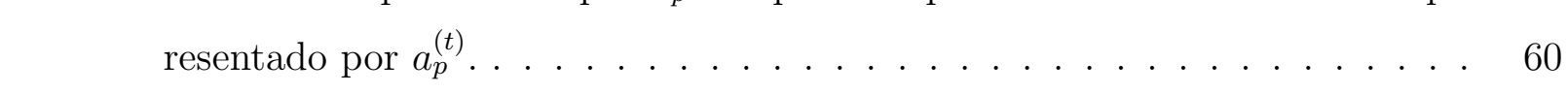

3.2 Representação artística do posicionamento do Fabry-Perot quando alocado no espaço colimado. . . . . . . . . . . . . . . . . 63

3.3 Gráfico da eficiência relativa de transmissão de um Fabry-Pérot em função da diferença de fase para diferentes finesses. . . . . . . . . . . . . . . 65

$3.4 \quad$ Formação de imagens - Representação simplificada. . . . . . . . . . . . . . 66

3.5 Estrutura de um cubo de dados. . . . . . . . . . . . . . . . . . . . 67

3.6 Comportamento periódico representado através des diversos anéis concêntricos

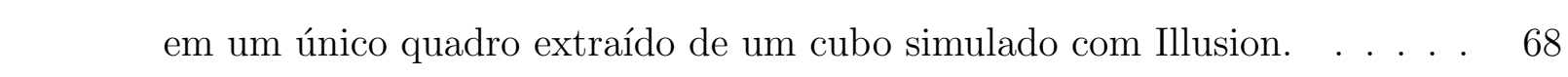

3.7 Intervalo espectral livre. . . . . . . . . . . . . . . . . . 69

3.8 Confusão espectral causada pela presença de um comprimento de onda fora - do FSR observado . . . . . . . . . . . . . . . . . . . 70

3.9 Superfície monocromática dentro de um cubo de dados. . . . . . . . . . . . 71

3.10 Imagem contendo informação espacial que será distribuída em um cubo de

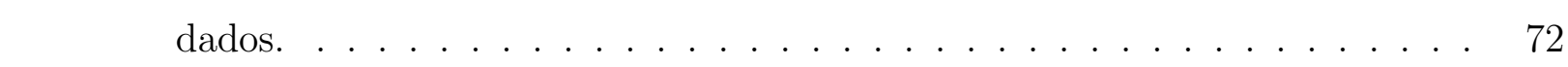

\begin{tabular}{|l|l|l|l|l|}
\hline 3.11 Imagens de um cubo criado com Illusion utilizando a imagem & 3.10 & como \\
\hline
\end{tabular} - dado de entrada . . . . . . . . . . . . . . . . . . . . . 72 
3.12 Imagens obtidas colapsando os $10,20,30$ e 40 primeiros quadros do cubo citado acima . . . . . . . . . . . . . . . . . . . . . 73

3.13 Cubo contendo duas superfícies monocromáticas. . . . . . . . . . . . . . 73

3.14 Raw cube. À esquerda, uma representação artística da fonte monocromática e uniformemente distribuída sobre uma superfície. À direita, o primeiro, o $11^{\circ}$, o $21^{\circ}$ e o $31^{\circ}$ quadros pertencentes um cubo criado com Illusion. . . . . 75

3.15 Spectrum cube. À esquerda, representação artística da fonte contendo comprimentos de onda arbitrários e à direita um cubo criado com Illusion para propósitos de visualização apenas. . . . . . . . . . . . . . . . . . . . 76

3.16 Image Cube. À esquerda uma representação artística das características da fonte. À direita, repete-se a imagem da borboleta aplicada ao Illusion para propósitos didáticos apenas. Um objeto astronômico mais realista não possuiria informação visual relevante o suficiente neste contexto. . . . . . . 76 



\section{Lista de Tabelas}

2.1 Constantes para a equação de Sellmeier (eq. 2.3 ) para $\lambda$ em $\mu m$. . . . . . 38

2.2 Parâmetros físicos das redes escolhidas. . . . . . . . . . . . . . . . . . . . . 50

2.3 Rede \#WTX01 . . . . . . . . . . . . . . . . . . . . . . . . . . . . . . . . . 51

2.4 Rede \#WTX02 . . . . . . . . . . . . . . . . . . . . . . . 52

2.5 Rede \#WTX03 . . . . . . . . . . . . . . . . . . . . . . . . . 52

2.6 Rede \#WTX04 $\ldots \ldots \ldots \ldots \ldots$

2.7 Rede \#WRX01 . . . . . . . . . . . . . . . . . . . . . . . . . . . . . . . 54

2.8 Rede \#WRX02 $\ldots \ldots \ldots \ldots \ldots \ldots$

2.9 Rede \#WRX03 $\ldots \ldots \ldots \ldots$ 



\section{Sumário}

1. Introdução . . . . . . . . . . . . . . . . . . . . . . . 21

1.1 iBTF e a combinação da luz espalhada . . . . . . . . . . . . . . . . . . 26

1.2 Os anéis de Fabry-Pérot $\ldots \ldots \ldots$. . . . . . . . . . . . . . . . 29

1.3 Explicitando objetivos $\ldots \ldots \ldots \ldots$. . . . . . . . . . . . . . 31

2. Modelando e escolhendo redes VPH . . . . . . . . . . . . . . . . . . . . . . . . . 33

2.1 Representação e Notação . . . . . . . . . . . . . . . . . . . . . . . . . . 36

2.2 Modelo de Kogelnik . . . . . . . . . . . . . . . . . . . . . . . . . . . . . . . 39

$2.3 \quad$ Análise Rigorosa de Ondas Acopladas . . . . . . . . . . . . . . . . . . . . . 44

2.4 Simulações e Resultados $\ldots \ldots \ldots$. . . . . . . . . . . . . . . . . . . . . . . . . 48

3. Fabry-Pérot e Illusion . . . . . . . . . . . . . . . . . . . . . . 57

3.1 Interferência de Raios Múltiplos . . . . . . . . . . . . . . . . . . . . . 60

3.2 Obtendo dados $\ldots \ldots \ldots \ldots$

3.3 Periodicidade . . . . . . . . . . . . . . . . . . . . . . . . . . . 67

3.4 Ajuste de Fase . . . . . . . . . . . . . . . . . . . . . . 71

3.5 Sintetizador de dados Illusion $\ldots \ldots \ldots$. . . . . . . . . . . . . 74

4. Conclusão . . . . . . . . . . . . . . . . . . . . . . 77

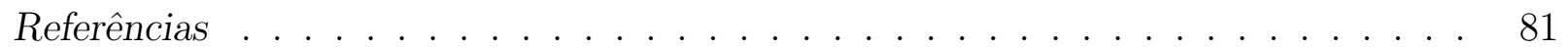


Anexo

A. Pôster-ADASS2009 . . . . . . . . . . . . . . . . . . . 87

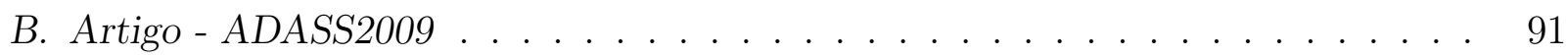


Capítulo 1

\section{Introdução}

A principal motivação para a realização deste nosso trabalho foi um instrumento chamado Brazilian Tunable Filter Imager ou, simplesmente, BTFI. Este instrumento, juntamente com outros dois, começou a ser desenvolvido para aproveitar a oportunidade criada com a construção do telescópio SOAR (Southern Astrophysical Research Telescope). Este telescópio, com um espelho principal de 4,1m de diâmetro, foi desenvolvido através de uma parceria entre o Brasil, os Estados Unidos com o Observatório Internacional de Cerro Tololo, a Universidade da Carolina do Norte e a Universidade do Estado de Michigan e o Chile. Sua construção findou em julho de 2002 e o comissionamento à comunidade científica realizou-se em 2003.

Atualmente, nosso país possui 34\% de participação neste telescópio refletidos em tempo disponível para a comunidade científica brasileira. Neste cenário, o Brasil recebeu a chance de desenvolver equipamentos que pudessem ser acoplados ao telescópio em questão. Com isso, surge também a oportunidade de capacitar novos profissionais na área tecnológica voltada para o desenvolvimento de equipamentos para estudos científicos, conhecer e familiarizar-se com tecnologias já estudadas e utilizadas no exterior e fazer uso da indústria brasileira como uma forma de incentivo à colaboração entre o meio acadêmico e o meio tecnológico e industrial.

Atualmente, três são os instrumentos que estão em desenvolvimento para o SOAR. O primeiro deles é o chamado de SIFS, cuja sigla significa SOAR Integral Field Unit Spectrograph ou, numa tradução literal, Espectrógrafo de Unidade de Campo Integral do SOAR. Sua construção é dividida em duas diferentes partes: uma frente óptica acoplada ao foco Nasmyth do telescópio contendo uma matriz de 26x50 microlentes conectadas à um 
espectrógrafo de bancada através de um cabo contendo 1300 fibras ópticas com 11 metros de comprimento, possibilitando espectroscopia em três dimensões (duas coordenadas espaciais e uma espectral).

O espectrógrafo é constituído de um conjunto de redes de difração holográfica que permitem obter espectros de $3500 \AA$ à $10000 \AA$ com resoluções espectrais entre $5000 \mathrm{e}$ 20000 chegando a cobrir 8" x 15" do céu com 0,30" para cada microlente, conforme Lepine (2003).

Um outro instrumento desenvolvido para o SOAR é o chamado STELES (SOAR Telescope Echelle Spectrograph - Castilho et al. (2004)). Este instrumento foi projetado para acoplar-se permanentemente a uma das saídas do foco Nasmyth do telescópio. A luz recebida é separada em dois diferentes canais: um no azul indo de $3000 \AA$ à $5500 \AA$ e outro entre $5300 \AA$ e $8900 \AA$ no vermelho. Cada um dos canais possui uma rede de difração holográfica para separar as ordens de interferência mais baixas e uma rede de difração do tipo echelle. Esta configuração permite alcançar resoluções espectrais de até 70.000. Em outras palavras, a largura à meia altura da linha principal de emissão do hidrogênio $\left(H_{\alpha}\right)$ cujo comprimento de onda é de $6563 \AA$ seria observada com uma largura à meia altura (FWHM) de $0,1 \AA$ aproximadamente.

O último desta geração de instrumentos voltados para o SOAR é justamente o BTFI (imagem 1.1). Este é um instrumento ainda em desenvolvimento no departamento de astronomia do Instituto de Astronomia, Geofísica e Ciências Atmosféricas (IAG) da Universidade de São Paulo (USP) em colaboração com outros institutos da própria USP, como o Instituto de Física (IF), a Escola Politécnica (POLI), instituições como o Instituto Nacional de Pesquisa Espacial (INPE), o Laboratório Nacional de Astrofísica (LNA), a Universidade Federal do Pampa (Unipampa), a Universidade Estadual de Santa Cruz (UESC), além de instituições internacionais como o Laboratoire d'Astrophysique de Marseille em Marseille na França e a Universidade de Montreal no Canadá.

O BTFI, assim como o SIFS, também é um instrumento de espectroscopia em três dimensões armazenando não apenas a informação espectral de um objeto como a informação espacial. Como consequência, seus dados serão obtidos no formato de cubos hiperespectrais compostos por uma sequência de imagens obtidas em diferentes comprimentos de onda de modo que cada pixel represente o espectro de um ponto no espaço. 

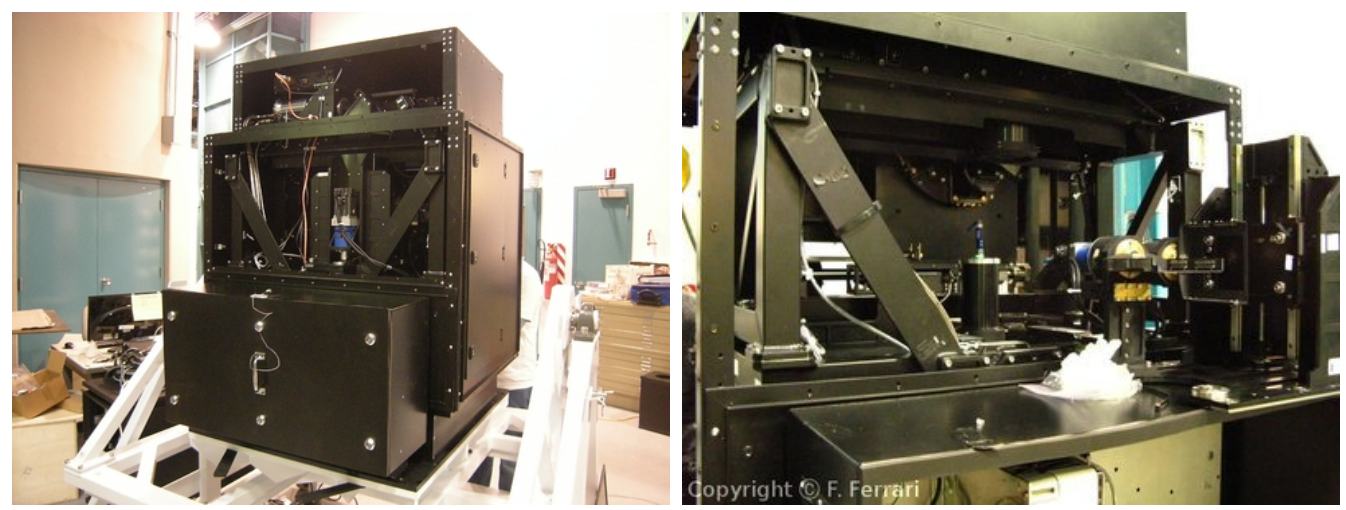

Figura 1.1: Imagens do BTFI. À esquerda, foto do instrumento como um todo. À direita, foco dado na montagem mecânica do iBTF.

Para realizar tal tarefa com um alto desempenho, este instrumento conta com o uso de duas tecnologias inéditas dentro da área de desenvolvimento de equipamentos para telescópios. A primeira delas é um tipo especial de detector chamado EMCCD (Electron Multiplying Charge Coupled Device) onde é possível aplicar uma alta diferença de potencial $(40 \mathrm{~V})$ entre os eletrodos que transportam a carga coletada pelo detector. Com essa diferença de potencial cada elétron é multiplicado pelo efeito denominado multiplicação por avalanche. Dessa forma o ruído introduzido durante a leitura torna-se praticamente nulo se comparado com o sinal que foi anteriormente multiplicado. Isto permite com que este detector seja lido a uma taxa muito maior $(10 \mathrm{MHz})$ do que os convencionais $(1 \mathrm{MHz})$. Em outras palavras, um baixo nível de ruído é obtido mesmo com altas velocidades de leitura.

A segunda novidade dentro do BTFI é a utilização de um filtro ajustável chamado iBTF ou imaging Bragg Tunable Filter (Blais-Ouellette et al. (2006)). Este equipamento atua como um espectrógrafo de baixa resolução espectral mantendo a informação espacial do objeto observado. A seleção do comprimento de onda é feita através da orientação relativa entre o eixo óptico e as superfícies de duas redes de difração holográficas dispostas uma atrás da outra ao longo do eixo óptico (em série) e com suas superfícies paralelas entre si. Com este dispositivo, resoluções espectrais $(\lambda / \Delta \lambda)$ compreendidas entre 5 e 100 e entre 200 à 2000 podem ser obtidas conforme as especificações técnicas do par de redes utilizadas.

Para atender a necessidade de realizar-se observações de alta resolução espectral no caso de estudos de cinemática de objetos astronômicos ou da determinação precisa de perfis de linhas de emissão serão utilizados filtros ajustáveis do tipo Fabry-Pérot (FP). 


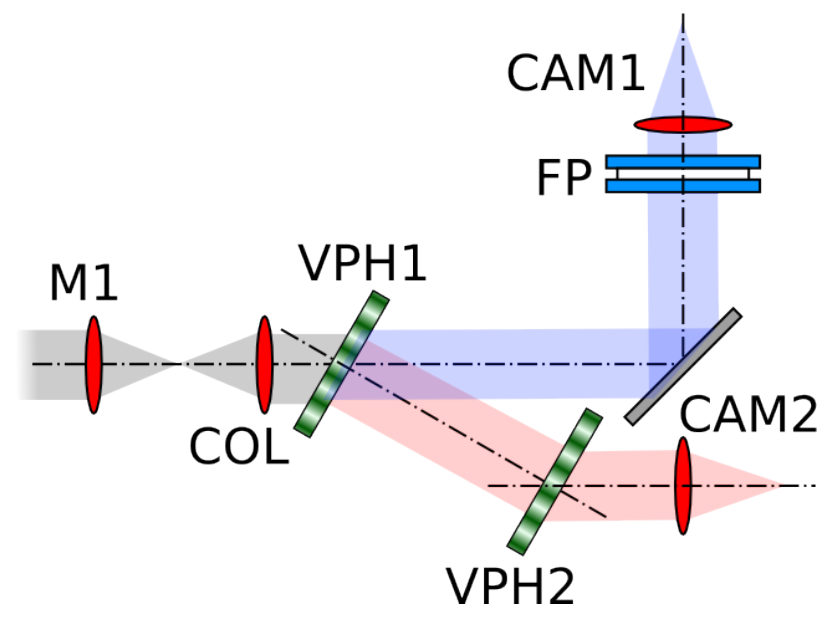

Figura 1.2: Esquema simplificado do instrumento BTFI mostrando a atuação dos filtros Fabry-Pérot (FP) e do iBTF, representado por duas redes de difração holográficas (VPH1 e VPH2). M1 simboliza o espelho principal do telescópio, COL é o colimador e CAM1 e CAM2 são as câmeras ópticas acopladas a cada um dos filtros.

Aqui, os modelos mais recentes possuem a capacidade de atuar desde baixas ordens de interferência até ordens altíssimas. Estes Fabry-Pérots serão responsáveis pela obtenção de imagens iluminadas apenas por uma banda estreita centrada em um comprimento de onda determinado pela distância entre as placas do étalon, como também são conhecidos. Sendo assim, é possível obter-se uma resolução espectral de até 35000, o que corresponde a uma largura à meia altura de aproximadamente $0,2 \AA$ no caso de $\left[H_{\alpha}\right] 6563 \AA$, por exemplo.

Os dois filtros espectrais são utilizados simultaneamente já que o Fabry-Pérot atua na banda de luz que passa através do iBTF sem ser capturada (ordem 0 de interferência da redes do iBTF), conforme mostra a figura 1.2. A combinação destas tecnologias permite um instrumento altamente versátil, compacto e com um baixo custo e com a possibilidade de ser projetado e construido em um espaço de tempo relativamente curto.

Além de todas estas inovações, o BTFI também poderá ser acoplado ao módulo de óptica adaptativa SAM (SOAR Adaptative Optics) que permite um campo de visão de até 3.0 arcominutos quadrados e resolução espacial de 0.3 a 0.5 arcosegundos conforme o comprimento de onda e uma amostragem de, aproximadamente, 0.12 arcosegundos por píxel no detector. Caso o contrário, ele também poderá operar de modo que a resolução seja limitada pela turbulência atmosférica onde os valores típicos de resolução espacial por volta de 0.7 arcosegundos.

Como parte da lista de requisitos para seu pleno funcionamento, um novo sistema 
de software para o controle de dispositivos, previsão e análise da qualidade de sinal e tratamento de dados passou a ser desenvolvido para o instrumento em foco.

Nele, o sistema de controle integra diversos módulos independentes em um grande núcleo que recebe comandos de alto nível e os distribui entre os diversos dispositivos de hardware. Esta estrutura, conhecida como estrutura em forma de estrela dentro da engenharia de software, permite que dispositivos sejam removidos ou inseridos no sistema sem a necessidade de comprometê-lo como um todo facilitando, inclusive, a manutenção dos código de controle.

Além disso, este núcleo de comandos comunica-se com o sistema de redução de dados, chamado Butterfly, através de um servidor TCP/IP para o envio de comandos e NFS (Network File System) para a transferência de grandes quantidades de dados. Este pacote envolve rotinas como a correção de fase e a calibração de comprimento de onda, além de ferramentas para a visualização de cubos de dados, ajuste de anéis e análise do paralelismo entre as placas do Fabry-Pérot.

O Butterfly foi desenvolvido com a filosofia de um software livre, bem estruturado e bem documentado, de modo que possa ser aprimorado e reaproveitado no futuro. Escrito em Python, uma linguagem de programação gratuita e de altíssimo nível, o sistema de redução de dados está sendo desenvolvido com o objetivo de ser uma ferramenta de uso simples, rápido e robusto.

Uma das nossas maiores contribuições para o projeto BTFI e para o desenvolvimento das rotinas que compõem o sistema Butterfly foi um sintetizador de cubos de dados obtidos com Fabry-Pérot chamado Illusion. Parte da importância deste software consiste compreensão do processo de criação de cubos de dados com Fabry-Pérots. Por outro lado, ela foi vital para criar dados que pudessem servir de referência para a criação das rotinas mencionadas acima.

Uma outra contribuição está relacionada com o problema de escolha das redes de difração a serem utilizadas no iBTF. Para tal, diferentes modelos numéricos foram estudados e implementados. Utilizando estes modelos, um conjunto de redes foram escolhidas e estão em processo de compra.

Participamos também do desenvolvimento de uma ferramenta computacional criada para prever a qualidade da informação obtida com o BTFI utilizando conceitos de razão 
sinal-ruído. Esta ferramenta será implementada junto a uma página na Web para que astrônomos interessados em utilizar o nosso instrumento possam ter uma idéia de que tipo de ciência pode ser feita com ele.

Mesmo que as atividades junto ao projeto BTFI tenham abrangido diferentes contextos, esta dissertação ficará limitada à descrição dos modelos criados na simulação de imagens obtidas com Fabry-Pérot e dos modelos estudados para a previsão da eficiência das redes de difração holográficas visando escolher as mais apropriadas ao projeto.

Uma breve apresentação sobre o funcionamento dos filtros iBTF, Fabry-Perot e da estrutura de dados gerada será dada antes da apresentação da dissertação em si. Após as apresentações, será dedicado um capítulo para cada um dos itens mencionados descrevendo detalhadamente a evolução e o estado dos modelos estudados e implementados.

\section{1 iBTF e a combinação da luz espalhada}

O primeiro módulo a entrar em funcionamento dentro do instrumento BTFI será o filtro hiperespectral chamado iBTF. Como o próprio nome sugere, o imaging Bragg Tunable Filter é um filtro utilizado na obtenção de imagens que pode ser ajustado para diferentes comprimentos de onda de acordo com o chamado Critério de Bragg, uma equação que relaciona as características físicas do sistema, a geometria do sistema e o comprimento de onda selecionado, sendo bastante utilizada para determinar a distância entre planos atômicos em estruturas cristalinas utilizando a difração de raios X.

Este equipamento utiliza duas redes de difração holográficas em série para atuar como filtro. Estas redes são obtidas quando um filme fino de um material holográfico, como a gelatina dicromada ou o vidro dopado, é depositado sobre um substrato (vidro ou cristal de quartzo) e é exposto a um padrão de interferência entre duas ondas planas coerentes ligeiramente defasadas entre si. Este padrão é gravado em todo o volume do material holográfico da mesma forma que um filme fotográfico grava uma imagem quando exposto à luz. O resultado final é um meio com índice de refração variando periodicamente em torno de um valor médio e é justamente esta modulação no índice de refração a responsável pela dispersão da luz por esta rede.

Na literatura, estas redes são chamadas de Volume-Phase Holographic Gratings, redes VPH ou mesmo VPHG. O termo "volume" é utilizado para especificar redes que possuem 

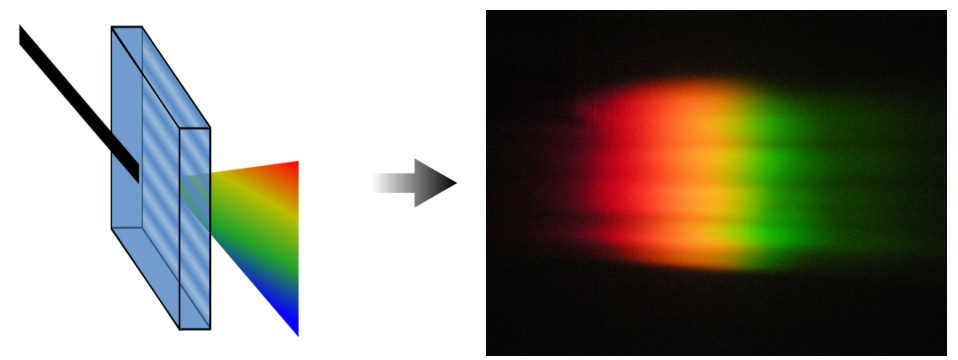

Figura 1.3: Feixe de luz originado em um cabo contendo diversas fibras ópticas e espalhado por uma rede de difração holográfica. O desenho à esquerda representa a primeira ordem de difração da primeira rede, ilustrada na foto à direita.

uma modulação do índice de refração dentro de todo o seu volume. Na prática, existem redes cuja variação do índice de refração ocorre apenas em sua superfície. Entretanto, dentro de todo o corpo desta dissertação, apenas as redes do primeiro tipo serão citadas.

As diferenças entre redes VPH e redes de difração comuns vão muito além da sua construção. Nas redes comuns, cada fenda é considerada uma nova fonte luminosa puntual e a inferterência entre elas ocorre em sua amplitude. No caso de uma VPH, a interferência entre os raios que emergem da rede acontece devido à variação de fase que é adicionada a cada um deles. Outra grande diferença é que as redes holográficas podem ser ajustadas para possuir um pico máximo em diferentes comprimentos de onda, de acordo com o ângulo que a luz incide sobre ela.

Assim como uma rede comum, parte da luz incidente em uma VPH é transmitida/refletida normalmente, i.e., sem sofrer espalhamento algum. Esta parte corresponde à chamada difração de ordem zero. No caso do iBTF utilizado dentro do BTFI, a ordem zero da primeira rede é utilizado como canal de entrada para o filtro Fabry-Pérot, explicado com mais detalhes posteriormente.

O restante da luz segue em diferentes ângulos de acordo com o seu comprimento de onda e a sua ordem de interferência. No caso das redes comuns, este espalhamento ocorre em uma única direção de acordo com a orientação das suas fendas. Com isso, a informação espacial é comprometida mas a informação espectral torna-se evidente. O mesmo ocorre quando a luz atravessa apenas uma das redes utilizadas no iBTF (figura 1.3).

Entretando, VPHGs possibilitam que a luz espalhada por uma primeira rede seja recombinada ao incidir sobre uma segunda rede desde que elas sejam idênticas entre si e que estejam orientadas corretamente. Como resultado, tem-se uma imagem filtrada em 

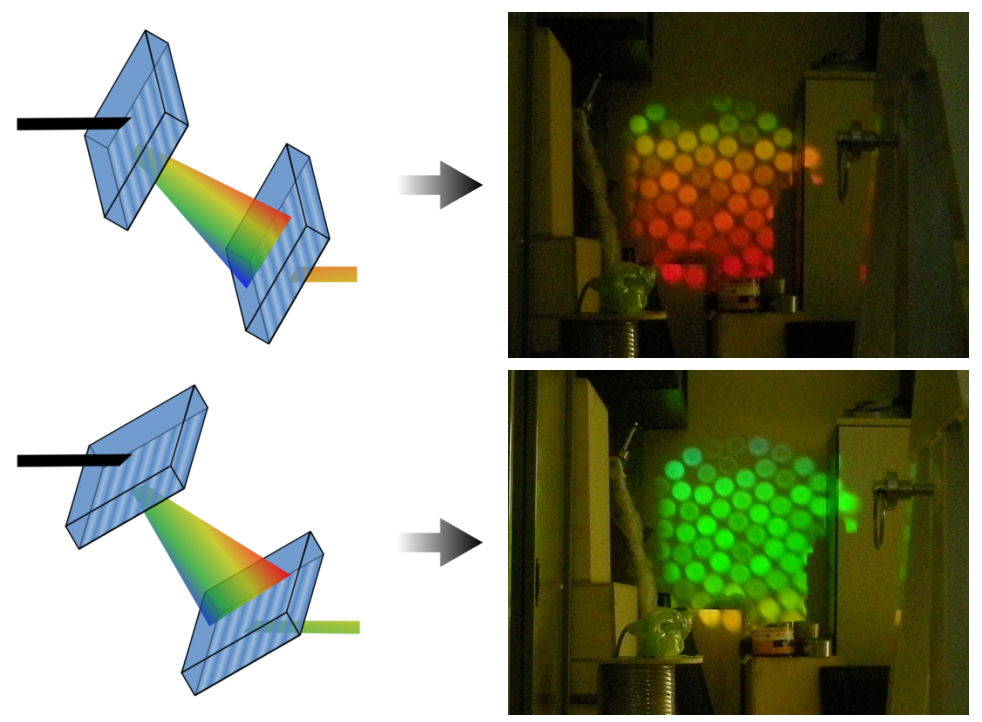

Figura 1.4: À esquerda: representação simplificada de duas redes de difração em duas diferentes configurações. À direita, fotos obtidas em laboratório mostrando um feixe de luz proveniente de um cabo de fibras ópticas iluminado por uma lâmpada incadescente passando através do iBTF com as redes a $45^{\circ}$ (figuras superiores) e $35^{\circ}$ (figuras inferiores).

um comprimento de onda determinado pelas características das redes e pela geometria do sistema. Este comprimento de onda central pode ser ajustado simplesmente mudando-se o ângulo relativo entre as superfícies das redes e o eixo óptico do sistema, justificando o nome de filtro ajustável (figuras 1.4).

Os limites espectrais alcançados por uma rede de acordo com os ângulos definem o intervalo espectral (spectral range) de uma rede de difração holográfica. No caso do BTFI, sua construção opto-mecânica permite apenas ângulos compreendidos entre $25^{\circ}$ e $45^{\circ}$. Sendo um pouco mais prático, o alcance espectral de uma VPH é definido pelos comprimentos de ondas obtidos ao posicionar as redes entre os dois ângulos citados acima.

Entretanto, teoricamente falando não há nenhuma equação direta que descreva analiticamente este comportamento. Na prática, utiliza-se o Critério de Bragg para se determinar as características que uma rede deve ter para que um determinado comprimento de onda desejado atravesse o filtro quando as redes estiverem orientadas à $35^{\circ}$. Isto determina o centro da região espectral em que o iBTF atua com eficiência dentro das especificações técnicas.

Outra característica importante de uma rede de difração é a sua largura de banda, muitas vezes definida como a largura à meia altura (FWHM) ou pela sua resolução es- 
pectral. Como será mostrado mais adiante, alguns modelos fornecem uma aproximação grosseira da largura de banda de uma VPH.

A fim de cumprir a promessa feita no início do seu desenvolvimento de varrer todo o espectro óptico a partir do ultra-violeta (UV) próximo até o infra-vermelho próximo (IR) com resoluções espectrais indo de 5 até 2000, é necessário obter um conjunto completo de redes de difração holográficas centradas em diferentes comprimentos de onda e com resoluções espectrais.

A escolha das redes de difração holográficas que serão utilizadas no iBTF foi feita utilizando modelos numéricos estudados com esta finalidade. Os modelos estudados serão apresentados no capítulo 2 seguindo um nível crescente de complexidade e detalhamento. Nesse capítulo, também será dada uma breve descrição do software desenvolvido, exemplos de simulações de redes de difração holográficas e a lista de redes selecionadas.

\subsection{Os anéis de Fabry-Pérot}

O segundo filtro utilizado dentro do instrumento BTFI será um filtro do tipo FabryPérot (FP). Para ser mais exato, o BTFI conta com dois filtros deste tipo. O primeiro deles é posicionado junto à roda de filtros acoplada à entrada do instrumento. Sua principal função é realizar uma pré-seleção das ordens de interferência.

O outro Fabry-Perot, é posicionado no espaço onde a luz é colimada, logo após o iBTF recebendo a ordem zero da primeira rede de difração. Este segundo FP é quem recebe atenção especial nesta dissertação de mestrado visto que ele é quem realmente exerce a função de filtro interferencial na construção de cubos de dados hiperespectrais.

De uma maneira geral, a teoria envolvida no estudo de espectros já é conhecida desde o final do século XIX, quando os cientistas Charles Fabry e Alfred Pérot construíram a primeira versão desse magnífico instrumento. Sua construção relativamente simples permite que resultados analíticos e aproximações utilizando séries infinitas prevejam com bastante precisão a eficiência deste instrumento.

Um Fabry-Pérot, ou étalon como também é chamado, é composto basicamente por duas placas de vidro (ou algum tipo de cristal) paralelas entre si, separadas por uma pequena distância formando uma cavidade óptica. As superfícies de cada uma destas placas voltadas para a cavidade recebe um tratamento especial visando um alto coeficiente de reflexão. 
Veremos mais tarde que a reflectância destas superfícies internas está diretamente ligada com a qualidade do espectro obtido.

Um raio de luz que entra nesta cavidade óptica sofre múltiplas reflexões antes de conseguir sair novamente. Em cada uma dessas reflexões, uma pequena porção da luz escapa desta cavidade. Deste modo, todos estes raios que escapam acabam interferindo entre si e, consequentemente, apenas um comprimento de onda consegue atravessar o FP.

Devido a sua simetria axial, a resposta de um Fabry-Pérot iluminado por um feixe monocromático é um conjunto de anéis concêntricos representando diferentes ordens de interferência. O diâmetro destes anéis está relacionado com o comprimento de onda da fonte, do ângulo com que um determinado raio pertencente ao feixo incide sobre o FP e da distância entre as duas placas de vidro.

Consequentemente, uma única imagem não é o suficiente para recuperar toda a informação espacial contida no feixe de entrada. Uma técnica empregada atualmente é a realização de uma varredura variando continuamente a distância entre as placas, muitas vezes chamada de gap, enquanto várias imagens são obtidas. Conforme o gap vai aumentando, os anéis vão crescendo até atravessar todo o campo do detector.

Este conjunto de imagens forma o que é chamado de cubo de dados ou cubo hiperespectral. Nele, a informação relacionada com um comprimento de onda em específico está distribuída por todo o cubo. Um tratamento especial chamado correção de fase deve ser realizado para reordenar o cubo de modo que cada um dos seus quadros (eixos X e Y) contenha toda a informação relacionada com um comprimento de onda em específico.

Além de separar os comprimentos de onda misturados dentro de um cubo obtido com Fabry-Pérot, é necessário identificar cada pico de transmissão. Em outras palavras, a chamada calibração em comprimento de onda faz com que o eixo $\mathrm{Z}$ do cubo de dados contenha informações espectrais sobre o objeto observado.

No final, o cubo é obtido de tal forma que cada um dos quadros seja uma imagem monocromática e, analisando-se um mesmo píxel numa posição fixa dentro do cubo, seja possível obter o espectro da região correspondente.

Uma das propostas do BTFI é possuir um pacote de redução de dados semi-automático de modo que o astrônomo usuário entre apenas com os parâmetros necessários para uma observação completa e obtenha diretamente os dados já reduzidos e corrigidos. O sistema 
em desenvolvimento encarregado deste tipo de tratamento de dados é chamado de Butterfly Software System. Este sistema será o responsável não apenas pela calibração e correção de fase do cubo de imagens como também pela quantificação do paralelismo entre as placas, tratamento de ruídos, etc.

Os pacotes em desenvolvimento utilizam um software chamado Illusion Data-Cube Synthesizer criado com o intuito de gerar cubos hiperespectrais através de uma modelagem numérica dos filtros Fabry-Pérot posicionados no feixe colimado do aparato óptico do BTFI. A segunda parte deste trabalho apresentará com mais detalhes um pouco da teoria envolvida na transmissão de luz através dos FPs, a formação de um cubo de dados e, como resultados finais, os tipos de cubos que podem ser gerados utilizando-se o Illusion.

\subsection{Explicitando objetivos}

Parte do trabalho realizado junto ao instrumento BTFI teve um caráter experimental, como a participação no alinhamento óptico do instrumento como um todo, testes de controle dos motores responsáveis pelo movimento das redes de difração do iBTF, mapeamento de zonas de risco em que os suportes mecânicos para as redes podem colidir com outros equipamentos óptico, foram de grande importância tanto para o desenvolvimento do instrumento quanto para a formação na área.

Entretanto, queremos deixar claro aqui que a presente dissertação possui um foco maior na parte de modelagem numérica dos equipamentos até agora descritos. Através desta modelagem numérica é possível conhecer melhor o equipamento e atacar problemas específicos simulando diferentes e possíveis situações.

Além disto, conforme já foi dito, temos também a questão da integração desses modelos com o restante dos pacotes em desenvolvimento para o tratamento e redução dos dados obtidos com o instrumento em questão.

No caso específico de redes de difração holgráficas, a principal motivação para recorrer aos modelos computacionais foi o custo de cada uma destas redes. Por serem encomendadas especialmente para o caso do BTFI, seu custo pode variar de 500 à mais de 60000 dólares dependendo do material holográfico utilizado na sua construção e a sua espessura.

No mercado existem softwares comerciais especializados em simulações de redes de difração de todos os tipos, incluindo as holográficas. Além do problema do alto custo 
das licenças, não seria possível integrar este tipo de software com o restante desenvolvido especialmente para o BTFI.

No caso de filtros Fabry-Pérot, o desenvolvimento de um pacote de simulação de dados obtidos com este filtro visou o entendimento pleno do processo de criação de um cubo de dados. Além disto desejava-se estudar com maior cautela e detalhamento os diversos problemas relacionados dentro do contexto deste tipo de filtros.

Por fim, buscava-se utilizar este pacote de sintetização de dados na elaboração e nos testes de novos softwares aplicados à Fabry-Pérot, especialmente ao caso do BTFI.

Apresenta-se agora todo um capítulo relacionado com as simulações de redes de difração holográficas, modelos e resultados. Posteriormente será apresentado o capítulo que trata dos filtros Fabry-Pérot de uma forma bastante didática e focada em dados tridimensionais. O último capítulo resumirá os resultados obtidos em ambas vertentes da dissertação apresentando onde os softwares criados tem sido utilizados e o que ainda precisa ser feito em cada um deles. 
Capítulo 2

\section{Modelando e escolhendo redes VPH}

Na introdução deste trabalho, relatou-se a importância das redes de difração holográficas dentro do projeto BTFI. Reforçando um pouco o que já foi dito, estas redes são os elementos ópticos principais para o filtro chamado iBTF ou imaging Bragg Tunable Filter. Seu nome sugere o critério que define o comprimento de onda que é selecionado com este filtro que é dado pela equação de Bragg (Kittel (1953)).

Originalmente, esta equação é aplicada na caracterização de estruturas cristalinas metálicas. Para ser mais específico, ao incidir um feixe de raios $\mathrm{X}$ sobre uma estrutura deste tipo, ele pode sofrer difração em determinados ângulos. Sabendo-se o comprimento de onda da fonte e o ângulo em que há um pico de difração é possível determinar-se a distância entre dois planos paralelos de átomos dentro da estrutura cristalina. A dispersão ocorre quando a diferença de caminho óptico entre a onda refletida no primeiro plano e a onda refletida no plano subsequente é um múltiplo inteiro do comprimento de onda. Esta diferença de caminho óptico é representado em vermelho na figura 2.

Nela o comprimento de onda está representado pela letra grega $\lambda$, o ângulo com que o feixe incide sobre o material analisado é representado pela letra $\theta$ e a distância entre dois planos é dada pela letra $a$. A letra $m$ é um número inteiro qualquer e está relacionado com a ordem de interferência. Através de geometria simples, conclui-se que a equação de Bragg pode ser representada como a equação 2.1 .

$$
m \lambda=2 \operatorname{asin}(\theta)
$$

Conforme mencionado anteriormente, nas redes VPH o índice de refração varia periodicamente. Em alguns modelos ela chega a ser aproximada a um seno, cosseno ou até 


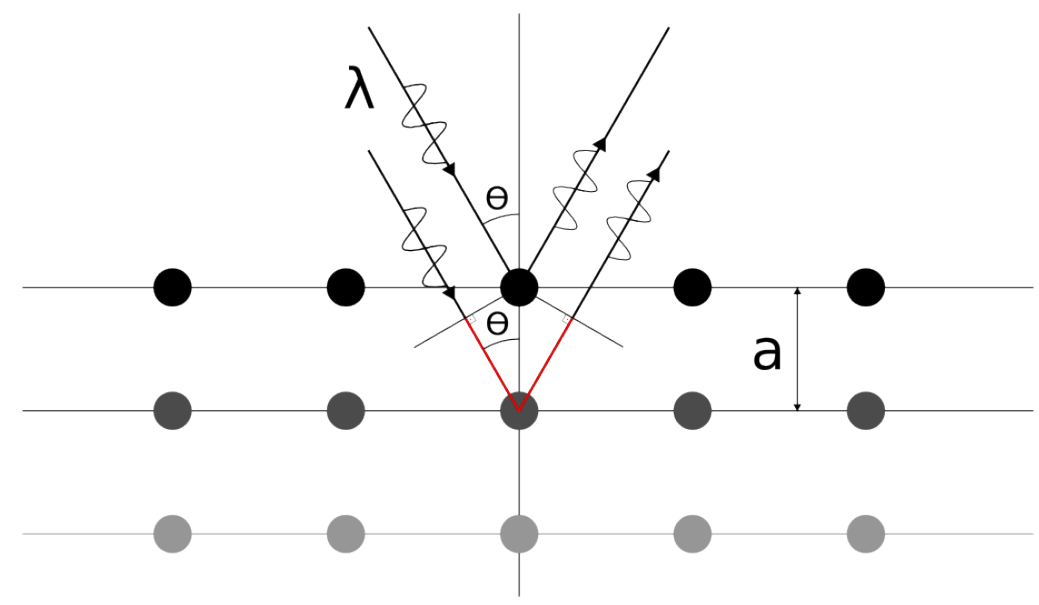

Figura 2.1: Representação esquemática da diferença de caminho óptico entre dois feixes luminosos incidindo com o mesmo ângulo sobre um material cristalino qualquer.

mesmo numa série de Fourier. De qualquer modo, dentro do material holográfico é possível encontrar vários planos cujo índice de refração são idênticos. Isto justifica o uso da equação de Bragg adaptada ao caso de VPHGs, conforme será mostrado durante o formalismo a seguir.

Esta variação no índice de refração é gravada no material holográfico, tal como gelatina dicromada (dichromated gelatin ou $D C G$ ) ou vidro dopado (doped-glass ou $D$ - $G$ ), da mesma forma que uma imagem é gravada numa placa fotográfica. A diferença das duas é que, numa placa fotográfica, a intensidade luminosa é gravada em um material sensível à luz enquanto num holograma a informação armazenada é a fase da luz que é gravada ao modular o índice de refração. No caso, o filme holográfico é exposto a um padrão de interferência entre dois feixes luminosos monocromáticos e coerentes entre si. Este padrão de interferência é o responsável pela modulação do índice de refração do material holográfico. Este padrão é gravado em todo o volume da rede e, não apenas em sua superfície, justificando o fato de que, em inglês, estas redes têm o nome de Volume-Phase Holographic Gratings (VPHGs ou redes VPHs). A figura 2.2 mostra uma fotografia tirada de uma rede de difração holográfica.

Geralmente não temos distinção na nomeclatura de redes de difração holográficas com hologramas apenas na superfície ou em todo o seu volume. Para evitar qualquer tipo de confusão, as únicas redes a serem tratadas neste documento são aquelas cujo holograma é gravado em todo o seu volume. 


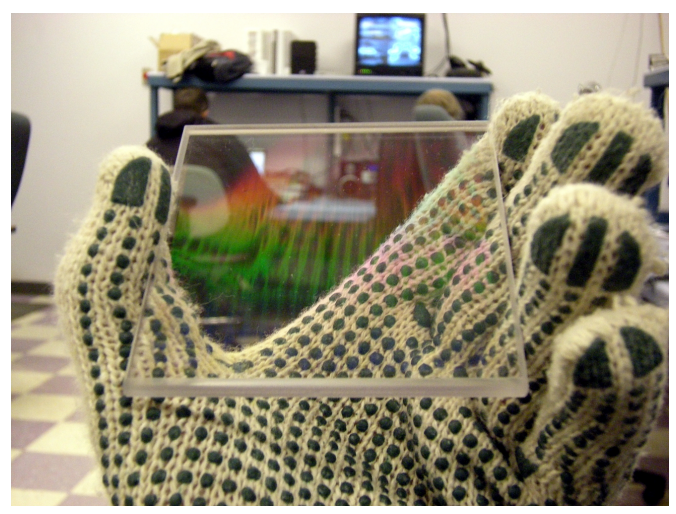

Figura 2.2: Imagem obtida em laboratório de uma rede de difração holográfica.

O modo com que esta modulação é gravada no filme holográfico define qual é o comportamento final de uma rede VPH. No caso, as grandezas que o caracterizam e que realmente interessam no ponto de vista científico são o comprimento de onda central, i.e., o comprimento de onda observado ao posicionar ambas as redes a $35^{\circ} \mathrm{em}$ relação ao eixo óptico do sistema, a resolução espectral, definida como a razão entre o comprimento de onda de interesse e a largura da banda selecionada à meia altura do pico de eficiência e o intervalo espectral compreendido entre os comprimentos de onda obtidos com as redes orientadas nos ângulos mínimo e máximo possíveis de acordo com a construção do instrumento.

O processo de escolha do conjunto completo de redes que acompanharão o instrumento BTFI no telescópio SOAR depende intrinsicamente do estudo entre a relação estre suas características físicas e ópticas. Para tal, dois modelos teóricos foram estudados e um software foi desenvolvido utilizando-se cálculo numérico para prever a eficiência das VPHGs.

O primeiro destes modelos, chamado de modelo de Kogelnik, considera a interferência entre a onda incidente e a onda emergente fazendo diversas aproximações e limitandose ao caso de redes de difração mais espessas. Sua maior vantagem é a simplicidade e versatilidade no sentido de que permite que redes com ângulo de deslocamento arbitrário sejam simuladas.

O modelo de análise rigorosa de ondas múltiplas é uma extensão do modelo de Kogelnik a ordens maiores de interferência mas veta-se o caso em que o ângulo de inclinação entre a reta normal ao plano de modulação do índice de refração e a normal à superfície da rede é nulo (modo puro de reflexão).

Antes de apresentar cada um destes modelos estudados, é interessante descrever de- 
talhadamente uma das possíveis representações das redes de difração holográficas. Desta forma, uniformizando-se a linguagem empregada, é possível facilitar a compreensão e a comparação entre estes modelos. No final do capítulo, serão apresentadas as redes VPH escolhidas para uso no BTFI bem como as justificativas que levam a tal escolha.

\subsection{Representação e Notação}

Redes de difração holográficas são caracterizadas principalmente pela modulação periódica do seu índice de refração. Justamente pelo fato desta variação ocorrer periodicamente, é justificável dizer que a distância entre dois planos consecutivos cujos valores do índice de refração são idênticos é o período da modulação do índice de refração ou, simplesmente, o período da rede de difração. Alguns autores também costumam chamar este parâmetro de constante de rede. Entretanto, é mais comum representarmos esta variável pela frequência linear da rede, analogamente às redes comuns.

Em segundo lugar, o índice de refração de uma rede em específico varia entre um determinado valor máximo e um valor mínimo, sempre centrados no índice de refração do material antes da modulação. As diferenças entre este máximo e este mínimo definem a amplitude da modulação do índice de refração. É muito comum também definir este parâmetro através da razão entre a amplitude da rede e o índice de refração médio, chamado de força da rede de difração.

Um terceiro parâmetro importante na construção de uma rede holográfica é o ângulo que define direção em que a modulação do índice de refração ocorre, comumente chamado de ângulo de inclinação da rede. Este ângulo é medido em relação ao eixo perpendicular à superfície das redes, possuindo valores positivos quando deslocado no sentido anti-horário.

O último parâmetro físico relevante nos modelos a seguir é a espessura da rede de difração holográfica. De um modo simples, esta é a espessura que o filme holográfico depositado entre as duas placas de vidro possui podendo variar de poucos microns até cerca de $2 \mathrm{~mm}$, sendo limitado pelos processos de fabricação existentes. A espessura da rede interfere diretamente na resolução espectral com que ela irá trabalhar. Redes mais espessas costumam ser fabricadas com vidro dopado enquanto as mais finas são feitas com gelatina dicromada cada uma com suas particularidades no processo de fabricação.

A representação dos modelos exige não apenas os parâmetros intrínsecos às redes de 


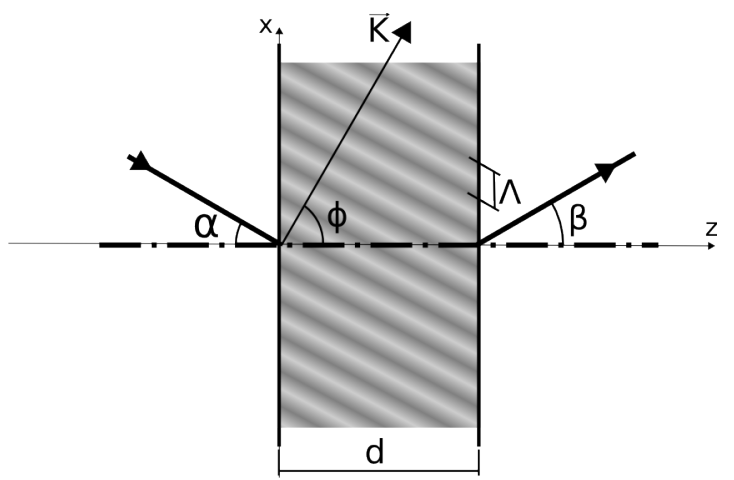

Figura 2.3: Representação genérica de uma rede de difração. Veja a definição das variáveis no texto.

difração, mas também variáveis relacionadas com as condições em que esta se encontra. Primeiramente, é de suma importância definir um sistema de coordenadas.

Sua origem é definida, então, como o ponto em que o raio de luz incide sobre a rede. A partir deste ponto, define-se o eixo $\mathrm{Z}$ através da reta normal à superfície da rede com valores crescentes seguindo-se o sentido de propagação da luz. Paralelo à rede e contido no plano de incidência (plano do papel) encontra-se o eixo X com valores crescentes no sentido para cima. Nesta configuração o eixo Y é definido automaticamente considerando o fato de que este deve ser perpendicular aos outros dois eixos.

O sistema como um todo é montado de tal forma que a direção da modulação do índice de refração da rede holográfica está também contida no plano de incidência. Com esta configuração, o raio de luz que chega na rede, o que sai dela e a direção de modulação encontram-se no plano ZX, fazendo com que todo o tratamento seja simplificado ao caso bidimensional.

As variáveis descritas são representadas graficamente na figura 2.3 onde $\alpha$ e $\beta$ são os ângulos de incidência e de difração, $\Lambda$ é o período da rede VPH, $d$ é a espessura do material holográfico e $\phi$ representa o ângulo entre o eixo principal da rede (eixo Z) e o chamado vetor da rede $\vec{K}=2 \pi / \Lambda$ que define a direção da modulação. O índice de refração e a amplitude da sua modulação, mostrado pelas listras cinzas da figura em questão, são definidos pelas variáveis $n$ e $\Delta n$, respectivamente.

Nos modelos em questão, o substrato é considerado como muito espesso e as reflexões na interface entre ele e o ar são desprezadas bem como as reflexões na sua interface com o material holográfico. O ângulo de incidência no ar $\alpha_{a r}$ é definido como o ângulo entre o raio 
Tabela 2.1 - Constantes para a equação de Sellmeier (eq. 2.3 para $\lambda$ em $\mu m$

\begin{tabular}{lccccccc}
\hline Material & $\mathrm{A}$ & $\mathrm{B}$ & $\mathrm{C}$ & $\mathrm{D}$ & $\mathrm{E}$ & $\mathrm{F}$ & $\mathrm{G}$ \\
\hline Fused Silica & 1 & 0.6962 & 0.06840 & 0.4079 & 0.1162 & 0.8975 & 9.8962 \\
$\mathrm{Si}$ & 1 & 10.6684 & 0.3015 & 0.0030 & 1.1347 & 1.5413 & 1104.0 \\
GaAs & 3.5 & 7.4969 & 0.4082 & 1.9347 & 37.17 & 0 & 0 \\
\hline
\end{tabular}

incidente de luz e o eixo Z, sendo positivo no sentido anti-horário. Dentro do substrato, o ângulo de incidência $\alpha$ deve ser corrigido utilizando a Lei de Snell (eq 2.2):

$$
\sin \left(\alpha_{a r}\right) n_{a r}=\sin (\alpha) n
$$

Onde $n$ é o índice de refração do substrato, calculado em função do comprimento de onda $\lambda$ de acordo com a equação de Sellmeier, mostrada na equação 2.3 abaixo:

$$
n(\lambda)=A+\frac{B \lambda^{2}}{\lambda^{2}-C^{2}}+\frac{D \lambda^{2}}{\lambda^{2}-E^{2}}+\frac{F \lambda^{2}}{\lambda^{2}-G^{2}}
$$

Constantes para alguns materiais são mostradas na tabela 2.1, obtida originalmente em Saleh e Teich (2007), no caso do comprimento de onda ser dado em micrometros.

O ângulo de inclinação da rede é a principal responsável no comportamento das VPHGs é quanto ao modo em que elas atuam (figura 2.4). Quando a direção em que a oscilação ocorre é paralela ao eixo principal da rede, i.e., quando os planos com índice de refração constante são paralelos à sua superfície, a maior parte da dispersão da luz ocorre quando esta é refletida. Num outro extremo, quando a direção da modulação ocorre perpendicularmente ao eixo normal à rede, ou seja, os planos cujo índice de refração é constante são perpendiculares à superfície da rede, a VPHG atua em modo de transmissão.

Genericamente falando, o ângulo de inclinação da rede, representado por $\phi$, pode assumir qualquer valor entre $0^{\circ}$ e $90^{\circ}$. O modo de atuação é determinado então pelos modelos a serem apresentados. Entretanto, sabe-se que, nos limites apresentados acima, a rede atua apenas em um dos modos. E estes foram os únicos casos estudados. Redes com outros ângulos de inclinação não chegaram a ser estudadas pelo simples fato de não serem do interesse do projeto. 


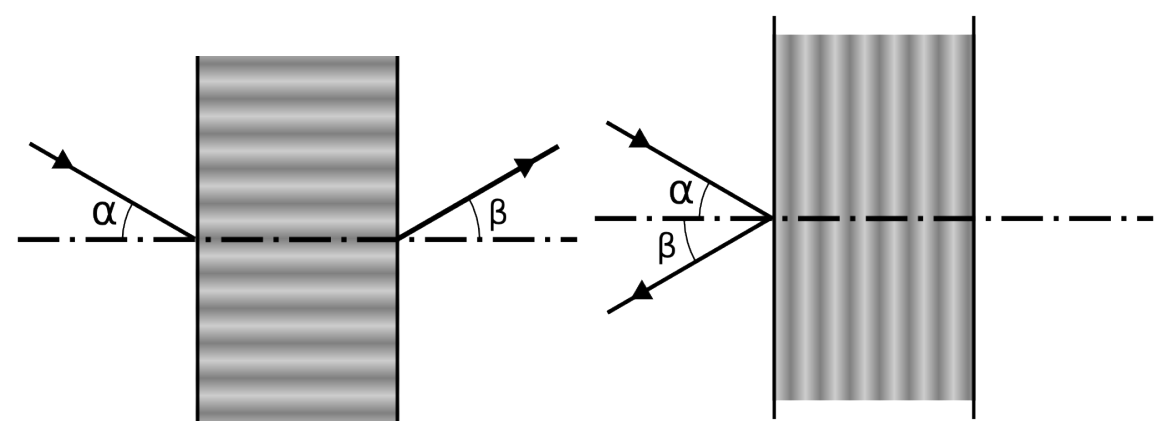

Figura 2.4: Modos de atuação de uma VPH. A figura à esquerda representa uma rede atuando em modo de transmissão. A da direita representa uma rede em modo reflexão.

Por fim, o comprimento de onda que é selecionado pela VPH é determinado utilizando a condição de Bragg, já apresentada neste capítulo. Na sua versão adaptada para redes VPH, a equação 2.1 assume a forma da equação 2.4. No caso em que a condição de Bragg é satisfeita, os ângulos $\alpha$ e $\beta$ são iguais entre si, sendo substituídos por $\theta$. Este caso é explicitado através do índice 0 no comprimento de onda e no ângulo de incidência.

$$
m \lambda_{0}=2 n \Lambda \cos \left(\phi-\theta_{0}\right)
$$

Utilizando a notação e a linguagem descritas, a descrição dos modelos torna-se muito mais simples e mais clara. Partindo do modelo mais simples, o primeiro a ser apresentado é o modelo de Kogelnik.

\subsection{Modelo de Kogelnik}

O modelo de Kogelnik é um dos mais simples encontrado na literatura. Seu nome é dado ao autor do artigo entitulado Coupled Wave Theory for Thick Hologram Gratings (teoria de ondas acopladas para redes de difração holográficas espessas), Kogelnik (1969). Como o seu próprio nome diz, este modelo considera a existência de ondas acopladas por uma rede de difração holográfica espessa. As ondas consideradas são representadas pela luz incidente e pela primeira ordem de difração

Este modelo utiliza diversas considerações durante o desenvolvimento do seu formalismo matemático. O próprio título deste artigo já demonstra uma primeira restrição quanto à espessura da rede. O parâmetro numérico que determina se uma rede holográfica é espessa ou não é a sua profundidade óptica, definida na equação 2.5 onde as variáveis utilizadas 
seguem a notação da seção anterior. No caso, são consideradas redes espessas aquelas com $Q>>1$, sendo $Q=10$ um valor razoável.

$$
Q=\frac{2 \pi \lambda d}{n \Lambda^{2}}
$$

Esta restrição é consequência de várias outras considerações feitas no modelo. Uma delas é a respeito da troca de energia entre as duas ondas acopladas. Considerando-se que esta troca é realizada lentamente dentro da rede de difração, derivadas de segunda ordem que surgem nas equações diferenciais acopladas (Eq. 2.17 e 2.16) podem ser ignoradas.

A modulação do índice de refração é dada indiretamente. Numa primeira instância, o formalismo faz uso da modulação da permissividade elétrica $\epsilon$ e da condutividade elétrica $\sigma$ do material holográfico (eq. 2.6). Em ambas as equações, o índice 0 representa o valor médio de cada um dos parâmetros e $\Delta$ representa a amplitude da modulação da variável em questão. Vale lembrar também que $\vec{r}$ é o vetor posição de um ponto qualquer no espaço.

As redes são dispostas de tal forma que o vetor $\vec{K}$ que define a direção com que a modulação ocorre está sempre contido no plano definido pelo raio que incide na rede e o eixo perpendicular à ela (plano XZ - eq. 2.7).

$$
\begin{gathered}
\epsilon(x, z)=\epsilon_{0}+\Delta \epsilon \sin (\vec{K} \cdot \vec{r}) \\
\sigma(x, z)=\sigma_{0}+\Delta \sigma \sin (\vec{K} \cdot \vec{r}) \\
\epsilon(x, z)=\epsilon_{0}+\Delta \epsilon \sin [K(x \sin \phi+z \cos \phi)] \\
\sigma(x, z)=\sigma_{0}+\Delta \sigma \sin [K(x \sin \phi+z \cos \phi)]
\end{gathered}
$$

No caso das redes simuladas para o BTFI, considera-se que o material holográfico é um dielétrico perfeito com condutividade elétrica nula e com uma pequena variação na permissividade elétrica $\left(\Delta \epsilon<<\epsilon_{0}\right)$. Esta consideração faz com que, de imediato, o índice de absorção do material seja desprezado e que o problema volte a ser descrito unicamente por $\Delta n$ através de uma aproximação de primeira ordem utilizando Série de Taylor (eq. 2.8).

$$
\Delta n=\frac{1}{2} \frac{1}{\sqrt{\epsilon_{0}}} \Delta \epsilon
$$

Feitas as considerações relacionadas com o meio com que a luz propaga, utiliza-se as equações de Maxwell em todo o espaço para chegar-se à equação de onda para o campo 
elétrico $E$ (eq. 2.9). A princípio, considera-se apenas o caso em que o campo elétrico é tangencial à superfície da rede de difração (polarização S). Nela, $\nabla^{2}$ é o operador escalar laplaciano, $E(x, z)$ é a amplitude complexa da componente $\mathrm{Y}$ do campo elétrico e $k$ é a constante de propagação, descrita pela equação 2.10 .

$$
\begin{gathered}
\nabla^{2} E+k^{2} E=0 \\
k^{2}=\beta^{2}+4 \kappa \beta \cos (\vec{K} \cdot \vec{r})
\end{gathered}
$$

As duas constantes que surgem na definição da constante de propagação dentro da rede são chamadas de constante média de propagação ( $\beta$ - eq. 2.11) e constante de acoplamento $(\kappa$ - eq. 2.12). A justificativa para o nome de cada uma dessas variáveis virá conforme conveniente.

$$
\begin{gathered}
\beta=\frac{2 \pi n}{\lambda} \\
\kappa=\frac{\pi \Delta n}{\lambda}
\end{gathered}
$$

Neste ponto é feita a suposição de que apenas duas ondas permeiam o espaço. A primeira delas é chamada de onda referência $(R)$ e ela representa o feixe de luz que incide sobre a rede. A segunda onda $(S)$ representa a luz difratada. Assim, o campo elétrico que permeia o espaço é dado pela superposição destas duas ondas.

$$
E=R(z) e^{-j \vec{\rho} \cdot \vec{r}}+S(z) e^{-j \vec{\sigma} \cdot \vec{r}}
$$

Os vetores que aparecem na exponencial são os vetores de propagação de cada uma das ondas e $j=\sqrt{-1}$. O fato de que ambos estejam relacionados com $\beta$ justifica sua denominação. O vetor $\vec{\rho}$ aponta a direção que a luz seguiria na ausência da VPHG. O vetor $\vec{\sigma}$ é obtido impondo-se a condição de que $\vec{\sigma}=\vec{\rho}-\vec{K}$ (figura 2.5.

$$
\vec{\rho}=\beta\left(\begin{array}{c}
\sin (\theta) \\
0 \\
\cos (\theta)
\end{array}\right)
$$




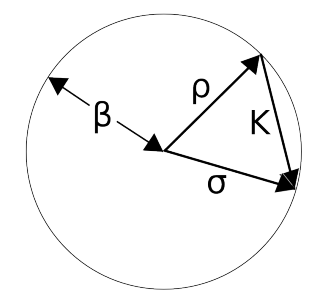

Figura 2.5: Diagrama de vetores para incidência satisfazendo critério de Bragg.

$$
\vec{\sigma}=\beta\left(\begin{array}{c}
\sin (\theta)-\frac{K}{\beta} \sin (\phi) \\
0 \\
\cos (\theta)-\frac{K}{\beta} \cos (\phi)
\end{array}\right)
$$

Finalmente o sistema de equações diferenciais de segunda ordem são obtidas aplicandose as equações 2.13 e 2.10 na equação de onda 2.9. As duas equações que aparecem no sistema são acopladas entre si através da variável $\kappa$, justificando o termo constante de acoplamento.

$$
\begin{aligned}
R^{\prime \prime}-2 j R^{\prime} \rho_{z}+2 \kappa \beta S & =0 \\
S^{\prime \prime}-2 j S^{\prime} \sigma_{z}+\left(\beta^{2}-\sigma^{2}\right)+2 \kappa \beta R & =0
\end{aligned}
$$

Neste sistema de equações, as aspas representam as derivadas de primeira e segunda ordem em relação à direção Z. $\rho_{z}$ e $\sigma_{z}$ representam a componente nesta mesma direção dos vetores de propagação definidos anteriormente.

A solução para as equações diferenciais é iniciada desprezando-se as derivadas de segunda ordem. Tal operação leva em consideração o fato de que a troca de energia entre as duas ondas envolvidas ocorre lentamente dentro da rede. De certa forma, este é um dos motivos pelo qual este formalismo é aplicado apenas em casos de redes mais espessas. Além disto, considera-se que esta troca de energia seja dada apenas dentro da rede e apenas na direção z.

Os cálculos realizados são separados nos casos em que a rede atua em modo de transmissão ou em modo de reflexão. O modo de atuação de uma rede de difração é determinado através do fator de inclinação $c$ da rede (eqs. 2.18), definido como a razão entre os cossenos diretores $c_{R}$ e $c_{S}$. Em casos que $c>0$, tem-se uma rede atuando em modo de transmissão. 
Para $c$ com valores negativos, a rede atua em modo de reflexão. A linha que separa um modo de outro surge no limite em que $c$ tende ao infinito.

$$
\begin{aligned}
c & =-\frac{c_{R}}{c_{S}} \\
c_{R} & =\cos \theta \\
c_{S} & =\cos \theta-\frac{K}{\beta} \cos \phi
\end{aligned}
$$

A primeira consequência direta na escolha do modo de atuação de uma rede está nas equações de contorno do sistema. Em ambos os casos, toda a energia é contida na onda de referência no ponto em que a luz incide sobre a rede e cai a zero conforme o acoplamento e a troca de energia entre ela e a onda difratada ocorre.

Resolvendo as equações diferenciais acopladas definidas anteriormente, encontra-se uma expressão analítica que descreve a amplitude da onda S. A intensidade relativa, ou melhor, a eficiência de uma rede, seja em modo de transmissão ou em modo de reflexão é dado pela equação 2.19 .

$$
\eta=\frac{\left|c_{S}\right|}{c_{R}} S S^{*}
$$

Para ondas de transmissão, a onda difratada é nula na origem e cresce conforme propaga-se para a direita. Neste caso, a eficiência total obtida da onda refratada é dada pela equação 2.20 .

$$
\eta=\frac{\sin ^{2} \sqrt{\nu^{2}+\xi^{2}}}{1+\frac{\xi^{2}}{\nu^{2}}}
$$

Onde,

$$
\begin{aligned}
\nu & =\frac{\kappa d}{\sqrt{c_{S} c_{R}}} \\
\xi & =\frac{\vartheta d}{2 c_{S}}
\end{aligned}
$$

A variável $\vartheta$ (eq. 2.23) que aparece na última equação é chamada de parâmetro de defasagem. Seu papel principal é medir o quão longe se está da condição de Bragg. Este parâmetro é utilizado tanto no caso de transmissão quanto no caso de reflexão. 


$$
\vartheta=K \cos (\phi-\theta)-\frac{K^{2}}{4 \pi n} \lambda
$$

Voltando novamente às condições de contorno, o caso de difração causada por reflexão mantém a condição em que a onda de referência é nula na origem. A diferença está no fato da onda difratada ser nula na extremidade oposta ao ponto de incidência, ou seja, em $z=d$. A eficiência total refletida é dada então pela equação 2.24

$$
\eta=\left(1+\frac{\left(1-\frac{\xi^{2}}{\nu^{2}}\right)}{\sinh ^{2} \sqrt{\nu^{2}-\xi^{2}}}\right)^{-1}
$$

Neste caso, $\xi$ e $\nu$ são dados por:

$$
\begin{aligned}
\nu & =\frac{j \kappa d}{\sqrt{c_{S} c_{R}}} \\
\xi & =-\frac{\vartheta d}{2 c_{S}}
\end{aligned}
$$

A generalização deste modelo é feita de forma a manter todo o formalismo e substituindose apenas a constante de acoplamento. Ela surge da generalização em que considera-se que o campo elétrico está contido no plano de incidência (XZ). Neste novo formalismo, a equação de onda é escrita para a grandeza vetorial $\vec{E}$ ao invés de aplicar-se unicamente sua amplitude complexa. Após manipulação matemática análoga ao caso de polarização S descrita até agora, uma nova constante de acoplamento surge conforme a equação 2.27 .

$$
\kappa_{\|}=-\kappa \cos 2\left(\theta_{0}-\phi\right)
$$

Obter a eficiência de uma onda refletida/transmitida passa a ser uma tarefa trivial sendo suficiente a substituição de $\kappa$ por $\kappa_{\|}$nas equações 2.21 e 2.25. A eficiência total de uma onda difratada considerando-se uma fonte de luz não polarizada é dada simplesmente pela média aritmética dos dois casos descritos.

\subsection{Análise Rigorosa de Ondas Acopladas}

Seguindo uma mesma linhagem que o modelo anterior, a Análise Rigorosa de Ondas Acopladas, ou RCWA (Rigorous Coupled-Wave Analisys), descrita por completo em Moharam e Gaylord (1981), segue um formalismo matemático que cai num sistema de equações 
diferenciais acopladas de segunda ordem. Além disso, da mesma forma que o modelo de Kogelnik, supõe-se que o campo elétrico possui apenas uma componente perpendicular ao plano de incidência (polarização S).

Enquanto o modelo de Kogelink considera simplesmente a existência de duas ondas luminosas durante todo o processo de difração, criando a necessidade de tratar-se os modos de reflexão e de transmissão separadamente, o modelo tratado nesta sessão possui uma abordagem mais ampla considerando simultaneamente a onda de incidência, ondas refletidas e ondas transmitidas.

Primeiramente, divide-se o espaço em três regiões distintas. A primeira delas é aquela que contém o feixe incidente. Junto com ele, esta região é permeada com as ondas refletidas pela rede de difração representadas por sua amplitude normalizada $R_{i}$ onde $i$ é um número inteiro qualquer representando o índice da onda em questão. A região definida após a rede de difração contém as ondas que puderam ser transmitidas através da rede representadas por $T_{i}$. As ondas que se propagam no interior da rede são representadas por $S_{i}(z)$. Matematicamente falando, estas três regiões podem ser definidas como:

- Região 1: $z<0$

- Região 2: $0<z<d$

- Região 3: $z>d$

Além de considerar um número maior de ondas, este modelo não impõe limitação alguma sobre a amplitude da oscilação do índice de refração. Desta forma, o modelo trabalha inteiramente com a amplitude de oscilação da permissividade elétrica do material holográfico. A única consideração quanto aos meios de propagação é a de que os três meios possuam a permeabilidade magnética idêntica à do vácuo.

O campo elétrico em cada uma das regiões é definido como a superposição de todas as ondas existentes naquele meio. A primeira condição imposta é a de que $E_{1}, E_{2}$ e $E_{3}$ - notação utilizada para representar a amplitude complexa de cada um dos campos nas 
regiões 1,2 e 3, respectivamente - devem estar em fase nas interfaces entre duas regiões consecutivas.

A equação de onda é mais uma vez aplicada à região interna da rede (eq. 2.9) considerando-se que a constante de propagação $k$ é igual à $\left.2 \pi \lambda^{-1} \sqrt{(} \epsilon(x, z)\right)$. Utilizandose novamente a equação 2.7 e supondo que infinitas ondas coexistem dentro da rede de difração, é possível obter-se um sistema com infinitas equações diferenciais de segunda ordem acopladas entre si (eq. 2.28).

$$
A S_{i}^{\prime \prime}=B S_{i}^{\prime}+C S_{i}+D S_{i+1}+E S_{i-1}
$$

A equação acima foi escrita apenas para ilustrar como que a i-ésima onda está acoplada às suas vizinhas. As constantes $\mathrm{A}, \mathrm{B}, \mathrm{C}, \mathrm{D}$ e E são constantes que dependem de diversas variáveis relacionadas com a configuração do sistema. Por razões de clareza e simplicidade optou-se por não defini-las neste trabalho. Para obter-se o formalismo completo o leitor deve consultar o artigo original - Moharam e Gaylord (1981).

O índice "i" representam as diferentes ordens de interferência e seu valor máximo depende da precisão exigida na simulação. Este sistema de equações é obtido diretamente aplicando-se a equação que descreve a modulação do índice de refração em função de um cosseno (analogamente à eq 2.6) na equação de onda aplicado ao campo elétrico no interior da rede. Nesta região, o campo elétrico é dado pela superposição de um número arbitrário de ondas com índice "i". No caso, a onda de índice 1, está acoplada com as ondas de índice 0 e 2. A onda de índice 2, com as de índice 1 e 3 e assim por diante. Um número infinito de ondas pode ser considerado neste ponto e o limite máximo é determinado por limitações computacionais.

Este sistema pode ser reescrito na forma matricial considerando a amplitude normalizada de cada onda e de sua derivada de primeira ordem como variáveis de estado conforme a equação 2.29 onde $S_{i}^{\prime \prime}, S_{i}^{\prime}$ e $S_{i}$ são derivadas de segunda, primeira e zero ordem de cada uma das ondas $i$ consideradas. As constantes $a, b_{i}$ e $c_{i}$ estão intimamente relacionadas com a configuração do sistema e são descritas detalhadamente no artigo original. 


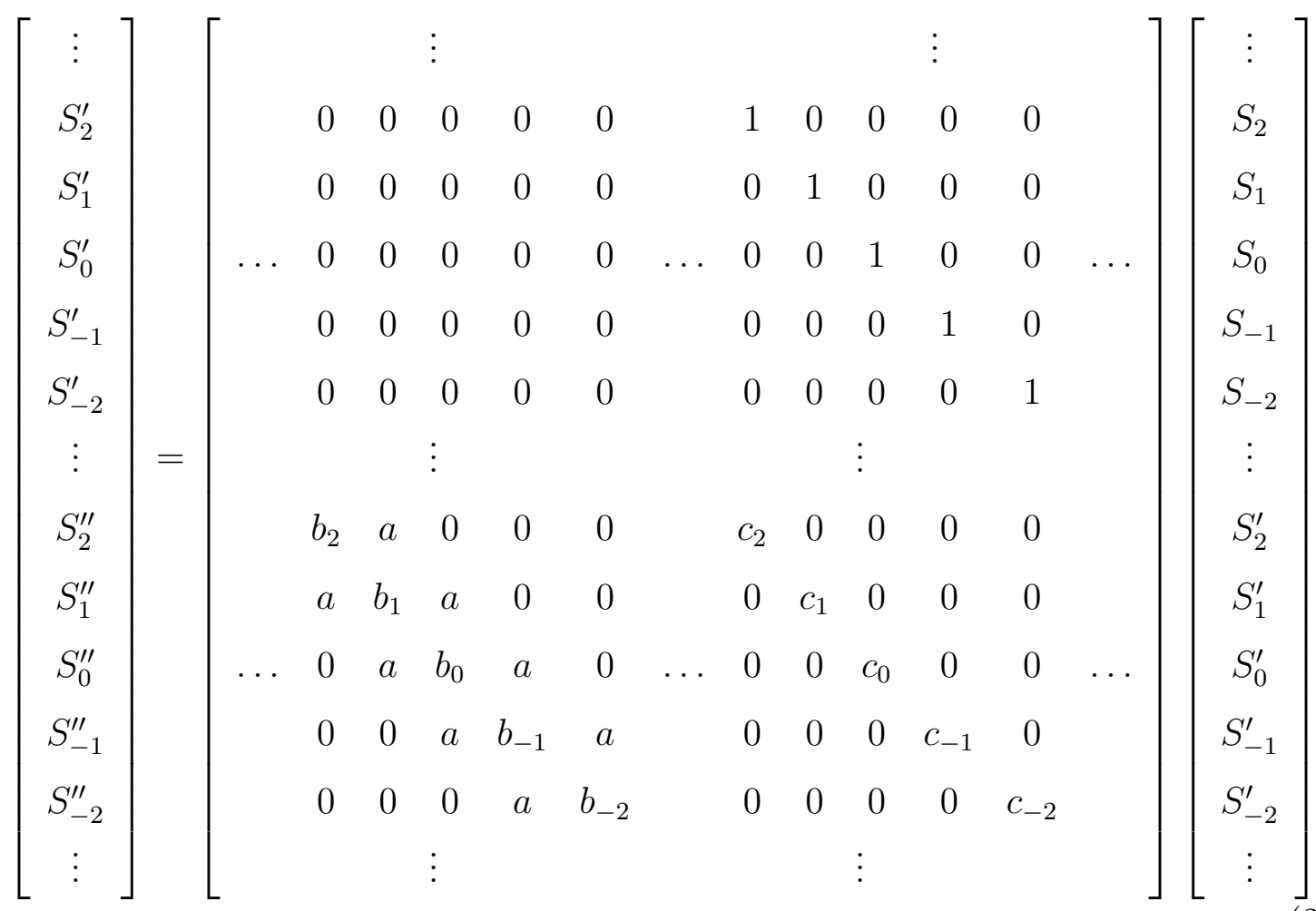

Uma mudança de base faz com que a amplitude de cada uma das ondas que propagam no interior da rede seja escritas como a combinação linear dos autovetores e autovalores desta matriz 2.30). Nela, $q_{m}$ é o m-ésimo autovalor e $w_{i m}$ é a m-ésima componente da i-ésima linha na matriz $[w]$ composta de autovetores. As constantes desta combinação linear são variáveis a serem determinadas junto com as amplitudes das ondas refletidas e transmitidas.

$$
S_{i}(u)=\sum_{m} C_{m} w_{i m} \exp \left(q_{m} u\right)
$$

Um sistema linear de equações é construído utilizando-se as condições de contorno em que o campo elétrico é tangente à superfície na origem e em $z=0$ e o mesmo para o caso em que o campo magnético é tangente. Com este sistema de equações é possível determinar cada uma das constantes $C_{m}$ e, através delas, obter-se $R_{i}$ e $T_{i}$.

A principal restrição deste modelo é quanto à direção de modulação do índice de refração. Nele, redes atuando unicamente em modo de reflexão não podem ser simuladas visto que, neste caso, há um número finito de períodos de modulação do índice de refração enquanto o formalismo utilizado dentro do contexto deste artigo é válido apenas para es- 
truturas periódicas infinitas. Conforme o ângulo $\phi$ de inclinação da rede se aproxima de $0^{\circ}$, todos os raios refletidos passam a convergir em uma única direção.

\subsection{Simulações e Resultados}

O trabalho realizado neste capítulo esteve em foco apenas na primeira metade do mestrado. Num primeiro momento, acreditava-se ser possível construir um novo software livre e bem documentado durante este período contendo o maior número de modelos possível visando simular a eficiência de redes de difração holográficas com as mais diversas características.

Este pensamento idealista foi alimentado até o ponto em que o Modelo de Kogelink foi implementado com sucesso. Mesmo sem cumprir as promessas de um software "amigável" com uma interface gráfica fácil de ser utilizada, este modelo foi mais do que o suficiente no contexto do BTFI. Neste ponto, o modelo havia sido implementado sem preocupação alguma com perdas por reflexão nas interfaces entre o ar e o substrato das redes ou devido à não uniformidade do filme holográfico.

A principal limitação deste modelo está relacionada com a espessura das redes VPH. Conforme já descrito, as aproximações feitas no desenvolvimento do modelo de Kogelnik são razoáveis apenas quando a profundidade óptica $Q$ de uma rede de difração é muito maior do que 1. Não só pela experiência obtida nas simulações como pelo estudo do modelo em questão, sabe-se que há uma relação direta entre a resolução espectral e a espessura de uma rede holográfica.

No caso do filtro iBTF, uma das redes escolhidas (a rede WTX03 na tabela 2.2) possui uma resolução espectral de aproximadamente 25, próximo ao limite inferior da resolução requerida. De acordo com as simulações, esta mesma rede possui uma espessura de $21 \mu \mathrm{m}$ e um período de $435 \mathrm{~nm}$. Sua profundidade óptica para um comprimento de onda de $5000 \AA$ é superior à 230, satisfazendo tranquilamente a condição mencionada anteriormente para aplicar-se o modelo em questão com segurança.

Resoluções espectrais mais altas são alcançadas utilizando-se redes de difração mais espessas. De acordo com os fabricantes contactados, os processos de fabricação atuais permitem que redes de difração holográficas possuam, no máximo, $2 \mathrm{~mm}$ podendo-se alcançar resoluções superiores à 3000 . 
As redes de difração holográficas foram escolhidas de modo a cobrir o máximo possível do espectro óptico cobrindo também parte do ultra-violeta próximo (até aproximadamente $3500 \AA$ ) e o infra-vermelho próximo (até aproximadamente $10000 \AA$ ).

Uma rede é modelada escolhendo-se primeiramente o comprimento de onda central e o seu modo de atuação (transmissão ou reflexão). Com isso e sabendo-se que, devido às limitações físicas e de construçao do BTFI, os ângulos mínimo e máximo de inclinação das redes em relação ao eixo óptico $(\theta)$ são $25^{\circ}$ e $45^{\circ}$, basta utilizar a equação de Bragg (eq. 2.4) aplicada às VPHGs para determinar o período de modulação de uma rede num ângulo médio de $35^{\circ}$.

O segundo requisito é a resolução espectral. Conforme já mencionado, sabe-se que este parâmetro é proporcional à espessura de uma rede de difração. Diversas simulações são realizadas, então, ajustando-se simultaneamente a espessura da rede e a amplitude de modulação, que possui uma forte influência na curva que descreve o comportamento do pico de eficiência de difração das redes de acordo com o ângulo de incidência.

$\mathrm{Na}$ literatura, é comum chamar a equação que descreve a eficiência de uma rede de difração a um determinado ângulo de função blaze. No caso das redes de difração holográficas, sua característica relacionada ao ajuste do comprimento de onda onde encontrase o pico de difração através do ângulo faz com que exista uma função que descreve a máxima eficiência obtida em cada comprimento de onda conforme os ângulos ajustados. É justamente esta função que descreve o poder de ajuste de uma rede VPG que é chamada de superblaze.

Através desta sequência, um conjunto de redes de difração holográficas foram escolhidas dentro de domínios de baixa, média e alta resolução espectral. A tabela 2.2 mostra as redes de difração que já foram obtidas ou estão em processo de compra para serem utilizadas no instrumento BTFI.

Seguindo-se a notação apresentada na seção 2.1. $d$ representa a espessura da rede, $\Lambda$ representa período da modulação do índice de refração, $f$ é o número de linhas por milímetro ou simplesmente a frequência linear e $\Delta n$ representa a amplitude da modulação do índice de refração. Os modos de atuação são representados por "TX" para modo de transmissão e "RX"' para redes que atuam em modo de reflexão. A letra "W" contida no nome das redes é utilizada para designar as redes de difração negociadas com a compania 
Tabela 2.2 - Parâmetros físicos das redes escolhidas.

\begin{tabular}{cccccc}
\hline \hline Nome & $d[\mu m]$ & $\Lambda[n m]$ & $f[$ lines $/ \mathrm{mm}]$ & $\Delta n[-]$ & Modo \\
\hline WTX01 & 42 & 435 & 2298,85 & 0,0065 & $\mathrm{TX}$ \\
WTX02 & 40 & 620 & 1612,90 & 0,01 & $\mathrm{TX}$ \\
WTX03 & 21 & 435 & 2298,85 & 0,013 & $\mathrm{TX}$ \\
WTX04 & 30 & 620 & 1612,90 & 0,013 & $\mathrm{TX}$ \\
WRX01 & 40 & 178 & 5617,98 & 0,008 & $\mathrm{RX}$ \\
WRX02 & 20 & 178 & 5617,98 & 0,018 & $\mathrm{RX}$ \\
WRX03 & 40 & 242 & 4132,23 & 0,01 & $\mathrm{RX}$ \\
\hline \hline
\end{tabular}

chamada Wasatch.

As tabelas 2.3 à 2.9 mostram os resultados numéricos para os ângulos de $25^{\circ}, 35^{\circ}$ e $45^{\circ}$ para cada uma das redes apresentadas. Referente a estas mesmas tabelas, são apresentados os gráficos que descrevem sua eficiência.

Conforme já mencionado, estas redes foram escolhidas visando cobrir diferentes regiões do espectro com diferentes resoluções espectrais. A decisão sobre este conjunto de redes foi tomada depois de diversas interações com outros membros do time participante do BTFI.

Nestes gráficos é interessando notar quais os parâmetros que influenciam diretamente no comportamento das redes em relação à largura de banda e ao intervalo espectral alcançado entre os ângulos de $25^{\circ}$ e $45^{\circ}$. Estes dois ângulos são impostos devido às limitações mecânicas da montagem do iBTF.

Dois exemplos a serem analisados são a rede WTX01 e a WTX03. As duas atuam de modo que a luz transmitida a $35^{\circ}$ possui um comprimento de onda igual à aproximadamente $5020 \AA$, se considerarmos uma tolerância de $15 \AA$. É interessante notar que o pico de eficiência a $25^{\circ}$ e a $45^{\circ}$ também estão bastante próximos. Isto mostra que a resolução espectral tem pouca influência no intervalo espectral em que a rede atuará.

No caso, a resolução espectral é definida pela espessura da rede. No caso em particular das duas redes dadas como exemplo, a resolução espectral é o dobro quando a espessura da rede também é o dobro. Em geral, pode-se dizer que a espessura é diretamente proporcional à resolução. Este fato é confirmado durante o texto do trabalho relacionado ao modelo de 
Tabela 2.3 - Rede \#WTX01

\begin{tabular}{ccccc} 
Angle & Bragg Wavelength & Efficiency & Bandwidth & Resolution \\
\hline $25.00^{\circ}$ & $3694.00 \AA$ & $61.56 \%$ & $91.00 \AA$ & 40.59 \\
$35.00^{\circ}$ & $5011.50 \AA$ & $92.94 \%$ & $100.00 \AA$ & 50.11 \\
$45.00^{\circ}$ & $6178.50 \AA$ & $79.40 \%$ & $98.50 \AA$ & 62.73 \\
\hline \hline
\end{tabular}

Figura 2.6: Rede \#WTX01

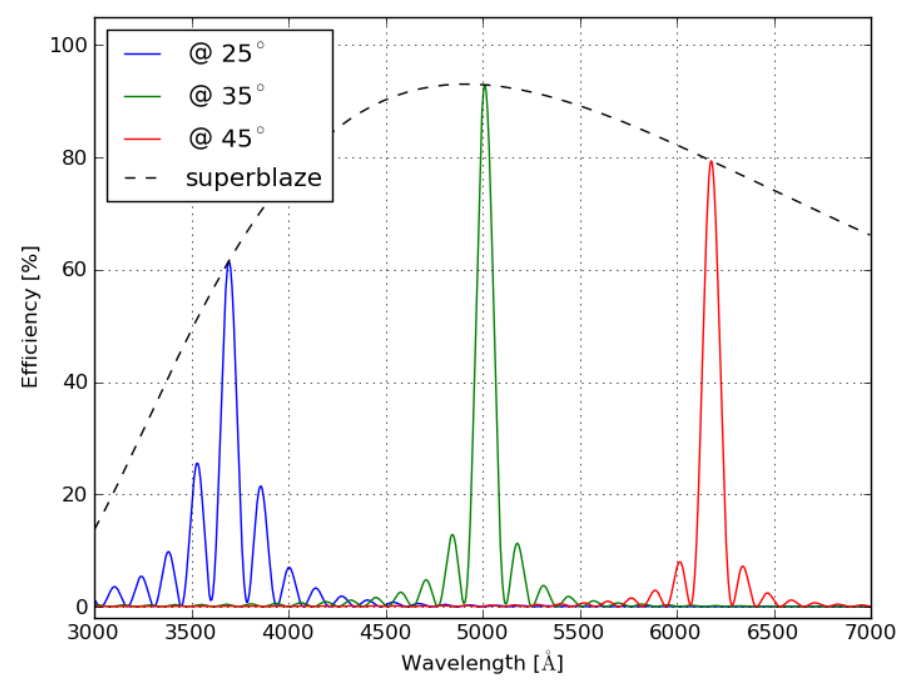

Kogelnik que diz que a resolução espectral está relacionada com a razão entre o a espessura do filme holográfico e o período de modulação (no caso de redes em modo de transmissão).

Comparando agora as redes atuando em modo de reflexão com as redes em modo de transmissão, temos um intervalo espectral de atuação muito menor. Este comportamento pode ser explorado no caso de redes com uma resolução espectral muito alta. Uma rede com alta resolução atuando em modo de transmissão é extremamente sensível ao ângulo com que a luz incide e pode ser uma fonte crítica de erros.

Um fator contra a utilização de redes em modo de reflexão envolve o período de modulação. Aplicando a equação de Bragg para redes de difração holográficas para um mesmo comprimento de onda num mesmo ângulo de incidência, temos que o período de modulação para redes RX é muito menor do que o de redes TX, implicando numa frequência linear muito mais alta, o que encarece o processo de fabricação. 
Tabela 2.4 - Rede \#WTX02

\begin{tabular}{ccccc} 
Angle & Bragg Wavelength & Efficiency & Bandwidth & Resolution \\
\hline $25.00^{\circ}$ & $5280.50 \AA$ & $56.56 \%$ & $188.50 \AA$ & 28.01 \\
$35.00^{\circ}$ & $7160.50 \AA$ & $92.19 \%$ & $211.00 \AA$ & 33.94 \\
$45.00^{\circ}$ & $8826.50 \AA$ & $80.15 \%$ & $208.50 \AA$ & 42.33 \\
\hline \hline
\end{tabular}

Figura 2.7: Rede \#WTX02

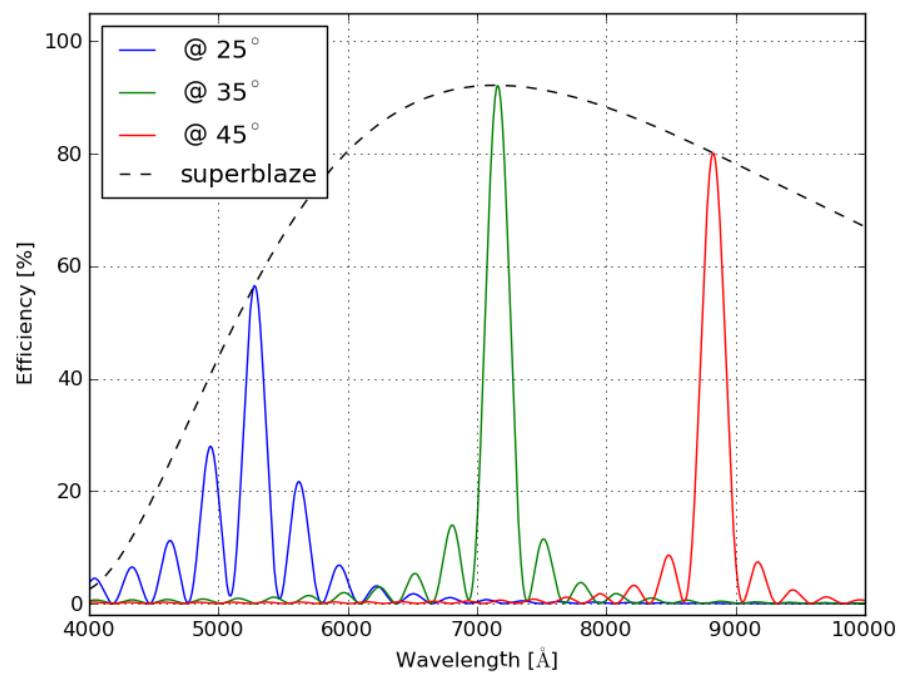

Tabela 2.5 - Rede \#WTX03

Angle Bragg Wavelength Efficiency Bandwidth Resolution

\begin{tabular}{lllll}
\hline $25.00^{\circ}$ & $3714.00 \AA$ & $62.53 \%$ & $182.50 \AA$ & 20.35 \\
$35.00^{\circ}$ & $5033.50 \AA$ & $93.01 \%$ & $200.50 \AA$ & 25.10 \\
$45.00^{\circ}$ & $6204.50 \AA$ & $79.22 \%$ & $197.50 \AA$ & 31.42 \\
\hline \hline
\end{tabular}


Figura 2.8: Rede \#WTX03

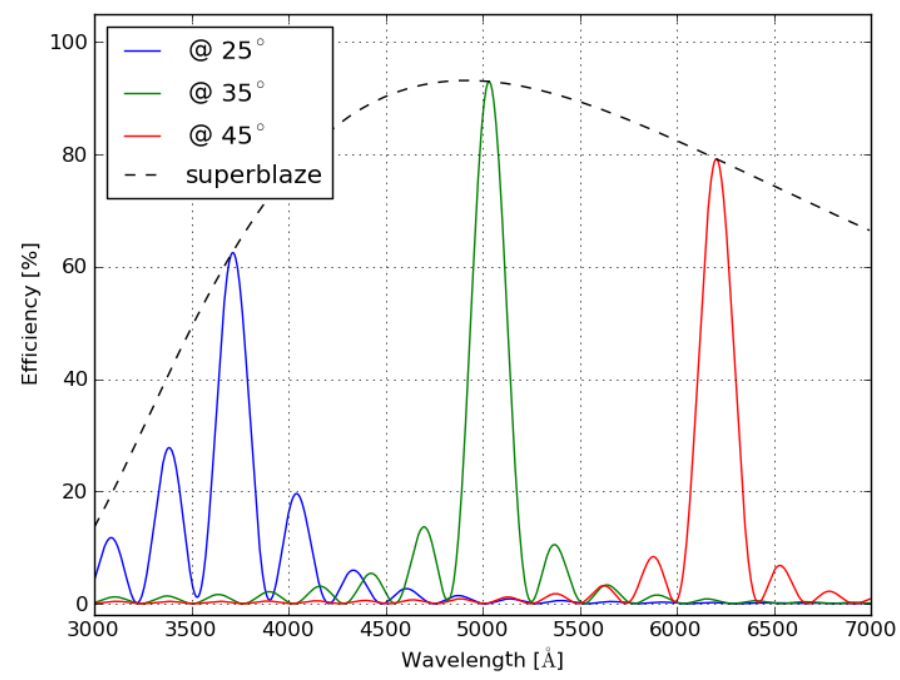

Tabela 2.6 - Rede \#WTX04

\begin{tabular}{ccccc} 
Angle & Bragg Wavelength & Efficiency & Bandwidth & Resolution \\
\hline $25.00^{\circ}$ & $5293.50 \AA$ & $62.23 \%$ & $256.00 \AA$ & 20.68 \\
$35.00^{\circ}$ & $7174.50 \AA$ & $92.79 \%$ & $283.00 \AA$ & 25.35 \\
$45.00^{\circ}$ & $8843.50 \AA$ & $79.08 \%$ & $279.00 \AA$ & 31.70 \\
\hline
\end{tabular}

Figura 2.9: Rede \#WTX04

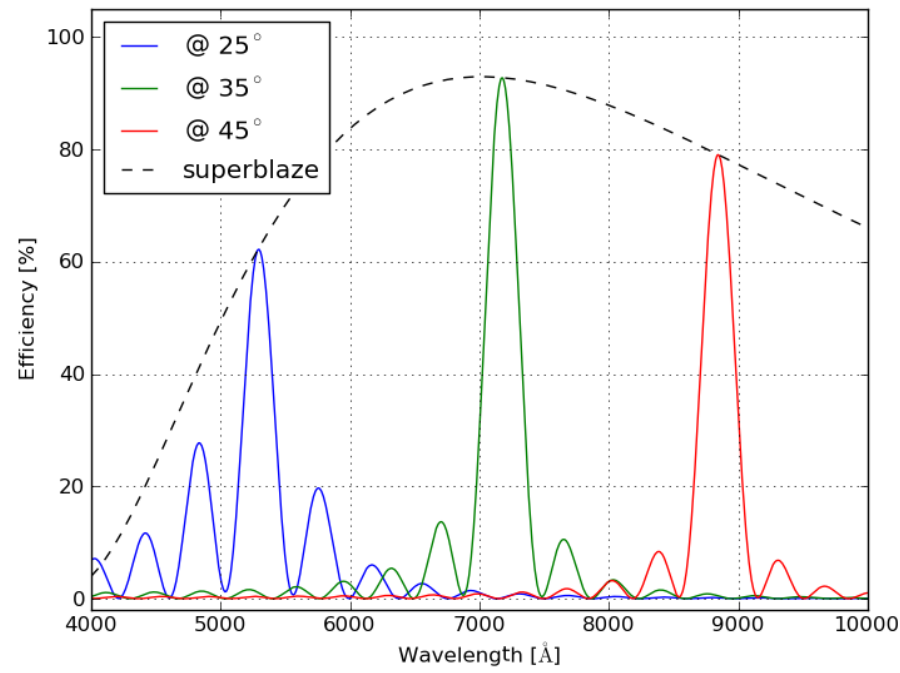


Tabela 2.7 - Rede \#WRX01

\begin{tabular}{ccccc} 
Angle & Bragg Wavelength & Efficiency & Bandwidth & Resolution \\
\hline $25.00^{\circ}$ & $5167.00 \AA$ & $90.48 \%$ & $39.00 \AA$ & 132.49 \\
$35.00^{\circ}$ & $4982.00 \AA$ & $89.26 \%$ & $37.50 \AA$ & 132.85 \\
$45.00^{\circ}$ & $4764.00 \AA$ & $86.29 \%$ & $36.50 \AA$ & 130.52 \\
\hline \hline
\end{tabular}

Figura 2.10: Rede \#WRX01

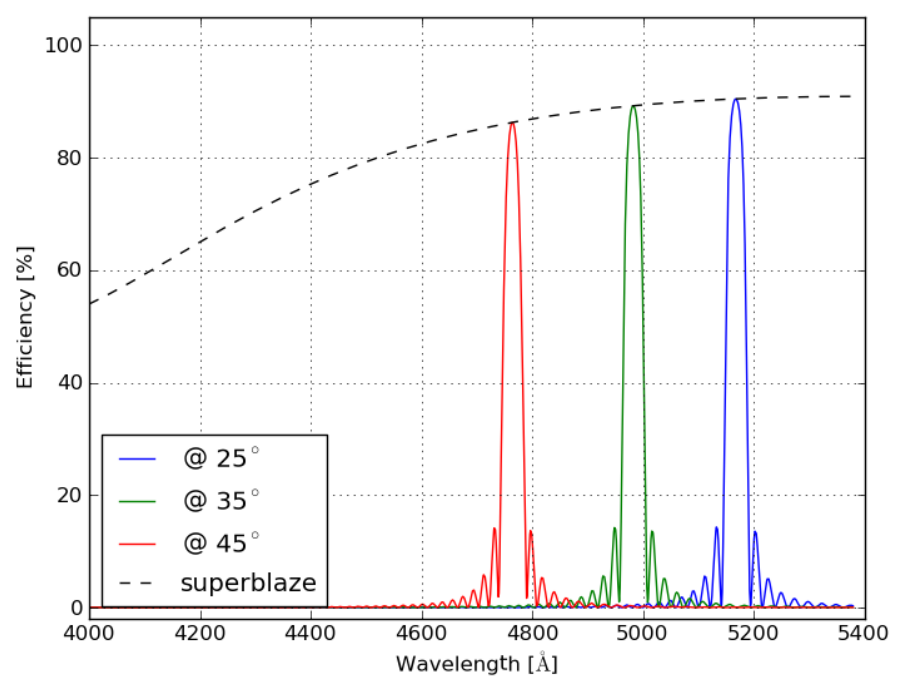

Tabela 2.8 - Rede \#WRX02

Angle Bragg Wavelength Efficiency Bandwidth Resolution

\begin{tabular}{lllll}
\hline $25.00^{\circ}$ & $5200.00 \AA$ & $93.68 \%$ & $84.00 \AA$ & 61.90 \\
$35.00^{\circ}$ & $5013.50 \AA$ & $92.61 \%$ & $81.00 \AA$ & 61.90 \\
$45.00^{\circ}$ & $4794.00 \AA$ & $89.94 \%$ & $78.50 \AA$ & 61.07 \\
\hline \hline
\end{tabular}


Figura 2.11: Rede \#WRX02

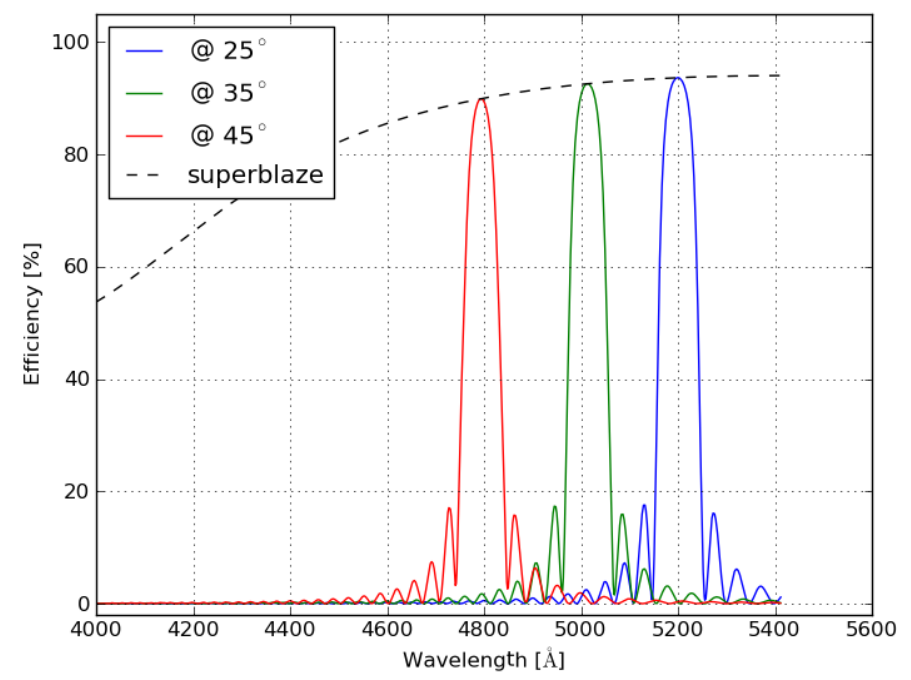

Tabela 2.9 - Rede \#WRX03

\begin{tabular}{ccccc} 
Angle & Bragg Wavelength & Efficiency & Bandwidth & Resolution \\
\hline $25.00^{\circ}$ & $6995.50 \AA$ & $87.59 \%$ & $68.50 \AA$ & 102.12 \\
$35.00^{\circ}$ & $6739.00 \AA$ & $86.28 \%$ & $66.00 \AA$ & 102.11 \\
$45.00^{\circ}$ & $6436.50 \AA$ & $83.12 \%$ & $64.50 \AA$ & 99.79 \\
\hline
\end{tabular}

Figura 2.12: Rede \#WRX03

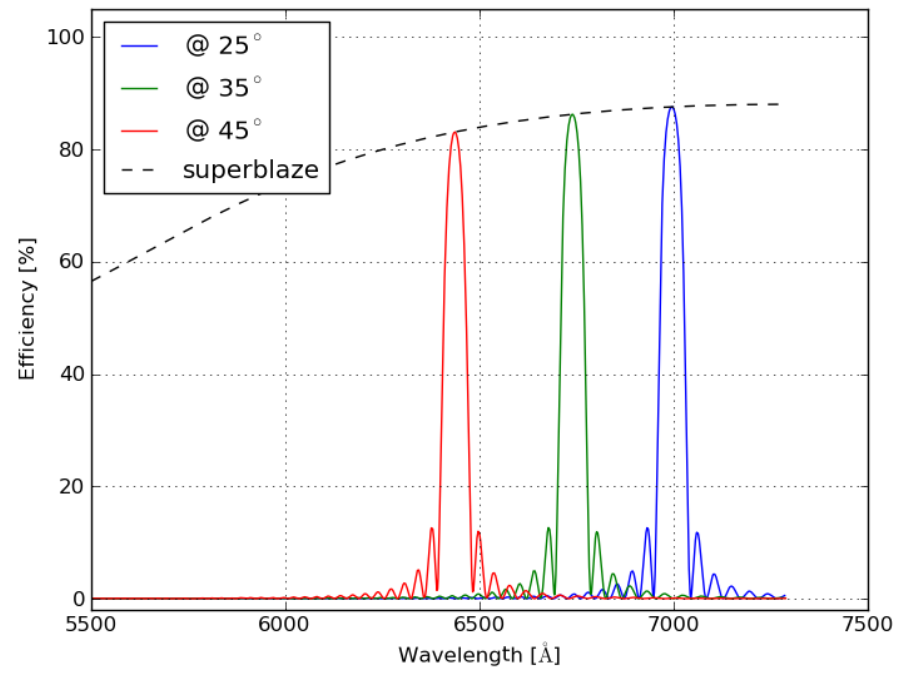


O fato de poder simular as redes desejadas com uma boa precisão tornou a implementação do modelo RCWA uma tarefa secundária. Aliado a isto, as dificuldades enfrentadas ao lidar numericamente com variáveis complexas e os problemas relacionados à organização da matriz de autovalores e autovetores estavam exigindo muito mais tempo do que havia disponível.

Foi então que julgou-se mais produtivo alterar parcialmente o foco do trabalho seguindo as necessidades do projeto BTFI. Com isso, o término da implementação numérica do modelo RCWA foi abandonado e deu-se início a um trabalho relacionado com simulação de filtros do tipo Fabry-Perot, descrito em detalhes no capítulo 3. 
Capítulo 3

\section{Fabry-Pérot e Illusion}

Em 1894, Charles Fabry, um grande cientista teórico, entrou para a Universidade de Marseille ocupando o lugar de Alfred Pérot em certas atividades acadêmicas. Desde então, os dois passaram a ter uma forte ligação e, através do vasto conhecimento em teoria eletromagnética que Fabry possuía, aliado às grandes habilidades de projetar e construir instrumentos de Pérot, um novo equipamento foi desenvolvido, segundo uma breve investigação histórica em Mulligan (1998). A primeira publicação oficial a respeito deste novo interferômetro ocorreu em 1897 no artigo Perot e Fabry (1987). Desde então, a utilização deste interferômetro, chamado pelos seus desenvolvedores originais de étalon, rendeu inúmeras publicações em física e, principalmente, em astronomia. Na literatura, o étalon é muito mais conhecido como filtro ou interferômetro Fabry-Pérot.

Suas primeiras aplicações envolveram a obtenção do espectro do sol conforme Perot e Fabry (1900, 1904), estudos sobre as linhas de emissão do ferro (Pfund (1908), Fabry e Perot (1901)) além da determinação do índice de viscosidade do ar (Fabry e Perot (1988)). Aproximadamente meio século mais tarde, Vaughan (1967) resume diversas aplicações atribuídas ao Fabry-Pérot como estudos envolvendo regiões HII (Georgelin et al. (1973), Fich et al. (1990)), medidas de deslocamento de linhas de emissão pelo efeito Doppler (Desai et al. (1982)) e polarimetria para observar o efeito Zeeman causado pelo campo magnético solar (Borra et al. (1973)).

Fabry-Pérots são interferômetros constituídos por duas placas de vidro paralelas entre si e dispostas coaxialmente a uma curta distância formando uma espécie de cavidade óptica. As superfícies voltadas para a região entre as placas recebem um tratamento especial para que tenham um alto índice de reflexão. Com isso, um feixe de luz que entra na cavidade 
sofre múltiplas reflexões e os raios de luz que conseguem escapar a cada reflexão interferem entre si fazendo com que o conjunto aja como um filtro espectral de altíssima resolução.

Nos modelos já fabricados, a distância que separa as duas placas é fixa ou possui um ajuste muito pequeno. Isto limita seu uso no que diz respeito à ordens de interferência e resolução espectral. Em geral, um FP deste tipo era fabricado visando uma resolução espectral em específico.

Com o avanço da tecnologia, a distância entre as placas do FP passou a ser controlada com maior precisão com a ajuda de capacitores elétricos e dispositivos piezoeletrônicos. Conforme já explicado anteriormente dentro do corpo deste trabalho, o ajuste da distância entre as duas placas ( $g a p$ ) de um Fabry-Pérot permite que diferentes comprimentos de onda sejam observados. Diferentes gaps também implicam em diferentes ordens de interferência e diferentes resoluções espectrais, podendo-se alcançar uma resolução de até 35000.

Além de atuarem como espectrógrafos, os Fabry-Pérots também podem atuar como filtros espectrais na obtenção de imagens. Entretanto, uma única imagem não é o suficiente para obter a informação espacial relacionada com um comprimento de onda em específico. $\mathrm{Na}$ realidade, cada quadro possui informações relacionadas a diversos comprimentos de onda diferentes apresentados em anéis de diferentes raios.

Um conjunto de imagens então é obtido de modo que possam ser tratadas a fim de recuperar a informação espacial de um alvo. Dois dos primeiros instrumentos a utilizarem este conceito foram o TAURUS (Atherton et al. (1982)) e o CIGALE (Boulesteix et al. (1984)). Em ambos os casos, os dados obtidos são uma coleção de imagens que, após receberem o devido tratamento, representam o alvo em comprimentos de onda consecutivos. Devido ao fato de representarem a informação espacial em dois eixos (XY) e a informação espectral em um terceiro eixo (Z), estas coleções de imagens são chamadas de cubos de dados ou, em inglês, data-cubes (DC).

Esta técnica utilizada para separar os comprimentos de onda existentes dentro de um cubo de dados é conhecida desde os primeiros cubos obtidos com Fabry-Pérot. O processo de correção de fase, como é chamada, é realizada em uma série de passos distintos envolvendo a obtenção de um cubo iluminando-se o FP com uma fonte monocromática, extraindo o chamado mapa de fase e utilizando-o para corrigir o cubo de imagens contendo o objeto observado como visto pela primeira vez em Barrell e Teasdale-Buckell (1951). 
Diversas rotinas têm sido desenvolvidas utilizando-se os mais variados pacotes computacionais como IRAF (Shopbell et al. (1992)), IDL (Daigle et al. (2006)) e até mesmo softwares completamente dedicados como, por exemplo, o AD-HOC (Boulesteix (1993)). Entretanto, a filosofia empregada no desenvolvimento do BTFI exigiu um novo pacote visando essencialmente integração com o resto do sistema, além de programação em alto nível, dentro do conceito de engenharia de software, e uma boa documentação.

Este novo sistema de reduções de dados obtidos com o BTFI, chamado de Butterfly, está em desenvolvimento e utiliza como dados de entrada cubos criados com um novo software chamado Illusion. O Illusion cria cubos sintéticos simulando imagens obtidas ao se observar diferentes tipos de fontes com um Fabry-Pérot.

Illusion foi criado para auxiliar tanto no desenvolvimento de um novo pacote para realizar a correção de fase de um cubo quanto na compreensão do mecanismo de formação dos anéis dentro de um cubo e, consequentemente, das imagens obtidas com um FabryPérot. Este programa foi de vital importância também para o desenvolvimento das novas rotinas que integram o sistema Butterfly.

No caso do BTFI, dois Fabry-Pérots atuarão em diferentes partes do caminho óptico a fim de desempenhar diferentes papéis. O primeiro deles é posicionado logo na entrada do intrumento. Este atuará como um filtro de baixa a média resolução espectral de modo a limitar o número de ordens de interferência.

O segundo Fabry-Pérot atua no espaço em que a luz está colimada, logo após o iBTF para ser mais preciso. Nesta configuração, toda a luz relacionada com um ponto em específico no céu incide com um mesmo ângulo sobre o Fabry-Pérot. A luz que consegue atravessar o étalon é, então, focada sobre o detector através de uma câmera óptica.

A versão atual do Illusion é utilizada para simular apenas cubos utilizando o segundo FP. As próximas sessões deste capítulo descreverão um pouco de teoria de interferência de raios múltiplos, conceito base utilizado no desenvolvimento de filtros FP, como é o processo de formação de imagens obtidas com FP, exemplos de imagens obtidas e problemas em potencial que podem ser atacados utilizando o software Illusion e minimizando a necessidade de obter-se dados com um instrumento verdadeiro. 


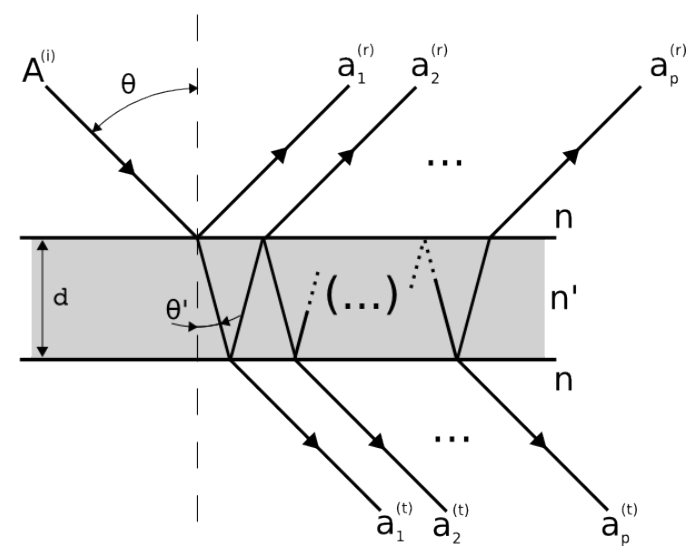

Figura 3.1: Representação gráfica de uma onda luminosa plana com amplitude $A^{(i)}$ incidindo sobre uma placa com superfícies planas e paralelas. O p-ésimo raio refletido é representado por $a_{p}^{(r)}$ enquanto o p-ésimo raio transmitido é representado por $a_{p}^{(t)}$.

\subsection{Interferência de Raios Múltiplos}

De uma maneira geral, existem diversas formas bem semelhantes de se tratar analiticamente o comportamento dos Fabry-Perots. Uma delas, segundo Born e Wolf (1999), é considerar o FP como uma placa com superfícies infinitamente planas e paralelas com espessura $d$ e índice de refração $n^{\prime}$ cercada em ambos os lados por um meio com índice de refração $n$ (figura 3.1).

Supõe-se agora que um feixe de luz com raios paralelos entre si e proveninente de um dos lados da placa descrita anteriormente incide com um ângulo $\theta$ sobre a interface entre os dois meios. Neste ponto, parte da luz é refletida de volta para o meio de onde ela veio e o restante é transmitido para o interior da placa. A porção de luz que é refletida/transmitida depende explicitamente do comprimento de onda, dos índices de refração dos dois meios e do ângulo de incidência (eq. 3.1 e 3.2.

$$
\left.\begin{array}{c}
t_{\|}=\frac{2 \sin \theta^{\prime} \cos \theta}{\sin \left(\theta+\theta^{\prime}\right) \cos \left(\theta-\theta^{\prime}\right)} \\
t_{\perp}=\frac{2 \sin \theta^{\prime} \cos \theta}{\sin \left(\theta+\theta^{\prime}\right)} \\
r_{\|}=\frac{\tan \left(\theta-\theta^{\prime}\right)}{\tan \left(\theta+\theta^{\prime}\right)} \\
r_{\perp}=-\frac{\sin \left(\theta-\theta^{\prime}\right)}{\sin \left(\theta+\theta^{\prime}\right)}
\end{array}\right\}
$$

Nas duas equações acima, $t_{\|}$e $t_{\perp}$ representam a porção de luz que é transmitida nas 
polarizações $\mathrm{P}$ e S respectivamente do meio $n$ para o meio $n^{\prime}$. Assim, a luz não polarizada é representada por $t$ e é obtida através da média aritimética das duas grandezas anteriores. O mesmo vale para $r, r_{\|}$e $r_{\perp}$. Os ângulos $\theta$ e $\theta^{\prime}$ representam o ângulo com que a luz viaja no meio com índice $n$ e $n^{\prime}$ respectivamente e estão relacionados entre si de acordo com a lei de Snell (3.3).

$$
n \sin \theta=n^{\prime} \sin \theta^{\prime}
$$

Sendo $A^{(i)}$ a amplitude complexa do campo elétrico da luz incidente, a luz que é refletida de volta nesta primeira interface é dada simplesmente por $r A^{(i)}$ enquanto a porção de luz que se propaga para dentro da placa é $t A^{(i)}$ e segue com a direção de propagação $\theta^{\prime}$. Ao encontrar a segunda interface, parte da luz escapa deste meio com amplitude $t t^{\prime} A^{(i)}$ e parte sofre reflexão interna com $t r^{\prime} A^{(i)}$. Aqui, $t^{\prime}$ e $r^{\prime}$ representam as proporções transmitida e refletida quando a luz parte do meio $n^{\prime}$ para o meio $n$ e podem ser obtidas através de uma mudança de variáveis nas equações 3.1 e 3.2 ou pelas relações explicitadas nas equações 3.4, 3.5 e 3.6 onde $R$ e $T$ são chamadas de reflectância e transmitância do sistema.

$$
\begin{gathered}
t t^{\prime}=T \\
r=-r^{\prime} \\
r^{2}=r^{\prime 2}=R
\end{gathered}
$$

Cada vez que a luz encontra uma das interfaces, uma diferença de fase $\delta$ (equação 3.7 ) é acrescida devido à diferença de caminho óptico entre a luz que chega neste ponto e a luz que chegou nesta mesma interface anteriormente.

$$
\delta=\frac{4 \pi}{\lambda} n^{\prime} d \cos \theta^{\prime}
$$

Superpondo um grande número de ondas refletidas de volta para a região do espaço onde a luz incide chega-se na equação 3.8 onde a amplitude da onda resultante é representada por $A^{(r)}$. O mesmo é feito com as ondas transmitidas de uma região para a outra onde a amplitude complexa é, então, representada por $A^{(t)}$ (equação 3.9 . 


$$
\begin{gathered}
A^{(r)}=\frac{\left(1-e^{j \delta}\right) \sqrt{R}}{1-R e^{j \delta}} A^{(i)} \\
A^{(t)}=\frac{T}{1-R e^{j \delta}} A^{(i)}
\end{gathered}
$$

Nota-se que a intensidade total de cada um dos feixes representados é dada pelo produto entre sua respectiva amplitude e seu complexo conjugado - por exemplo: $I^{(t)}=A^{(t) *} A^{(t)}$. Mantendo a notação com super-índices para identificar a luz incidente, refletida e transmitida chega-se nas equações 3.10 e 3.11 .

$$
\begin{aligned}
& I^{(r)}=\frac{4 R \sin ^{2} \frac{\delta}{2}}{(1-R)^{2}+4 R \sin ^{2} \frac{\delta}{2}} I^{(i)} \\
& I^{(t)}=\frac{T^{2}}{(1-R)^{2}+4 R \sin ^{2} \frac{\delta}{2}} I^{(i)}
\end{aligned}
$$

As equações acima podem ser reescritas em função de um novo parâmetro chamado Finesse (eq. 3.12) adquirindo uma forma mais simples como mostram as equações 3.13 e 3.14 ,

$$
\begin{gathered}
F=\frac{4 R}{(1-R)^{2}} \\
I^{(r)}=\frac{F \sin ^{2} \frac{\delta}{2}}{1+F \sin ^{2} \frac{\delta}{2}} I^{(i)} \\
I^{(t)}=\frac{1}{1+F \sin ^{2} \frac{\delta}{2}} I^{(i)}
\end{gathered}
$$

No caso de um Fabry-Perot, esta aproximação é valida se considerarmos que o meio $n$ representa as duas placas de vidro, separadas por uma fina "camada de ar" (da ordem de nanometros) representada pelo meio $n^{\prime}$. Além disso, as superfícies que fazem a interface vidro-ar e ar-vidro recebem um tratamento especial visando otimizar a transmitância no primeiro caso e a reflectância no segundo, fazendo com que estes dois íncides não dependam mais exclusivamente dos índices de refração dos dois meios. Unindo este fato ao de que as placas de vidro são espessas o bastante para que ocorram poucas reflexões em seu interior, temos o caso de um Fabry-Perot ideal e as equações acima podem ser utilizadas com precisão. 


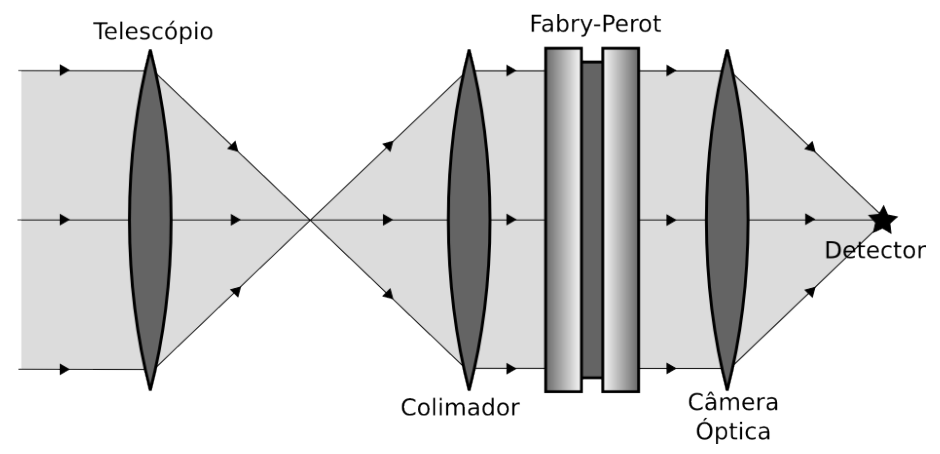

Figura 3.2: Representação artística do posicionamento do Fabry-Perot quando alocado no espaço colimado.

Mais detalhes sobre o formalismo apresentado serão explorados nas próximas seções conforme estuda-se o processo de formação de imagens utilizando-se Fabry-Perots posicionados no feixe colimado do sistema óptico do telescópio.

\subsection{Obtendo dados}

A estrutura de uma imagem obtida com um Fabry-Pérot não é tão trivial quanto pode parecer. Primeiramente, FPs costumam ser dispostos no espaço colimado de um telescópio (ou alguma outra montagem óptica). Desta forma, cada ponto no espaço da fonte será representado por um feixe luminoso paralelo entre si incidindo com um determinado ângulo sobre o interferômetro. Na realidade, a melhor posição de um filtro do tipo Fabry-Pérot é exatamente sobre a pupila do sistema, já que este é o ponto em que a maioria, senão todos, os raios luminosos passam.

Outra possível configuração é quando se tem o Fabry-Pérot disposto no diafragma principal da montagem óptica antes do colimador. Entretanto a sua resolução acaba sendo menor nesta configuração além de ser necessário um étalon muito grande para que toda a luz incida sobre ele. Sua função aqui passa a ser a de atuar como um pré filtro delimitando ordens indesejadas de interferência, facilitando a calibração do FP de alta resolução.

A versão atual de Illusion trabalha apenas no primeiro caso, representado na figura 3.2. Este caso, além de ser mais simples de ser tratado numericamente, é o modo mais utilizado.

Antes de qualquer consideração quanto ao sistema em si, vamos voltar um pouco e analisar graficamente as equações obtidas no final da sessão anterior. Primeiramente, 
vamos supor que os ângulos de incidência dentro de um telescópio são muito pequenos ou variam muito pouco. Com isso, consideramos $\theta$ como uma constante nas equações de Fresnell (eq. 3.1 e 3.2 e, consequentemente, os índices de transmissão e reflexão são considerados constantes para qualquer raio de luz proveniente de qualquer ponto da imagem.

Além disso, as superfícies do étalon recebem um tratamento especial visando otimizar a transmissão da luz na primeira interface e a reflexão no interior da cavidade óptica. Assim, os índices de reflexão/transmissão em cada uma das interfaces deixam de depender apenas dos índices de refração dos dois meios, dependência que aparece implicitamente na relação entre $\theta$ e $\theta^{\prime}$, e passam a ser parâmetros físicos dependentes do tipo de filme depositado sobre elas.

Com as considerações acima, $R$ e $T$ são valores fixos fornecidos pelos responsáveis pelo tratamento realizado nas superfícies das lâminas de vidro. A principal consequência é o fato de que a Finesse $F$ também é uma constante caracterizada pelas propriedades físicas do sistema, visto que é definida como função do índice de reflexão das superfícies em questão (eq. 3.12). Como também será mostrado posteriormente, a finesse possui um papel importante no nível de detalhamento do espectro que será obtido com o étalon. Assim, para um instrumento em específico, a distribuição de luz transmitida (ou refletida) depende unicamente da diferença de fase adicionada devido à diferença de caminho óptico existente.

Limitando-nos apenas ao caso de luz transmitida, a equação 3.15 mostra a relação entre a diferença de caminho óptico $\delta$ dentro da cavidade óptica do Fabry-Pérot em função do comprimento de onda da fonte $\lambda$ e do ângulo $\theta$ com que ela incide sobre o filtro. Conforme pode ser visto na figura 3.3 , picos de transmissão são observados toda vez que esta diferença de fase corresponde a um múltiplo inteiro de $2 \pi$. Nesta figura também é possível ver a relação da finesse de um Fabry-Pérot com a largura do perfil destes picos.

$$
\frac{\delta}{2 \pi}=m=\frac{2 n^{\prime} d \cos \theta}{\lambda}
$$

Partindo agora de um caso bem simples, vamos supor uma fonte luminosa monocromática uniformemente distribuída na entrada do telescópio de tal modo que cada ponto desta fonte incide sobre um diferente ponto do detector unidimensional, iluminando-o igualmente como 


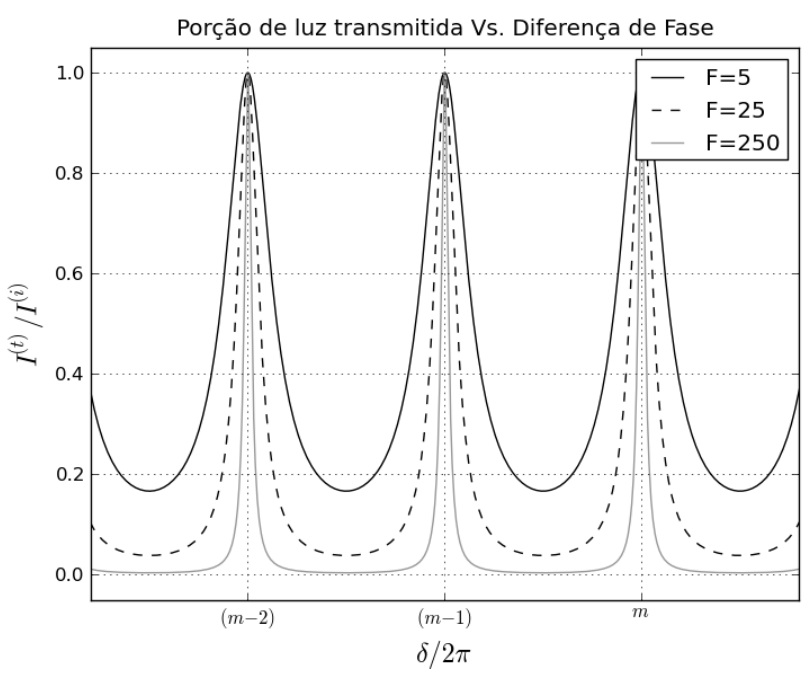

Figura 3.3: Gráfico da eficiência relativa de transmissão de um Fabry-Pérot em função da diferença de fase para diferentes finesses.

um todo (figura 3.4-a). Ao colocar um Fabry-Perot no feixe colimado de luz, o critério de seleção atua de modo que apenas raios que incidem com direções específicas se propaguem, lembrando que nossa fonte é monocromática e que não há comprimento de onda a ser selecionado. Este caso é representado na figura 3.4 b, onde o critério de seleção faz com que apenas os píxeis 1 e 3 sejam iluminados.

Se, por algum motivo qualquer, mudarmos um pouco o comprimento de onda do ponto no espaço relacionado ao pixel 1, a luz relacionada a ele já não consegue mais atravessar o Fabry-Perot e apenas o pixel 3 é iluminado (figura 3.4 c). A cor vermelha no pixel 1 mostra a alteração no comprimento de onda.

Por fim, a última variável que pode ser controlada é o tamanho do gap. Este parâmetro possui uma influência direta na seleção dos ângulos que satisfazem a equação do FP. Aumentando ou diminuindo o gap, os valor dos ângulos selecionados também aumentam ou diminuem. Este efeito pode ser visto na última imagem da figura 3.4. Se, antes do aumento da distância entre as placas, os píxeis iluminados eram o 1 e o 3, agora são os píxeis 2 e 4 que ficam iluminados. Vale lembrar que esta é apenas uma forma didática de explicar a formação de imagens obtidas com Fabry-Pérot.

Uma varredura completa com um étalon envolve tirar uma sequência de imagens aumentando gradativamente a distância entre as placas do FP de modo que a luz com um dado comprimento de onda consiga, em algum momento, iluminar todos os píxeis do detector. 

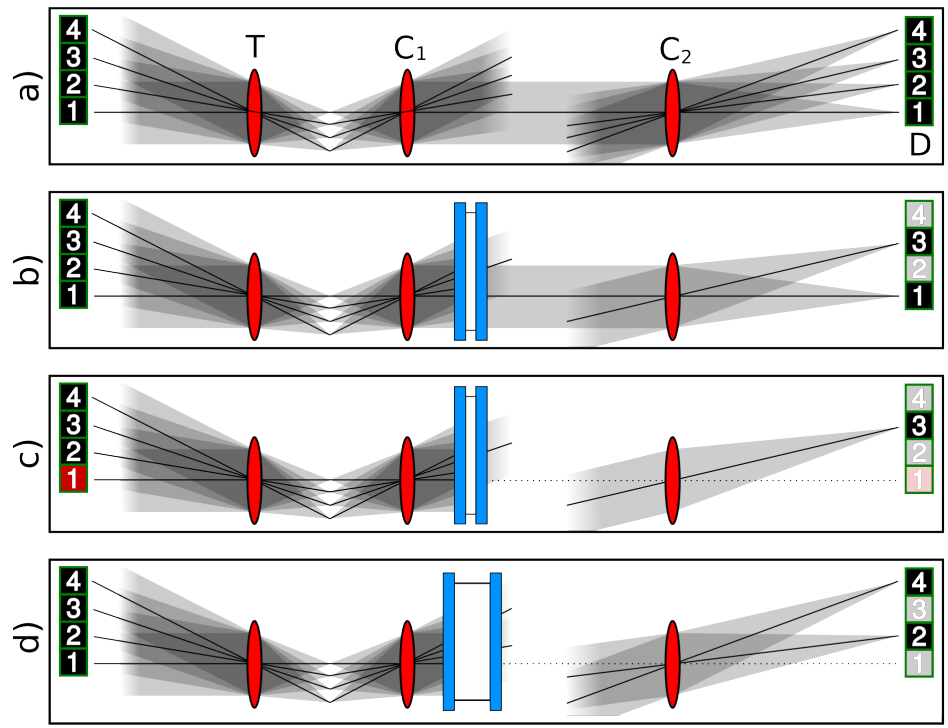

Figura 3.4: Formação de imagens - Representação simplificada.

No nosso exemplo acima, uma varredura completa foi feita com apenas duas "imagens".

Apesar do caso descrito ser unidimensional, a simetria axial do Fabry-Pérot faz com que ele possa ser extendido ao caso bidimensional facilmente. Neste novo cenário, as imagens obtidas são anéis concêntricos cujos raios estão diretamente relacionados com o ângulo selecionado pelo étalon pela equação 3.16 , onde $r$ é o raio de um determinado anel e $f$ é a distância focal da câmera óptica.

$$
\theta=\tan ^{-1} \frac{r}{f}
$$

Finalmente, um cubo de imagens é construído fazendo-se uma varredura variando continuamente a distância entre as lâminas de vidro enquanto imagens são obtidas e agrupadas sequencialmente. Assim, se "caminharmos" ao longo de um cubo de dados, veremos os anéis crescendo gradativamente em cada um dos quadros. Analisando agora um mesmo píxel em cada um dos quadros, teremos basicamente um espectro da fonte observada. Esta estrutura de um cubo de dados é representada pela figura 3.5 .

O produto de uma observação com um filtro do tipo Fabry-Pérot não é, inicialmente, um cubo $X \times Y \times \lambda$ conforme dito anteriormente. Se isto fosse verdade, haveria uma inconsistência entre este fato e o processo de formação de imagens explicado nesta seção. Um cubo obtido com Fabry-Pérot, na realidade, é estruturado como $X \times Y \times d$, lembrando 


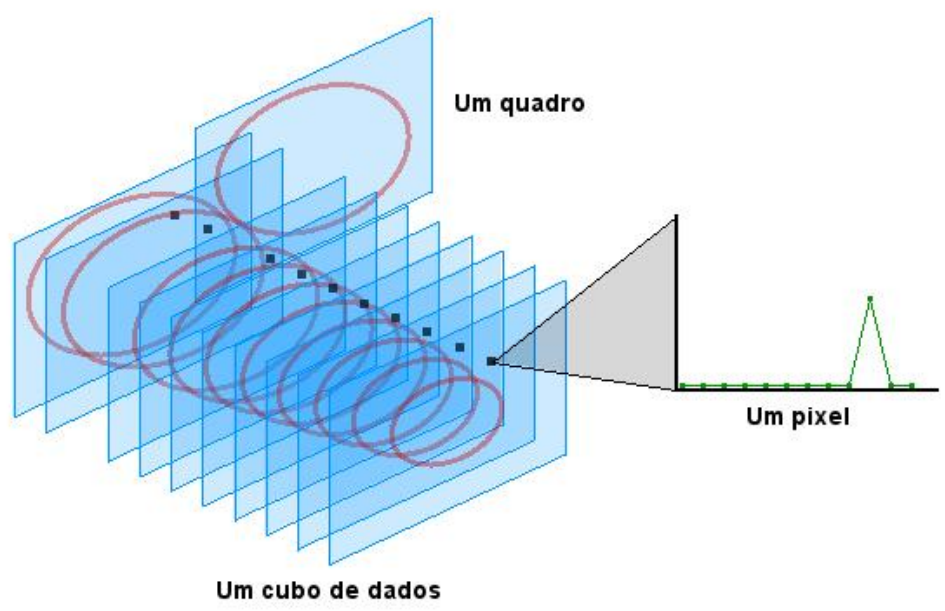

Figura 3.5: Estrutura de um cubo de dados.

que $d$ é o espaçamento entre as placas do Fabry-Pérot. Sendo assim, é necessário encontrar uma relação entre $d$ e $\lambda$ para cada ponto dentro do cubo de modo a reorganizar a informação na forma prometida inicialmente.

Durante este processo, algumas características intrínsecas aos cubos obtidos com FPs podem tornar este processo complicado em diversos aspectos. Um deles está relacionado com a periodicidade dos cubos de FP. O outro está relacionado justamente em buscar a informação relacionada com um dado comprimento de onda e reorganizá-la dentro do cubo.

\subsection{Periodicidade}

Como mencionado no início da seção anterior, um pico de transmissão ocorre toda vez que a diferença de caminho óptico é um múltiplo inteiro de $2 \pi$. Basicamente, existe uma certa periodicidade na transmitância dos FPs.

Devido à isto, numa situação real, é difícil (para não dizer impossível) identificar de imediato qual o comprimento de onda correspondente a um anel em especifico na imagem obtida com o detector sem que se tenha um número mínimo de informações. Uma forma de visualizar esta propriedade é através da formação dos diversos anéis em uma imagem, como nas figuras 3.6, ou nos diversos picos ao construir um gráfico da transmissão em função da diferença de caminho óptico, como na figura 3.7.

Conforme já mencionado, sabe-se que a distância entre dois picos de transmissão con- 


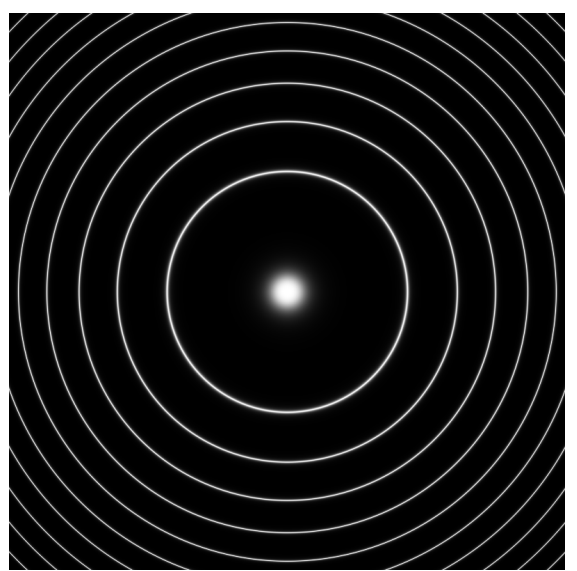

Figura 3.6: Comportamento periódico representado através des diversos anéis concêntricos em um único quadro extraído de um cubo simulado com Illusion.

secutivos relacionados ao mesmo comprimento de onda, dentro do domínio da diferença de caminho óptico $\delta$, é de $2 \pi$. Como $\delta$ depende tanto do comprimento de onda, quanto do ângulo de incidência do Fabry-Perot, quanto da distância entre as lâminas de vidro, existem diversas formas de analisar a distância entre dois picos consecutivos.

A primeira abordagem pode ser tomada se considerarmos uma fonte luminosa monocromática puntual iluminando o étalon de modo que o feixe luminoso incidente incida com um ângulo constante. Nesse contexto, a diferença de fase passa a ser uma variável que depende unicamente da largura do gap $d$ do FP. Escrevendo matematicamente a consideração feita no parágrafo anterior podemos escrever:

$$
\begin{aligned}
\frac{\delta(m+1)}{2 \pi}-\frac{\delta(m)}{2 \pi} & =1 \\
\frac{2 n(d+\Delta d)}{\lambda_{0}}-\frac{2 n d}{\lambda_{0}} & =1 \\
\Delta d & =\frac{\lambda_{0}}{2 n}
\end{aligned}
$$

Nela, $\Delta d$ define o intervalo no domínio da distância entre as duas placas que separa dois picos consecutivos (FSP na figura 3.7). Analogamente, calculamos a seguir esta distância no domínio espectral, onde o ângulo de incidência e o gap são tomados como constantes (equação 3.18) e a ordem de interferência $m$ é considerada como muito maior do que 1: 


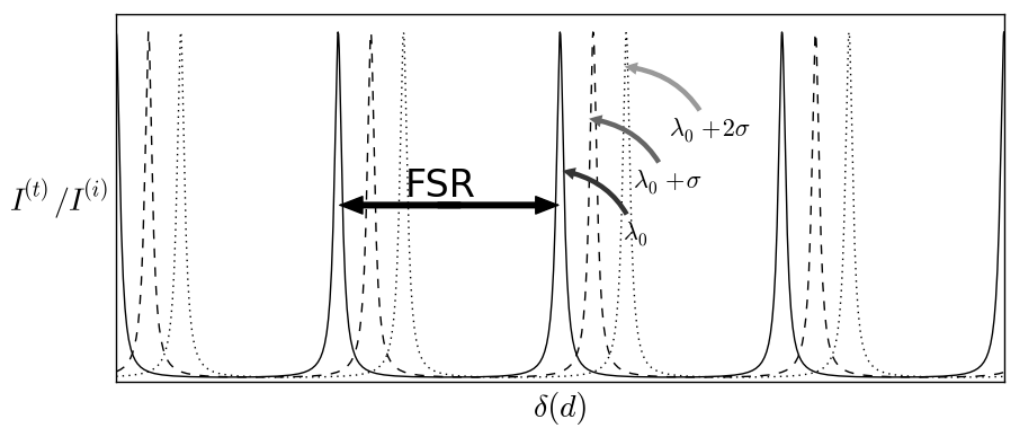

Figura 3.7: Intervalo espectral livre.

$$
\begin{aligned}
\frac{\delta(m+1)}{2 \pi}-\frac{\delta(m)}{2 \pi} & =1 \\
\frac{2 n d \cos \theta}{\lambda_{0}}-\frac{2 n d \cos \theta}{\lambda_{0}+\Delta \lambda} & =1 \\
\frac{1}{\lambda_{0}}-\frac{1}{\lambda_{0}+\Delta \lambda} & =\frac{1}{2 n d \cos \theta} \\
\Delta \lambda & =\frac{\lambda_{0}\left(\lambda_{0}+\Delta \lambda\right)}{2 n d \cos \theta} \\
\Delta \lambda & =\frac{\lambda_{0}+\Delta \lambda}{m} \\
\Delta \lambda-\frac{\Delta \lambda}{m} & =\frac{\lambda_{0}}{m} \\
\Delta \lambda & \approx \frac{\lambda_{0}}{m}
\end{aligned}
$$

A distância entre duas ordens de interferência é comumente conhecida como free spectral range (FSR) ou intervalo espectral livre, mesmo que seja definida em diferentes domínios, o que dificulta bastante a compreensão plena do verdadeiro significado deste parâmetro. Uma forma de visualizar sua importância é redesenhando cuidadosamente o gráfico transmitância relativa de um Fabry-Perot em função da sua diferença de fase. Consideramos novamente uma fonte monocromática puntual com comprimento de onda $\lambda_{0}$. Após uma varredura completa com um FP variando a distância entre as lâminas de vidro, obtém-se a curva que descreve a transmissão do étalon representada por uma linha contínua na figura 3.7.

Supondo agora que queremos realizar a mesma varredura, alterando apenas o comprimento de onda de nossa fonte para $\lambda_{0}+\sigma$. A curva que será obtida é idêntica à primeira salvo um pequeno deslocamento à direita (linha tracejada). A distância entre dois picos 


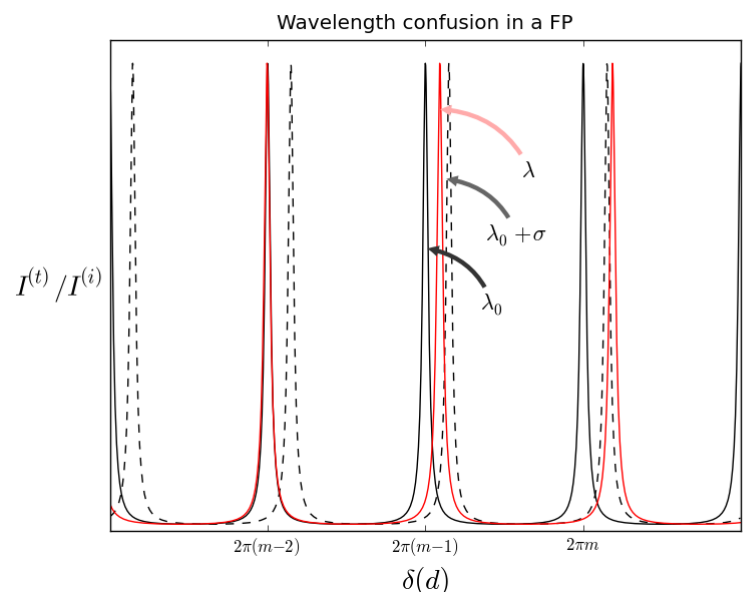

Figura 3.8: Confusão espectral causada pela presença de um comprimento de onda fora do FSR observado

ainda será $\Delta d$, visto que estamos variando apenas o tamanho do gap.

Um novo acrécimo fornecerá uma nova curva ainda mais deslocada para a direita e cujos picos ainda são separados por $\Delta d$ (linha pontilhada). Se formos aumentando gradualmente o comprimento de onda da fonte, quando esta possuir um comprimento de $\lambda_{0}+\Delta \lambda$, a curva que descreve a transmitância neste caso estará exatamente sobreposta com a curva que obtida para $\lambda_{0}$ tornando impossível distinguí-las.

A figura 3.8 mostra um caso em que considera-se que a fonte tenha três diferentes comprimentos de onda. Dois deles, em preto, estão dentro de um FSR. Em vermelho temos a terceira linha representando o terceiro comprimento de onda mais distante. É possível reparar que a distância entre os picos dos dois primeiros $\lambda$ 's é a mesma em diferentes ordens de interferência enquanto a do terceiro parece "caminhar" em meio ao espectro.

A explicação mais simples para este fato é a de que o FSR, seja no domínio do comprimento de onda ou do gap, depende do comprimento de onda observado. Numa situação real, esta luz cujo comprimento de onda difere completamente do que deseja-se observar pode causar uma grande confusão na interpretação dos resultados.

Existem várias formas de evitar esta confusão entre comprimentos de onda. Uma das mais simples é fazer uma pré-seleção dos comprimentos de onda utilizando-se um filtro interferométrico de baixa resolução espectral antes que a luz chegue no Fabry-Perot. 


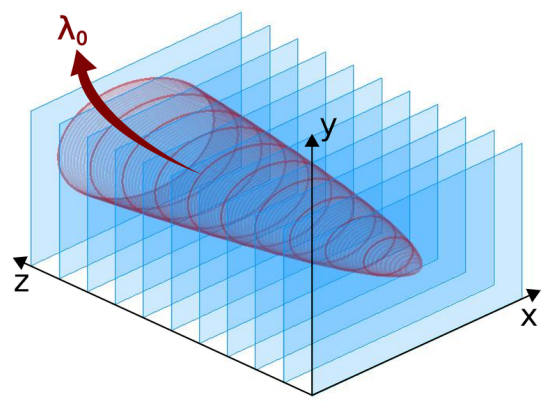

Figura 3.9: Superfície monocromática dentro de um cubo de dados.

\subsection{Ajuste de Fase}

Uma das outras características importantes relacionadas com cubos de dados obtidos com um Fabry-Pérot é a forma com que a informação se distribui ao longo de todo o cubo. Para exemplificar, vamos considerar uma fonte luminosa monocromática espacialmente distribuída de forma uniforme sobre um plano. Desta forma, na ausência de um FabryPérot, todos os píxeis de um detector são iluminados por igual.

Colocando agora um Fabry-Pérot no espaço colimado, exatamente como descrito nas seções anteriores, podemos construir um cubo de dados tirando uma sequência de fotos para consecutivos gaps. Como já mencionado, o cubo de imagens possuirá anéis concêntricos cujos raios aumentam conforme o gap aumenta. Dentro do cubo os anéis descrevem uma superfície parabólica monocromática (figura 3.9p).

Se, por algum motivo qualquer, quisermos colapsar o cubo na direção Z, ou seja, se somarmos todas as imagens em uma outra, teremos novamente uma imagem iluminada uniformemente. Em outras palavras, colapsando um cubo iluminado por uma fonte monocromática, podemos recuperar sua informação espacial, desde que a amostragem seja feito de maneira adequada.

Uma outra forma de visualizar este fato é utilizar o software chamado Illusion, que será descrito com mais detalhes na próxima seção, para simular um cubo de dados cuja informação espacial é descrita com uma imagem conhecida. Vamos supor a imagem 3.10 . Aplicando-a ao Illusion e simulando um cubo obtido com um Fabry-Perot de media resolução espectral (em torno de 20000) obtemos imagens como as apresentadas na figura 3.11 .

A imagem 3.12 mostra a soma das 10, 20, 30 e 40 primeiras imagens do cubo obtido na 


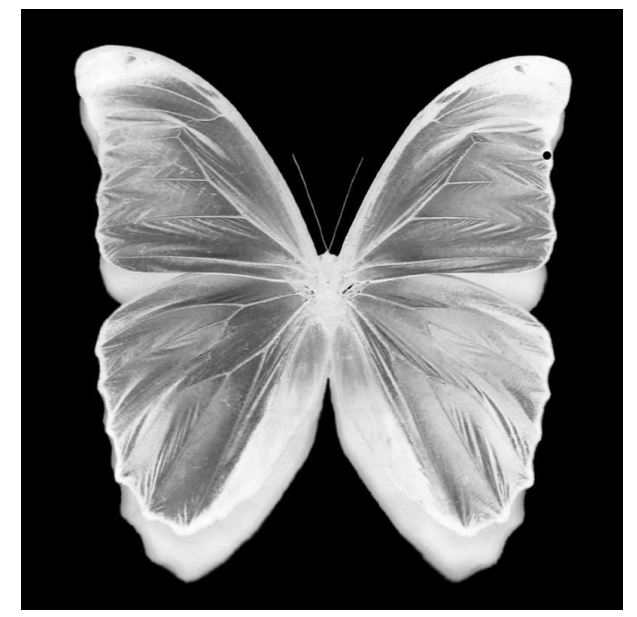

Figura 3.10: Imagem contendo informação espacial que será distribuída em um cubo de dados.
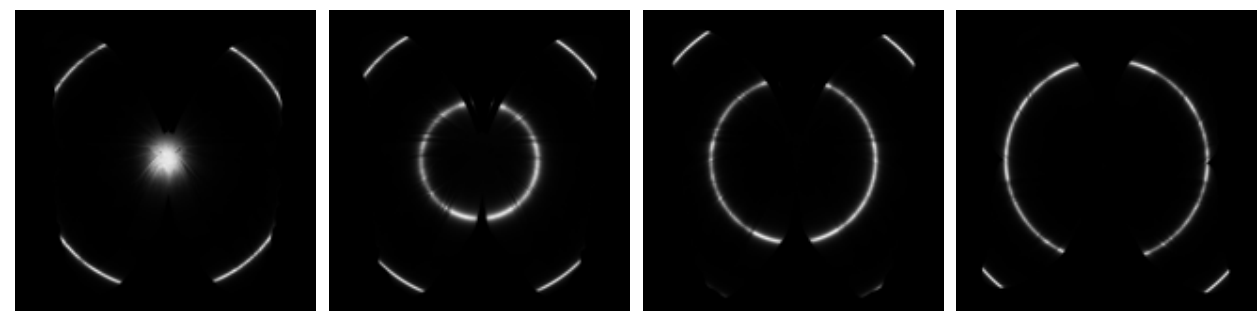

Figura 3.11: Imagens de um cubo criado com Illusion utilizando a imagem 3.10 como dado de entrada 

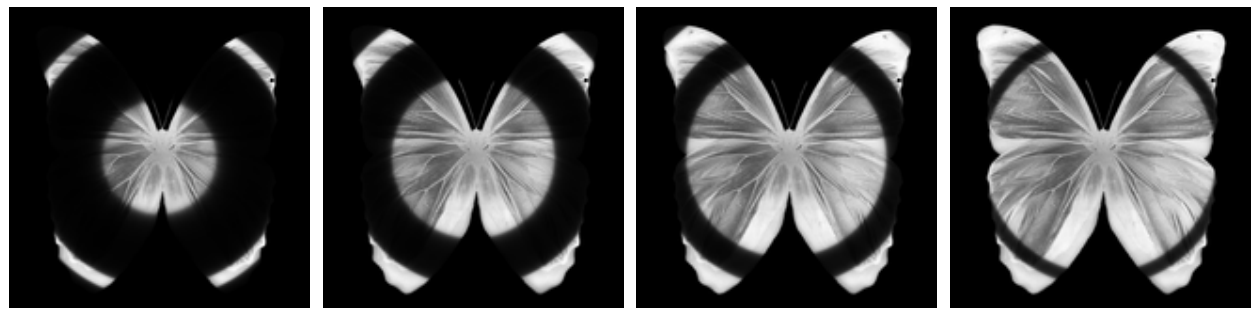

Figura 3.12: Imagens obtidas colapsando os 10, 20, 30 e 40 primeiros quadros do cubo citado acima.

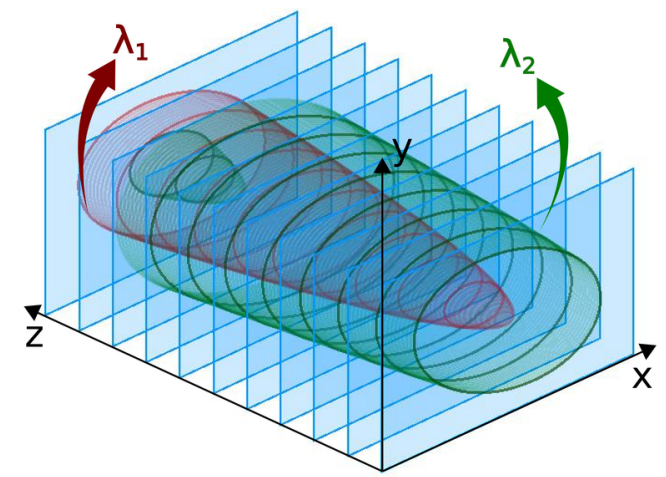

Figura 3.13: Cubo contendo duas superfícies monocromáticas.

simulação acima. O colapso de um cubo de dados recupera a informação espacial somente no caso em que a fonte é perfeitamente monocromática, i.e., temos um delta no seu espectro de emissão. Obviamente, o incremento do gap foi calculado de modo que não houvesse super ou sub amostragem (critério de amostragem de Nyquist).

Num cenário um pouco mais realista, nossa fonte luminosa possui um espectro contínuo ou diversas linhas de emissão. Cada comprimento de onda que a fonte possui aparecerá como uma nova superfície parabólica monocromática dentro do cubo, representada também por anéis em cada uma das imagens (figura 3.13). Aqui, se colapsarmos este cubo, perderemos toda a informação espectral do objeto.

Para que possamos ter acesso à informação espacial e espectral simultaneamente, precisamos separar a informação relacionada com cada um dos comprimentos de onda em quadros diferentes. Este procedimento, chamado de correção de fase, inicia-se obtendose um cubo de imagens de uma fonte luminosa uniformemente distribuida sobre o plano da imagem e com espectro monocromático. O resultado é nosso velho cubo povoado com anéis concêntricos em cada um dos seus quadros.

Analisando agora um determinado píxel $P(x, y)$ deste cubo, teremos seu espectro na 
direção $z(\delta)$. Se o cubo for construído de modo que uma varredura envolva apenas um único intervalo espectral livre, temos a certeza de encontrar apenas um pico neste espectro.

É determinada então a posição do pico de transmissão. Este valor é, então, guardado em uma nova imagem em um ponto cujas coordenadas $x$ e $y$ são as mesmas do píxel analisado.

Repetindo-se este processo todo para todos os $x$ e $y$ de um cubo temos o chamado mapa de fase. Este mapa, na realidade uma imagem 2D, nos diz quanto o espectro de cada píxel espacial dentro de um cubo deve ser deslocado (uma fase adicionada ou removida) para que a informação relacionada a um comprimento de onda em específico fique realinhada em um único quadro.

Os métodos utilizados para encontrar as posições dos picos de transmissão ou para aplicar a fase dentro do cubo de dados são objetos de estudo que fogem do escopo desta dissertação. Basicamente, diferentes técnicas existentes são aplicadas a um cubo de dados com os propósitos mencionados. Entretanto, vale mencionar que um dos grandes pontos em comum entre os algoritmos para reordenar um cubo de dados é o seu caráter periódico, utilizado para preencher as lacunas criadas ao deslocar-se o espectro.

Após todo o estudo realizado sobre o funcionamento dos Fabry-Pérots, apresenta-se agora um software utilizado para simular os dados obtidos com este instrumento facilitando a sua compreensão e auxiliando no desenvolvimento de novas rotinas voltadas para o tratamento de dados obtidos com FPs.

\subsection{Sintetizador de dados Illusion}

Conforme o próprio título desta sessão sugere, Illusion é um software desenvolvido para sintetizar cubos de dados simulando uma observação com Fabry-Pérot. Assim como no caso de simulações de redes de difração hologáficas, este programa foi desenvolvido em uma linguagem de programação chamada Python. Esta linguagem, por ser de alto nível, faz com que o código torne-se mais claro, limpo e organizado, facilitando sua compreensão e reutilização.

Para tornar o código ainda mais eficiente, utilizou-se bibliotecas numéricas como NumPy, SciPy e MatPlotLib. Para que fosse possível criar imagens no formato FITS, o padrão utilizado na astronomia, empregou-se o PyFits.

O programa em questão apresenta-se atualmente em diversas formas. Primeiramente, 


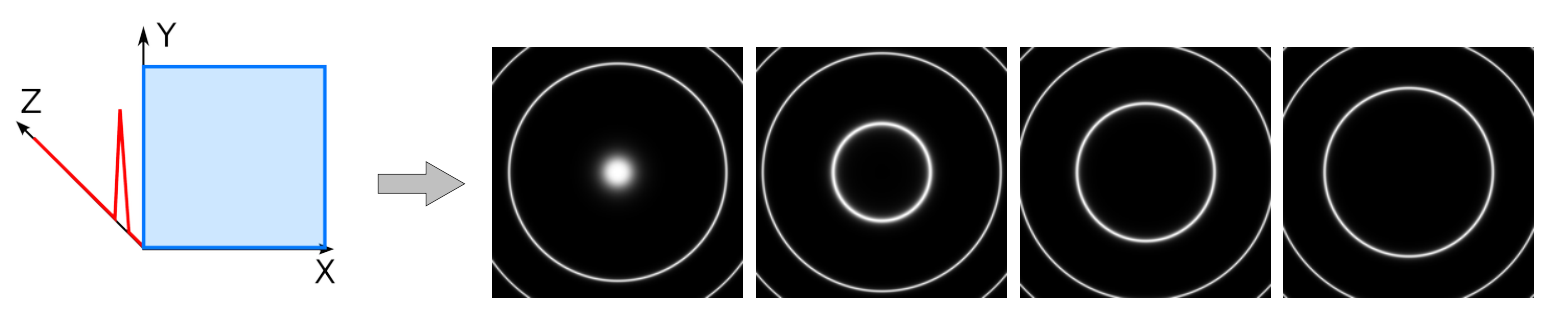

Figura 3.14: Raw cube. À esquerda, uma representação artística da fonte monocromática e uniformemente distribuída sobre uma superfície. À direita, o primeiro, o $11^{\circ}$, o $21^{\circ}$ e o $31^{\circ}$ quadros pertencentes um cubo criado com Illusion.

Illusion é um pacote a ser importado diretamente do interpretador interativo do Python como uma biblioteca qualquer. Criou-se também um script utilizando-se a mesma linguagem de programação para que fosse possível criar cubos de dados utilizando-se apenas uma linha de comando. Com este script foi possível criar uma interface gráfica, um servidor TCP/IP e uma interface HTML/PHP buscando fazer com que ele seja facilmente utilizado por usuários comuns.

Durante o decorrer deste capítulo, figuras como a 3.6 e a 3.11 mostram um pouco do que pode ser feito com Illusion. Dentro das definições criadas dentro do Illusion, é possível criar basicamente três tipos de cubos de dados diferentes. O primeiro deles, chamado de Raw Cube, é construído considerando-se a fonte como uma superfície uniformemente iluminada e possuindo apenas um comprimento de onda (figura 3.14). Este tipo de fonte representa uma fonte de calibração utilizada para criar um mapa de fase.

O segundo tipo de cubo, chamado de Spectrum Cube, é aquele obtido com uma fonte possuindo as mesmas características espaciais do caso anterior (superfície uniformemente iluminada) mas em diversos comprimentos de onda (figura 3.15). Este caso não é apenas interessante para tornar possível a visualização do modo com que a informação espectral é distribuída dentro do cubo como também para simular cubos de calibração para a determinação da real relação entre a distância entre as duas placas do étalon e o comprimento de onda (ou a posição do comprimento de onda dentro do cubo).

O último tipo de cubo criado é o chamado Image Cube, obtido utilizando-se uma imagem representando a informação espacial de um objeto astronômico qualquer em um comprimento de onda único (figura 3.16). Este último possui um caráter predominantemente didático já que, conforme mostrado na sessão anterior, ele pode ajudar a tornar claro os efeitos de colapso de um cubo na direção Z. 


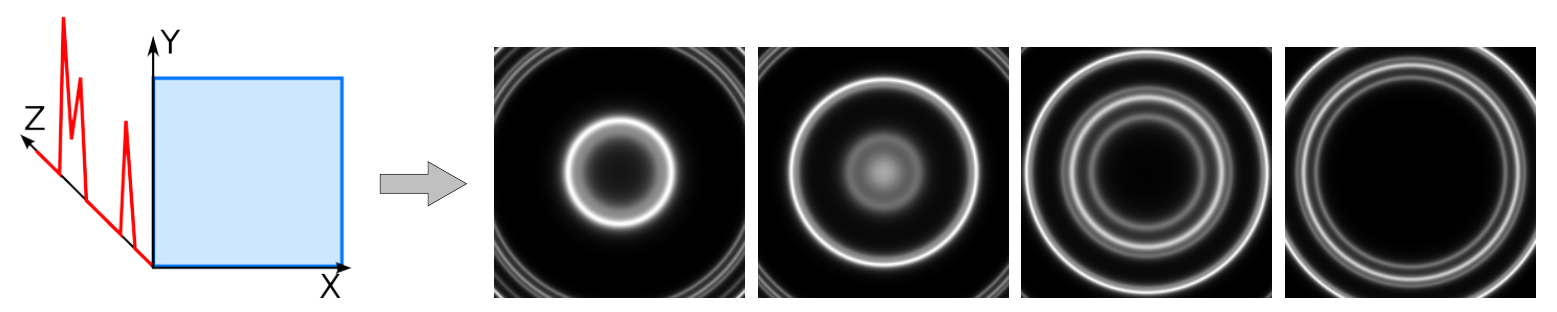

Figura 3.15: Spectrum cube. À esquerda, representação artística da fonte contendo comprimentos de onda arbitrários e à direita um cubo criado com Illusion para propósitos de visualização apenas.
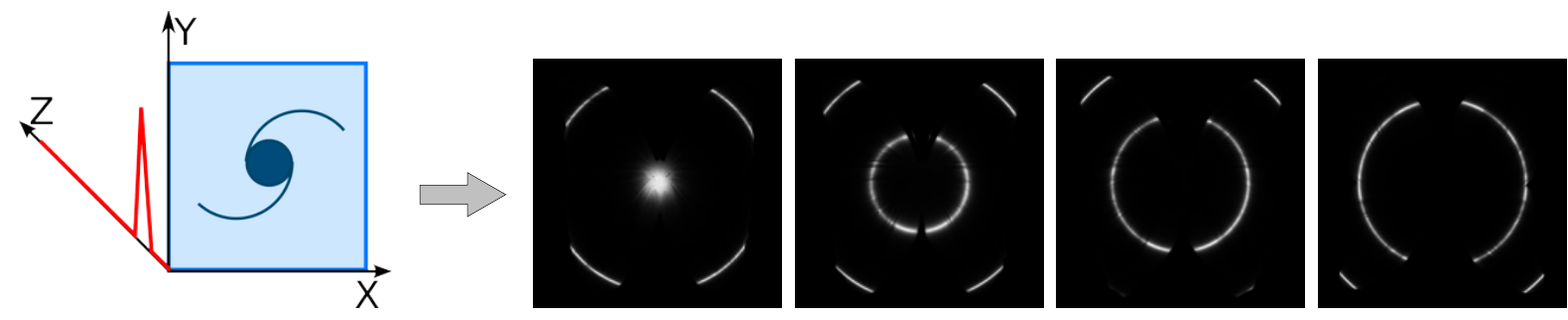

Figura 3.16: Image Cube. À esquerda uma representação artística das características da fonte. À direita, repete-se a imagem da borboleta aplicada ao Illusion para propósitos didáticos apenas. Um objeto astronômico mais realista não possuiria informação visual relevante o suficiente neste contexto.

Illusion tem sido utilizado em grande parte do desenvolvimento de uma nova biblioteca de redução e análise de dados voltada para o projeto BTFI. Novos algoritmos para o ajuste dos anéis e correção de fase foram desenvolvidos utilizando-se este programa e vêm sendo aplicados com sucesso a cubos de dados obtidos com instrumentos reais. Seu objetivo secundário de facilitar a compreensão do processo de formação de cubo também tem sido alcançado com sucesso em palestras e workshops sobre o instrumento. 
Capítulo 4

\section{Conclusão}

Após dois anos de trabalho junto ao projeto BTFI, este instrumento foi finalmente instalado no telescópio SOAR no último mês de julho. Durante o comissionamento, o conhecimento adquirido para o desenvolvimento deste trabalho foi de vital importância.

O BTFI possui dois módulos que atuarão simultaneamente: o iBTF, que criará cubos de baixa resolução espectral e que faz uso de duas redes de difração holográficas em série, e o Fabry-Pérot, uma espécie de filtro interferométrico já bastante conhecido dentro da comunidade científica e que fornecerá cubos de dados em alta resolução espectral.

Nesta primeira fase do comissionamento, apenas o módulo iBTF entrou em funcionamento deixando o canal em que o Fabry-Pérot funcionaria disponível para testes com alinhamento óptico e fotometria.

O iBTF conta com o uso de duas redes de difração holográficas em volume em série de tal forma que elas atuam como um filtro espectral de baixa resolução espectral. Nesta configuração, a primeira rede de difração atua sobre o feixe incidente dispersando a luz de modo semelhante às redes comuns. A segunda rede cancela, então, esta dispersão recuperando a informação espacial contida inicialmente no feixe luminoso e permitindo que apenas um certo comprimento de onda a atravesse. Este efeito é observado apenas nos casos em que as duas redes estejam completamente paralelas entre si.

Este conceito, que já havia sido testado com sucesso em laboratório, foi testado pela primeira vez no céu com o instrumento BTFI no SOAR durante o seu comissionamento. Pela primeira vez foi obtido o espectro de um instrumento astronômico utilizando-se a combinação de duas redes de difração holográficas como filtro. Estes dados não foram apresentados pois ainda estão em fase de redução. 
Ficou provado que os modelos utilizados para determinar a curva de eficiência das redes de difração holográficas foram satisfatórios. O objetivo principal do estudo destes modelos era a implementação de um software a ser utilizado para determinar as propriedades físicas de redes de difração de modo a obter o comportamento apropriado para observações astronômicas em todo o espectro, o que já foi feito de forma bastante satisfatória.

Mostrou-se que o comprimento de onda selecionado é determinado basicamente pelo período da modulação do índice de refração ou por sua frequência linear e pelo ângulo com que a luz incide nas duas redes conforme foi evidenciado pelo critério de Bragg (equação 2.4). A resolução espectral do filtro relaciona-se diretamente com a espessura das redes. Redes muito espessas possuem uma resolução maior do que redes mais finas.

Por fim, tendo o período da modulação e a espessura da rede determinados pelo comprimento de onda a ser transmitido de acordo com um certo ângulo de incidência e pela resolução espectral desejada, determina-se empiricamente a amplitude da modulação do índice de refração através de simulações consecutivas e buscando o caso com maior eficiência.

Dentre os três modelos estudados, o modelo de Kogelnik foi utilizado para determinar a eficiência das redes de difração utilizadas durante as primeiras observações com o BTFI e para auxiliar no processo de escolha das futuras redes que serão compradas para o instrumento. Apesar de ser limitado apenas para redes consideradas espessas, este modelo foi escolhido por sua simplicidade e pelo fato de que mesmo as redes mais delgadas a serem aplicadas no iBTF possuem uma profundidade óptica suficientemente grande.

O modelo de múltiplas camadas foi descartado pelo fato de utilizar um software designado para outros propósitos e também pela demora no tempo de processamento dos resultados. Este último fator é relevante se considerarmos que pretende-se utilizar as simulações envolvendo redes de difração holográficas dentro do software de controle do BTFI, o que exige uma resposta rápida do programa. Além de velocidade, precisa-se também que o programa seja facilmente integrado ao sistema do BTFI, o que mostrou-se demasiadamente complexo no caso do software mencionado.

Já a possibilidade de usar o modelo RWCA não foi completamente excluída. Entretanto, devido essencialmente a uma decisão tomada levando-se a urgência em termos simulações numéricas de dados obtidos com os Fabry-Pérot, a implementação deste modelo adquiriu um nível mais baixo de prioridade e acabou por não ser terminada. Somado a isto, vem 
o fato de que o modelo de Kogelnik já estava operacional e cobria as necessidades do instrumento.

Utilizando o modelo de Kogelnik, foi possível executar uma série de simulações com redes de difração até encontrar o conjunto de parâmetros físicos que melhor descrevem o comportamente desejado. A tabela 2.2 mostra todas as redes de difração escolhidas para serem encomendadas e utilizadas futuramente no BTFI. Das redes listadas na tabela 2.2 , apenas a primeira já foi realmente obtida. As demais ainda estão sendo compradas.

Testes de paralelismo entre as redes e a medida apropriada do seu desempenho serão realizadas no Laboratório Nacional de Astrofísica, em Itajubá - MG, nos próximos meses quando o módulo iBTF voltar ao Brasil.

O módulo relacionado com o Fabry-Pérot ainda não está operacional. Mesmo assim, graças ao desenvolvimento do software Illusion, utilizado a princípio para compreender melhor o mecanismo de criação de cubos de dados com filtros FP, bibliotecas de tratamento e redução de dados já estavam disponíveis quando o primeiro cubo de dados foi observado em julho junto ao SOAR utilizando-se o iBTF.

Mesmo sendo instrumentos que atuam de modo completamente diferentes entre si, os dados obtidos com um FP ou com um iBTF são bastante semelhantes em sua estrutura. A diferença reside basicamente na forma do mapa de fase. Enquanto mapas de fase obtidos de cubos de calibração observados com FP possuem um padrão radial, os cubos provenientes de observações realizadas com o iBTF possuem um mapa de fase linear, sendo muito mais simples que o caso dos Fabry-Pérots. Assim, da mesma forma que cubos obtidos com FPs, os cubos do iBTF também precisam passar pelo processo de correção de fase para que cada quadro contenha informação relacionada com apenas um comprimento de onda em específico.

Outro comportamento que facilita o tratamento dos dados obtidos com o iBTF em relação aos observados com Fabry-Pérot é seu caráter não periódico. Em outras palavras, em dados provenientes do iBTF, não há preocupação alguma com a repetição do perfil e transmissão. Após a correção de fase, ambos os dados seguem uma estrutura tridimencional idêntica: um cubo composto por diversos quadros contendo a informação espacial XY para um determinado comprimento de onda relacionado diretamente com uma coordenada Z

Conforme mostrou-se nesta dissertação, Illusion é um software desenvolvido para simu- 
lar a criação de cubos de dados através de observações com Fabry-Pérot de fontes luminosas de diversos tipos. Durante o seu desenvolvimento foi feito um estudo aprofundado sobre as características ópticas destes tipos de filtros representado neste trabalho através de um formalismo matemático simples.

Após este estudo, mostrou-se também quais elementos dificultam o entendimento da formação de cubo de dados obtidos com Fabry-Pérot. Um destes elementos estudados foi o caráter periódico dos dados obtidos com FP tanto no domínio espectral quanto no domínio espacial. Este problema é evitado buscando-se realizar observações dentro de um único intervalo espectral livre.

Mostrou-se também a forma com que a informação relacionada a um comprimento de onda em específico se distribui dentro de um cubo descrevendo uma superfície paraboloidal monocromática. Descreveu-se ainda o procedimento necessário para reordenar os comprimentos de onda em diferentes quadros do cubo fazendo uso do caráter periódico dos dados.

Illusion mostrou-se uma ferramenta simples porém muito útil para testar a eficácia de bibliotecas e pacotes de redução de dados.

Dentre os dois softwares desenvolvidos, apenas Illusion pode ser dado como completamente finalizado. Para o futuro, pensa-se em otimizar este programa para que possua um maior desempenho em termos de velocidade e interfaces gráficas ainda mais amigáveis. Já os módulos criados para a simulação de redes de difração holográficas, apesar de estarem funcionais e apresentarem resultados coerentes com as teorias estudadas, necessitam ser reescritos de forma a tornar os códigos mais legíveis, documentados e mais facilmente implementados em programas maiores. Esta ultima exigência surge da criação do novo ambiente de tratamento e redução de dados que está sendo desenvolvido para o BTFI.

Como fruto deste trabalho, um pôster foi apresentado na conferência "Astronomical Data Analisys and Software Systems" (ADASS) em outubro de 2009, em Sapporo, Japão. Com esta apresentação, também será publicado um artigo já submetido nos proceedings da conferência em questão (vide anexos $\mathrm{A}$ e B ). 


\section{Referências Bibliográficas}

Atherton P. D., Taylor K., Pike C. D., Harmer C. F. W., Parker N. M., Hook R. N., TAURUS: A wide-field imaging Fabry-Perot spectrometer for astronomy, MNRAS, 1982, vol. 201, p. 661

Barrell H., Teasdale-Buckell P., The Correction for Dispersion of Phase Change in FabryPerot Interferometers, Proceedings of the Physical Society B, 1951, vol. 64, p. 413

Blais-Ouellette S., Daigle O., Taylor K., The imaging Bragg tunable filter: a new path to integral field spectroscopy and narrow band imaging. In Society of Photo-Optical Instrumentation Engineers (SPIE) Conference Series , vol. 6269 of Society of PhotoOptical Instrumentation Engineers (SPIE) Conference Series, 2006

Born M., Wolf E., Principle of Optics 7th edn. Cambridge University Press, 1999

Borra E. F., Landstreet J. D., Vaughan Jr. A. H., High-Resolution Zeeman Polarimetry, ApJ, 1973, vol. 185, p. L145+

Boulesteix J., ADHOC Reference Manual, 1993

Boulesteix J., Georgelin Y., Marcelin M., Monnet G., First results from CIGALE scanning Perot-Fabry interferometer. In Society of Photo-Optical Instrumentation Engineers (SPIE) Conference Series, vol. 445 of Presented at the Society of Photo-Optical Instrumentation Engineers (SPIE) Conference, 1984, p. 37

Castilho B. V., Delabre B., Gneiding C. D., "A new concept for echelle spectrographs: the SOAR Telescope Echelle Spectrograph". In "Society of Photo-Optical Instrumentation 
Engineers (SPIE) Conference Series", vol. 5492 of Presented at the Society of PhotoOptical Instrumentation Engineers (SPIE) Conference, 2004, p. 433

Daigle O., Carignan C., Hernandez O., Chemin L., Amram P., Improved 3D Fabry-Perot data reduction techniques, Monthly Notices of the Royal Astronomical Society, 2006, vol. 368 , p. 1016

Desai J. N., Chandrasekhar T., Angreji P. D., Doppler shift measurements on the green coronal line - Evidence for largescale macroscopic mass motion, Journal of Astrophysics and Astronomy, 1982, vol. 3, p. 69

Fabry C., Perot "Mesure du coefficient de viscosité de l'air.", Ann. Chim. Phy., 1988, vol. 13 , p. 275

Fabry C., Perot A., "Measures of absolute wave-lengths in the solar spectrum and in the spectrum of Iron", Aastrophys. J., 1901, vol. 15, p. 261

Fich M., Dahl G. P., Treffers R. R., Fabry-Perot H-alpha observations of Galactic H II regions, AJ, 1990, vol. 99, p. 622

Georgelin Y. M., Georgelin Y. P., Roux S., Observations de nouvelles regions HII galactiques et d'etoiles excitatrices, A\&A, 1973, vol. 25, p. 337

Kittel C., Introduction to Solid State Physics. JOHN WILEY \& SONS, INC., 1953

Kogelnik H., Coupled wave theory for thick hologram gratings, The Bell System Technical Journal, Vol. 48, no. 9, November 1969, pp. 2909-2947, 1969, vol. 48, p. 2909

Lepine J. R. D. e. a., "SIFUS: SOAR integral field unit spectrograph". In Society of PhotoOptical Instrumentation Engineers (SPIE) Conference Series, vol. 4841 of Presented at the Society of Photo-Optical Instrumentation Engineers (SPIE) Conference, 2003, p. 1086

Moharam M. G., Gaylord T. K., "Rigorous coupled-wave analysis of planar-grating diffraction", J. Opt. Soc. Am., 1981, vol. 71, p. 811

Mulligan J. F., "Who were Fabry and Pérot?", American Journal of Physics, 1998, vol. 66, p. 797 
Perot A., Fabry C., "Mesures de longueurs d'onde dans le spectre solaire, comparison avec l'echelle de Rowland.", Compt. Rend., 1900, vol. 191, p. 700

Perot A., Fabry C., "Sur les longueurs d'onde des raies du spectre solaire et les corrections aux tables de Rowland.", Ann. Chim. Phys., 1904, vol. 27, p. 5

Perot A., Fabry C., "Sur les franges des lames minces argentées et leus application a la mesure de petites épasseur d'air", Ann. Chim. Phy., 1987, vol. 12, p. 459

Pfund A. H., " A redertemination of the wave-lengths of the standard Iron lines", Astrophys. J., 1908, vol. 28, p. 197

Saleh B. E. A., Teich M. C., Fundamental of Photonics 2nd edn. John Wiley \& Sons, Inc., 2007

Shopbell P., Bland-Hawthorn J., Cecil G., The Theory and Application of Fabry-Perot Phase Correction within IRAF. In Astronomical Data Analysis Software and Systems I , vol. 25 of Astronomical Society of the Pacific Conference Series, 1992, p. 442

Vaughan Jr. A. H., Astronomical Fabry-Perot Interference Spectroscopy, ARA\&A, 1967, vol. 5, p. 139 
Anexos 

Anexo A

\section{Pôster - ADASS2009}

Pôster apresentado durante a conferência Astronomical Data Analysis and Software System que aconteceu em outubro de 2009 em Sapporo, Japão. 



\section{Illusion - A Fabry-Perot Data-Cube Synthesizer \\ Quint, B.C.[1]; Taylor, K.[1]; Muramatsu, M.[1]; Ferrari, F.[2]; Mendes de Oliveira, C.[1]}

\section{ABSTRACT}

Illusion is a software package designed to synthesize Fabry-Perot data for the Brazilian Tunable Imager Filter (BTFI) project which is developing an instrument for the SOAR telescope at the Universidade de São Paulo in collaboration with several other institutes in Brazil, Canada and France. The Illusion package synthesizes data to help in the development of data-reduction routines, to train observers and to simulate observations in different contexts. The synthesized data are obtained using different kinds of sources located in the telescope's image plane modified by the Fabry-Perot Airy profile. The results are delivered as data-cubes in the FITS format and they have been a powerful resource in the development of new data-reduction routines and for the training of the BTFl's software and observing groups.

\section{INTRODUCTION}

Illusion is a package developed in the Python language to simulate Fabry-Perot data in the context of the BTFI instrument for SOAR This project requires the understanding of the interferometry underlying a Fabry-Perot as used as a tunable optical filter.

The synthetic data are recorded as a data-cube, with $x, y$ spatial and $z$ spectral dimensions. They are used to help in the development of a new library of programs to calibrate and reduce the real data, obtained with the instrument.

Illusion simulates data by considering four different kinds of sources (Monochromatic Flat, Monochromatic Image, Multi-spectral Flat ano Multi-spectral Image) to aid in different levels and requirements of the simulations.

\section{OPTICAL ARRANGEMENT}

Currently Illusion uses a classical arrangement for a Fabry-Perot, mounted at the pupil plane within the collimated section, such that interference fringes are formed on the detector con-focal with the image of the sky.

Fig. 1 shows the arrangement that Illusion uses to do the simulations.

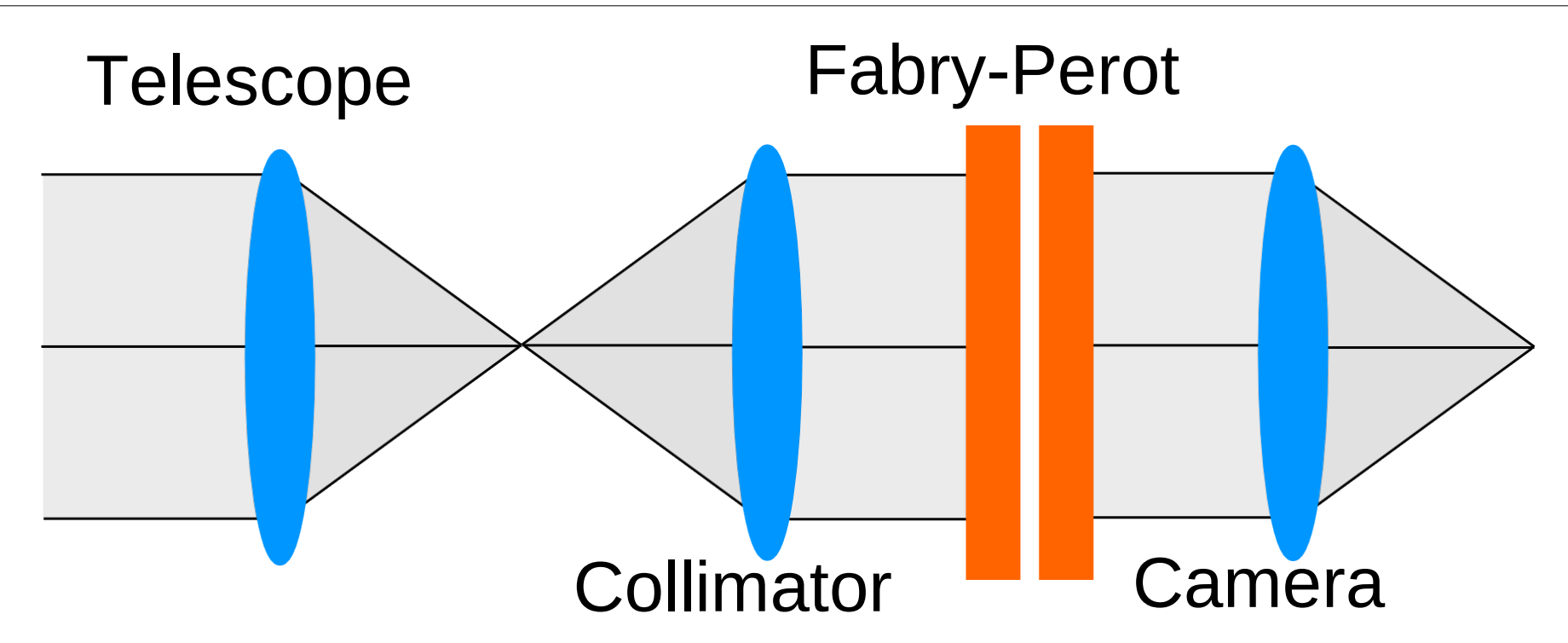

Figure 1 - Optical Arrangement
The ellipses in blue represent the optical system lenses (telescope, collimator and camera). The rectangles in orange represent the etalon plates.

\section{DATA-CUBE STRUCTURE}

The data-cube is stored as a FITS file containing a stack of tunable filter images centered at different wavelengths generally sampled at the Nyquist limit. The $X$ and $Y$ direction in a cube define the spatial information for a given wavelength while the $Z$ direction gives the spectral information for each pixel.

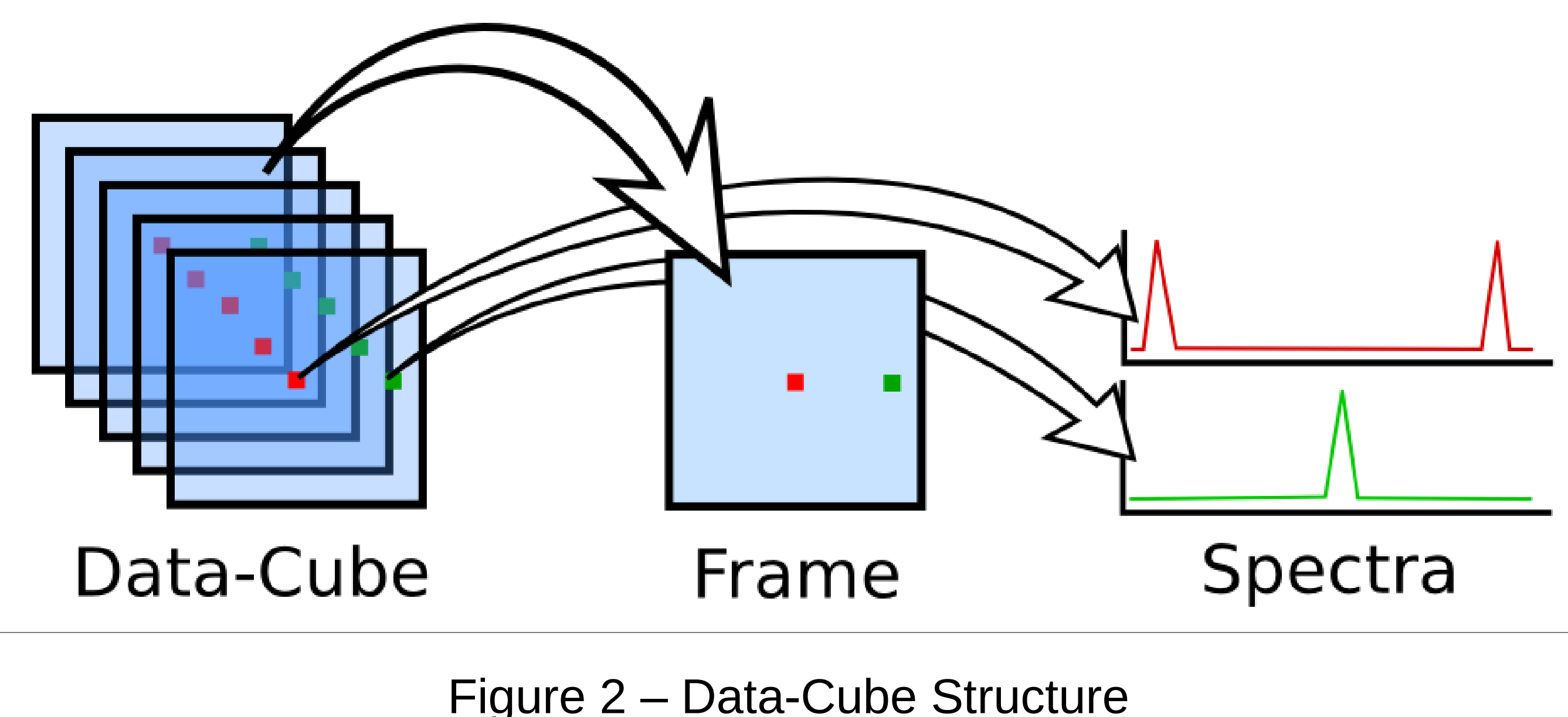

\section{SYNTHESIZED DATA}

The synthesized data shown below shows the results generated by a Fabry-Perot illuminated by a spatially uniform, $550 \mathrm{~nm}$ monochromatic source at a spectral resolution of 20,000 and with a finesse of 25 . The camera's focal length is $350 \mathrm{~mm}$ imaging onto a detector having pixels of $16 \mathrm{um}$.

Monochromatic Flat: the source is a monochromatic even Illuminated screen located at infinity. These images have $1600 \times 1600$ pixels.
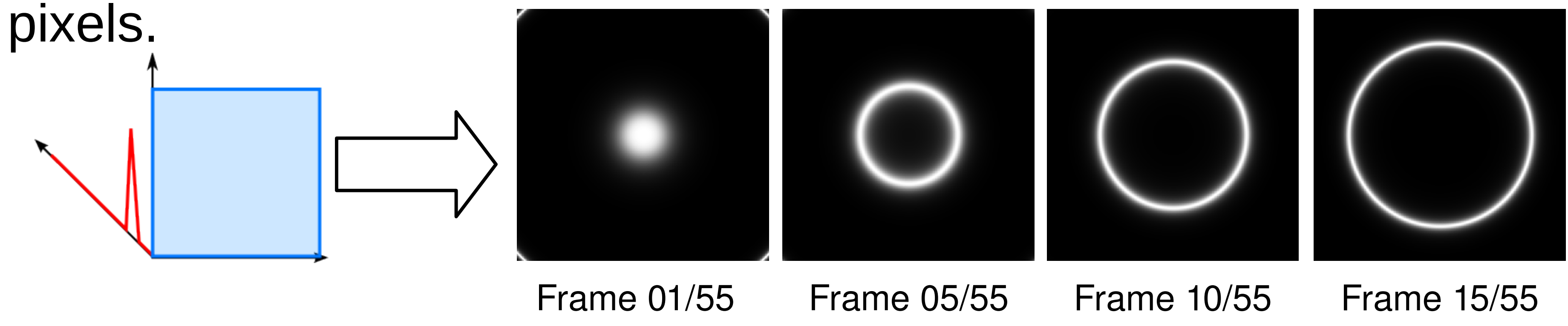

Frame 10/55 Frame 15/55

Multi-wavelength Flat: the source is spatially uniform but has three wavelengths of zero width. Here, the blue rings are at $470 \mathrm{~nm}$, the green ones are at $550 \mathrm{~nm}$ and the red ones are at $620 \mathrm{~nm}$. As before, each frame has $1600 \times 1600$ pixels.
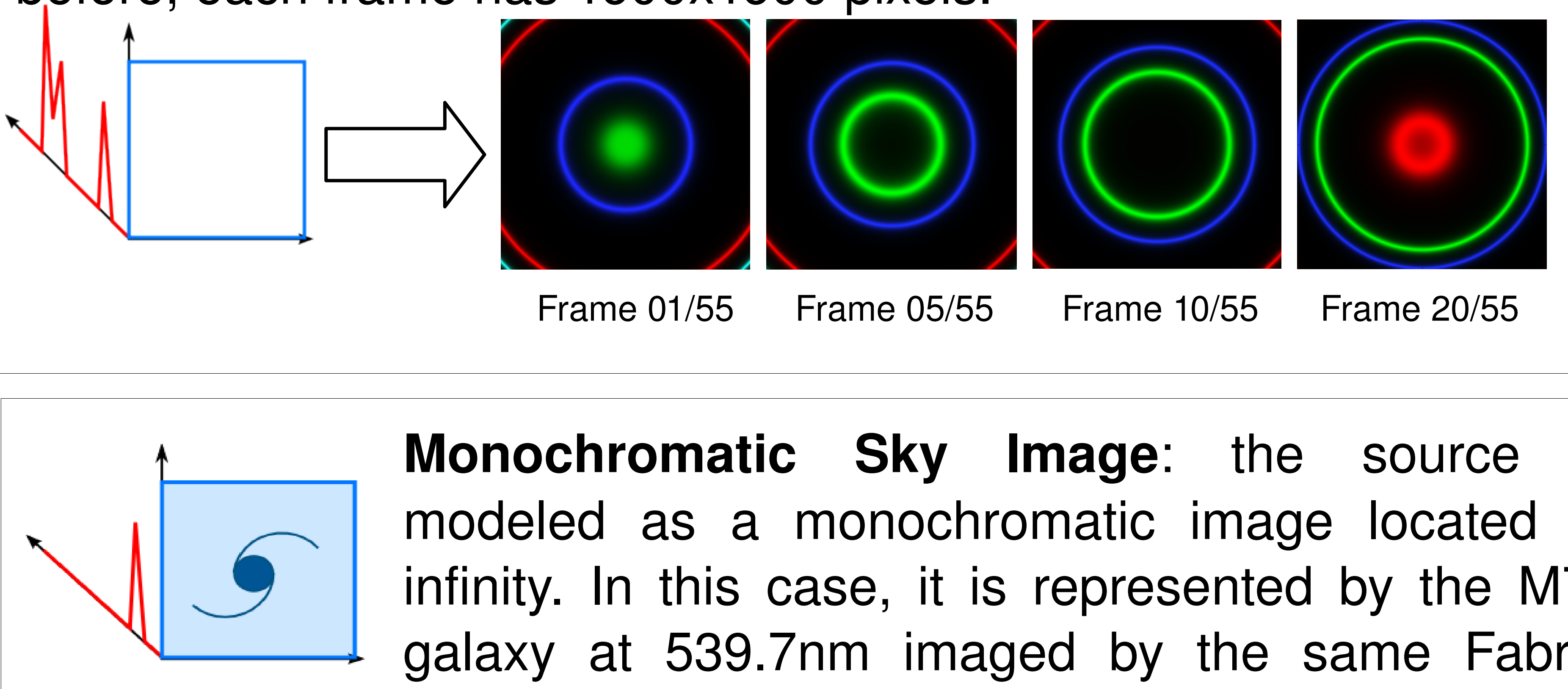

Monochromatic Sky Image: the source is modeled as a monochromatic image located at infinity. In this case, it is represented by the M74 galaxy at $539.7 \mathrm{~nm}$ imaged by the same FabryPerot. Here, each frame has $560 \times 560$ pixels.

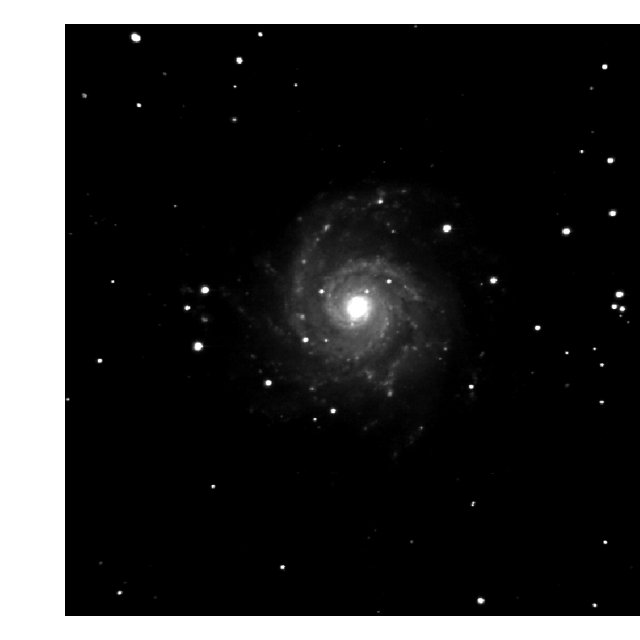

Original Image
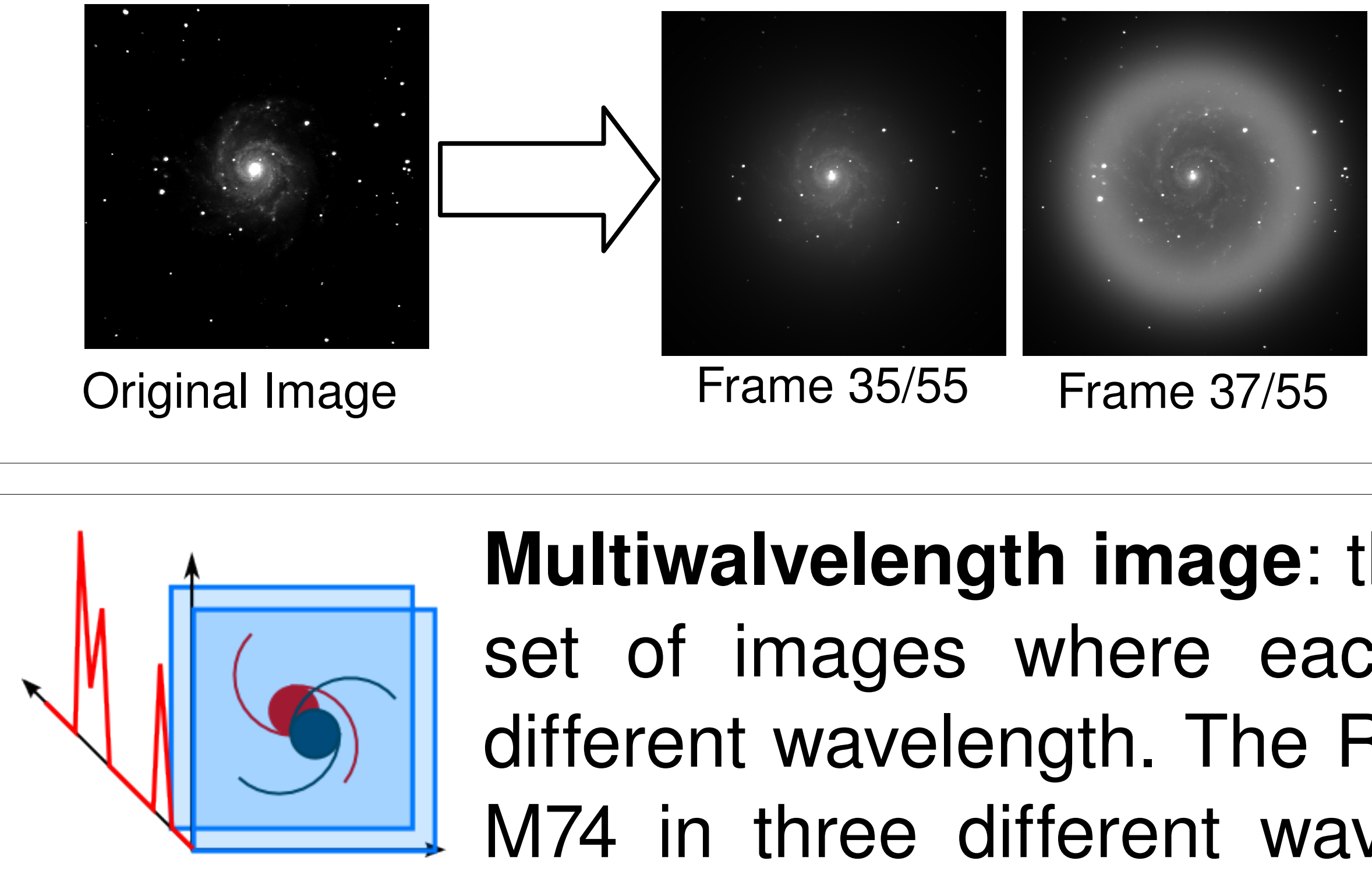

Frame 37/55
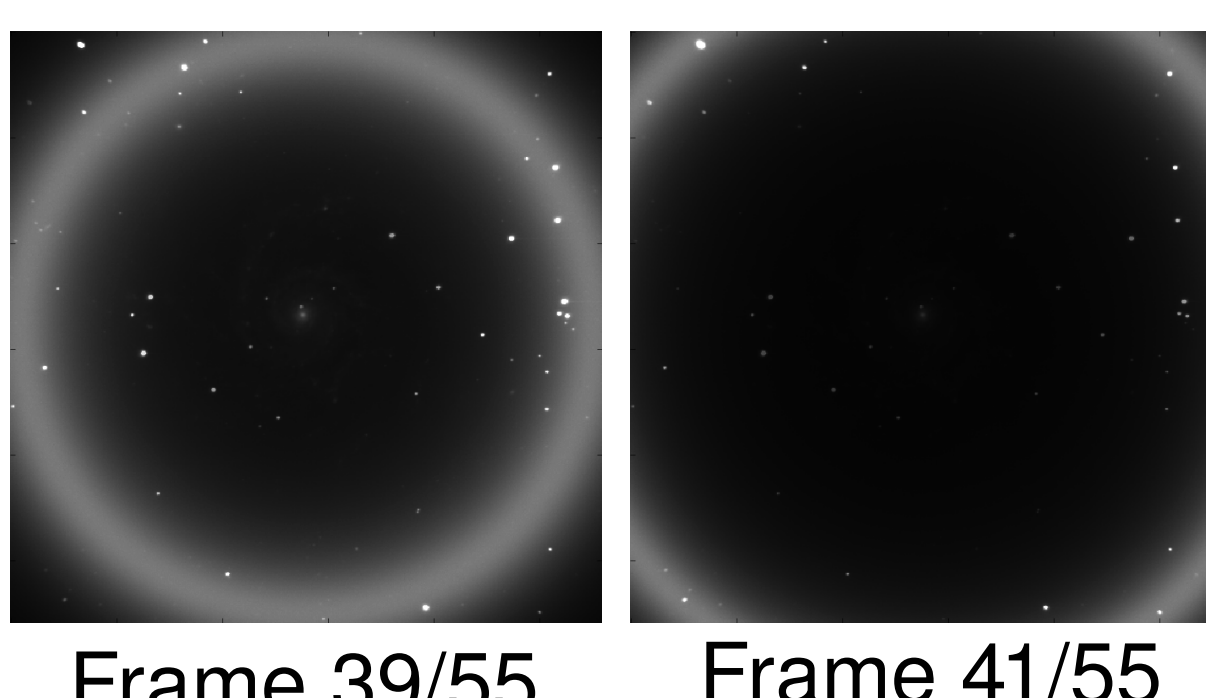

Multiwalvelength image: the simulated source is a set of images where each frame is taken at a different wavelength. The RGB images below show M74 in three different wavelengths: $642.5 \mathrm{~nm}(R)$, $539.7 \mathrm{~nm}(\mathrm{G})$ and $433.1 \mathrm{~nm}(\mathrm{~B})$. Again, the frames have $560 \times 560$ pixels.
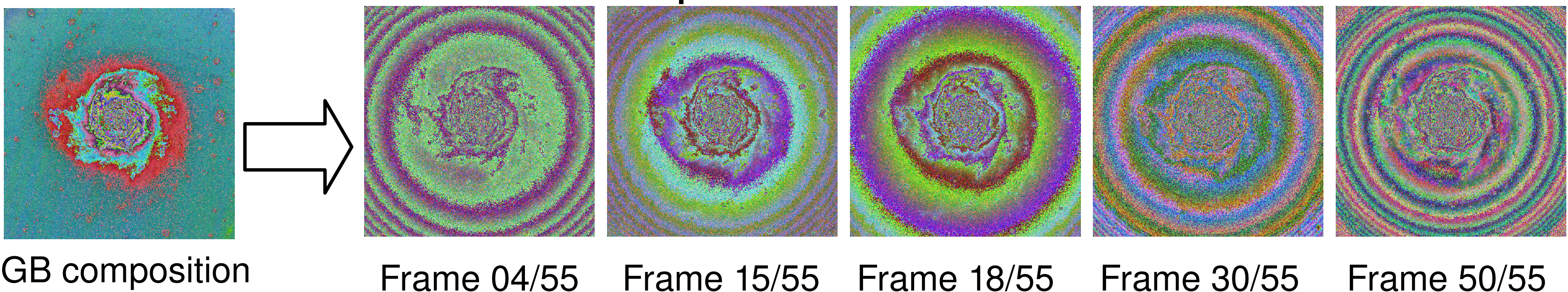

Frame 04/55 Frame 15/55 Frame 18/55 Frame 30/55 Frame 50/55 



\section{Anexo B}

\section{Artigo - ADASS2009}

Artigo a ser publicado nos proceedings da mesma conferência que o pôster apresentado no anexo A. O artigo já foi submetido e aprovado e aguarda publicação. 



\title{
Illusion - A Fabry-Perot Data-Cube Synthesizer
}

\author{
Bruno Corrêa Quint ${ }^{1,2}$, Keith Taylor ${ }^{1}$, Fabricio Ferrari ${ }^{3}$, Claudia \\ Mendes de Oliveira $^{1}$, Mikiya Muramatsu ${ }^{2}$
}

\begin{abstract}
Illusion is a software package designed to synthesize FabryPerot data for the Brazilian Tunable Imager Filter (BTFI) project which is developing an instrument for the SOAR telescope at the Universidade de São Paulo in collaboration with several other institutes in Brazil, Canada and France. The Illusion package synthesizes data to help in the development of data reduction routines, to train observers and to simulate observations in different contexts. The synthesized data are obtained using different kinds of sources located in the telescope's image plane modified by the Fabry Perot Airy profile. The results are delivered as data cubes in the FITS format and they have been a powerful resource in the development of new data reduction routines and for the training of the BTFI's software and observing groups.
\end{abstract}

\section{Introduction}

A new instrument called the Brazilian Tunable Filter Imager (BTFI) is being developed at the Universidade de So Paulo in collaboration with institutes like INPE, LNA (Brazil), LAM (France) and LAE (Canada) to be used at the SOAR Telescope, Chile. The instrument will use two Fabry-Perots (FPs): one in the pupil plane acting as a high resolution imaging interferometer and the other in the uncollimated image space as a low-resolution tunable filter. In addition it employs a new kind of tunable filter with a medium-to-low resolution capability. The iBTF (imaging Bragg Tunable Filter) was developed under a NASA grant (IS ???) at Caltech as described in Blais-Ouellette, Daigle \& Taylor (2006). The BTFI uses two EMCCDs (Daigle, Carignan \& Blais-Ouellette 2006) which allows for rapid scanning of the resultant data-cubes for both the filtered light and a complementary channel which can be used as a simultaneous monitor of sky conditions.

Some of the key issues in calibrating and controlling this highly versatile, multi-mode instrument are related to FPs; most notably, FP gap and parallelism instabilities and interference order confusion. These problems are intrinsic to all FPs as used in the varying gravitation vector and thermal environment typical of ground-based telescopes, however the fact that the particular FPs used in BTFI (SESO ref:???) have an etalon gap range of $\sim 250 \mu m$, rather than the typical $\sim 5 \mu m$ range aggravates the calibration problems.

\footnotetext{
${ }^{1}$ Inst. de Física (IF), Universidade de São Paulo (USP), São Paulo, Brazil

${ }^{2}$ Inst. de Astronomia, Geofísica e Ciências Atmosféricas (IAG), USP, São Paulo, Brazil

${ }^{3}$ Universidade Federal do Pampa (Unipampa), Bagé, Brazil
} 
For all FPs drifts in parallelism and gap cannot be avoided. They require periodic monitoring followed by rapid response corrections for optimal performance. Wavelength calibration and phase map correction (ref ???) require a resolution to the inherent order confusion that arises due to the periodicity of the spectral profile of a FP.

Illusion is a simple but powerful software tool that helps to solve these problems. Illusion encapsulates the 3D Airy function and can provide a datacube with full control of all parameters. In this way it is possible to model all instrumental configurations and to explore possible solutions well before the instrument is built and commissioned. The code is written in Python and packages such as NumPy, MatPlotLib, Scipy, TkInter and PyFits (Barret \& Bridgman 2006) are used. It can be also be imported as a package for automatic processes. Illusion is released under the GLP 3.0 license and hence anyone can use, distribute and modify it as required.

\section{Illusion Paper - Why is Illusion?}

As mentioned previously, Fabry-Perots are intrinsically unstable giving rise to, principally, problems like gap drift and non-parallelism of the etalon plates. Parallelism can, in most cases, be checked and corrected by visual inspection of the Fabry-Perot to empirically determine the degree of non-parallelism and to correct it. This eyeball inspection requires visual access to the FP when illuminated by a monochromatic light source. For the BTFI and for several other modern FP instruments, this is not possible. In this situation monitoring, measurement and correction processes have to be rapid, reliable and efficient. The only way of achieving this is to automate the process.

Software algorithms to deal with FP calibration and alignment issues are not straight forward since FPs generally work at high orders of interference, which means that the wavelength profile is periodic bringing with it an ambiguity usually referred to as order confusion. A method of determining the interference order at a particular wavelength of a calibration(and hence the etalon gap) is to use the FP optical delay equation (eq. 1 from Born \& Wolf 1999) together with the fact that the ordern is required to be an integer; a minimum of two calibration wavelengths are required in order to solve for $n$. Traditionally, such calculations are done off-line however the intention is to use Illusion to solve for this automatically. For BTFI this procedure is further complicated by the fact the etalons in question (ref ???) are of a new breed which allows for gap ranges in the order of $\sim 250 \mu \mathrm{m}$ as opposed to traditional FPs where the nominal gap can be varied only over a very much smaller $\sim 5 \mu \mathrm{m}$ range. This makes determining the etalon gap a far more critical and demanding challenge.

Again, automatic monitoring of FP drifts (gap and parallelism) and determination of the interference order are tasks which are informed by the Illusion code.

$$
\cos (\theta)=\frac{\lambda}{2 n l}
$$

The data cubes obtained with a scanning Fabry-Perot illuminated with monochromatic light contain $\mathrm{FP}$ rings with varying radii with depth into the 
cube. These rings form a 3D paraboloidal surface within the cube as a consequence of the optical path difference as changes. Rectification of the periodic paraboloidal structure to produce monochromatic slices in the data-cube is called phase correction which is implemented in $\mathrm{AD}-\mathrm{HOC}^{1}$, IRAF (Bland-Hawthorn, Shopbell \& Cecil 1992) and IDL (Daigle et al. 2006). However, some of these packages can not be integrated in other software because they are not open source, like AD-HOC. Others will not be used simply because BTFI software system was constrained to be writen only in Python and LabView to avoid confusion with many laguages.

\section{Illusion Paper - What is Illusion?}

The above issues can be addressed through modeling and analysis which is the main role of the Illusion package. Illusion can generate synthetic data with full control of all physical parameters that define the optical characteristics of a Fabry-Perot what also gives a better comprehention of FP data behaviour acording to that parameters. Algorithms for phase map and wavelength calibration can also be tested with precision due to the full control of parameters that exists. Also, the consequences of problems like non paralellism can be simulated by building a set of cubes with slightly different gaps and adding them.

Each region of the talon will provide a ring with different radii. When adding all of these rings, the result is a unique and broader ring. In other words, spectral resolution is degraded. A mask called Mexican Hat composed by four prisms can be placed in the collimated space right after the Fabry Perot to separate the beam in four regions and, hence, four rings are formed instead of only one. This can be modeled by building a set of data cubes with different gaps and putting them together (Figure 1). Each of these rings have different gaps and, consequently, different radii. By extracting the spectrum of a single pixel in the center of all those rings it becomes possible that each pixel has a transmission peak at different places. By adding those four smaller cubes, one can see the consequences of the non-parallelism.

That contradicts also the feeling that non-parallel plates would return distorted rings which is what most of inexperient people would think.

This modeling could be done on the fly by importing Illusion on Python interpreter or writing a small Python script. By having the basic data modeling, Illusion can simulate a large number of different situations turning possible even to build a dummy instrument.

\section{Conclusion}

Illusion is just starting has a released program. For the future, Illusion will become a large package that can simulates also Fabry-Perots data in the noncollimated space and iBTF data. The codes will be rewriten to achieve a better performance and to improve even more the modularity that is so important in

\footnotetext{
${ }^{1}$ http: //www . oamp.fr/adhoc/
} 

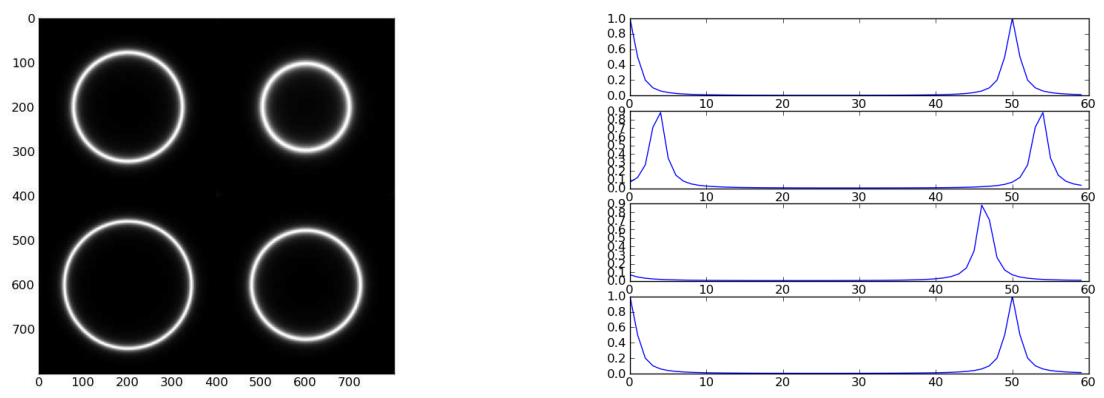

Figure 1. Two related graphics.

this kind of product. More realistic features including noise are already implemented, but only in a low level.

Acknowledgments. Illusion is part of the author master's thesis granted by CNPQ under the process number 136015/2008-5.

\section{References}

Blais-Ouellette, S., Daigle, O. \& Taylor, K. 2006, Proc. SPIE, 6269, 62695H

Daigle, O., Carignan, C. \& Blais-Ouellette, S., 2006, Proc. SPIE, 6276, 62761F

Bland-Hawthorn, J., Shopbell, P. \& Cecil, G. in ASP Conf. Ser. 25, ADASS I, ed. D. M.

Worrall, C. Biemesderfer, \& J. Barnes (San Francisco: ASP), 393

Daigle, O., Carignan, C., Hernandez, O., Chemin, L., Amram. P. 2006, Mon.Not.Roy.Astron.Soc., 368,1016

Barret, P. E. \& Bridgman, W. T. 2000, in ASP Conf. Ser. 216, ADASS IX, ed. N. Manset, C. Veillet, \& D. Crabtree (San Francisco: ASP), 67

Born, M. \& Wolf, E. 1999, Principle of Optics (Cambridge: Cabdridge University Press) 